Hélio Corrêa da Silva Júnior

Avaliação de inércia e amortecimento hidrodinâmicos em seções bidimensionais oscilando em balanço: influência de propriedades geométricas e inerciais 
Hélio Corrêa da Silva Júnior

\title{
Avaliação de inércia e amortecimento hidrodinâmicos em seções bidimensionais oscilando em balanço: influência de propriedades geométricas e inerciais
}

\author{
Dissertação apresentada à Escola \\ Politécnica da Universidade de São Paulo \\ para obtenção do título de \\ Mestre em Engenharia \\ Área de concentração: \\ Engenharia Naval e Oceânica \\ Orientador: Prof. Doutor \\ Mardel Bongiovanni de Conti
}


Hélio Corrêa da Silva Júnior

\title{
Avaliação de inércia e amortecimento hidrodinâmicos em seções bidimensionais oscilando em balanço: influência de propriedades geométricas e inerciais
}

\author{
Dissertação apresentada à Escola \\ Politécnica da Universidade de São Paulo \\ para obtenção do título de \\ Mestre em Engenharia \\ Área de concentração: \\ Engenharia Naval e Oceânica \\ Orientador: Prof. Doutor \\ Mardel Bongiovanni de Conti
}


FICHA CATALOGRÁFICA

Silva Júnior, Hélio Corrêa daAvaliação de inércia e amortecimento hidrodinâmicos emseções bidimensionais oscilando em balanço: influência de propriedades geométricas e inerciais / H.C. da Silva Júnior. -- São Paulo, 2011.85 p.Dissertação (Mestrado) - Escola Politécnica da Universidadede São Paulo. Departamento de Engenharia Naval e Oceânica.

1. Hidrodinâmica I. Universidade de São Paulo. Escola Poli-técnica. Departamento de Engenharia Naval e Oceânica II. t. 


\section{Dedicatória}

Dedico este trabalho a meus pais pelo apoio durante toda a vida, a Laudicéia pelo companheirismo e compreensão e a meus amigos sempre vigilantes. 


\section{Agradecimentos}

Ao professor Mardel Bongiovanni de Conti, pela orientação e pelo apoio durante o trabalho. Ao professor Moyses Szajnbok pelos sábios conselhos. Ao especialista de Laboratório Carlos Alberto Guedes Freire de Souza e ao engenheiro Guyon Ewen pelo competente trabalho realizado durante os ensaios. Ao professor Carlos Daher Padovezi pela motivação e ao professor Toshi Ichi Tachibana pela experiência transmitida. Aos colegas do Instituto de Pesquisas Tecnológicas que colaboraram muito nas discussões. Aos funcionários da Escola Politécnica que apoiaram a realização deste trabalho. 


\section{Resumo}

Consideram-se neste trabalho seções bidimensionais oscilando em balanço. Adotam-se modelos representativos do movimento segundo este único grau de liberdade. Estimam-se os parâmetros de inércia e de amortecimento hidrodinâmicos por meio de experimentos de decaimento. Simulações numéricas incorporando os parâmetros estimados experimentalmente, bem como previsões empíricas de resultados da literatura, são confrontadas à registros experimentais para verificação da adequação das previsões, e para avaliação da adequação dos modelos à representação da dinâmica da oscilação.

Com a metodologia de análise escolhida, avalia-se a influência de determinados parâmetros sobre as propriedades hidrodinâmicas; consideram-se variações: de proporções da seção, de posição vertical do centro de massa, de inércia própria em balanço, de forma do bojo, e quanto a presença de bolina e suas proporções.

Também é considerada a influência do ângulo inicial de banda nas propriedades hidrodinâmicas, bem como a participação da energia irradiada pela onda na energia acumulada pelo sistema anterior ao início do movimento.

Os elementos anteriores levam à proposição de orientações para avaliação da influência das propriedades geométricas e inerciais no comportamento do casco em balanço. 


\begin{abstract}
The scope of this work is the verification of hydrodynamic properties of two dimensional rolling sections. Analytical models of a single degree-of-freedom movement are adopted. The added inertia and damping are estimated by free decay tests. Numerical simulations with the obtained experimental parameters as well as empirical literature results are compared to the data tests in order to verify the adequacy of the procedures.

With the chosen method of analysis, the influence of the hydrodynamic parameters are verified. The following parameters are considered: the beam draft ratio, vertical position of center of gravity, moment inertia, bilge shape and the addition or not of bilge keels.

The initial angle of roll is also considered as well as the transport of the energy accumulated before the decay by the wave generated by the movement of the model.

These elements lead to the proposition of orientations for the verification of the influence of geometric and inertial properties in the behave of rolling two-dimensional sections.
\end{abstract}




\section{Lista de Figuras}

2.1 Sistema de coordenadas para uma onda progressiva. . . . . . . . . . . . . . . 11

2.2 Coluna de fluido considerada no equacionamento da densidade de energia superficial da onda por unidade de área. . . . . . . . . . . . . . . . . . . . . . 14

2.3 Diagrama do equilíbrio hidrostático de uma seção bidimensional. . . . . . . . . 18

2.4 Esquema das dimensões consideras nas seções ensaiadas para caracterização do escoamento oscilatório. . . . . . . . . . . . . . . . 21

2.5 Máximos locais sucessivos entre ciclos durante o decaimento. . . . . . . . . . . 24

2.6 Diagrama de um corpo suspenso por dois fios equilibrado em torno de seu centro de gravidade. . . . . . . . . . . . . . . . . . . . . . . 34

2.7 Projeção da força exercida pelo fio no plano horizontal. . . . . . . . . . . . . 34

3.1 Diagrama da proposta do trabalho. . . . . . . . . . . . . . . . . . 38

4.1 Diferentes geometrias testadas. . . . . . . . . . . . . . . . . . . . 39

4.2 Desenho esquemático do canal de testes. . . . . . . . . . . . . . . . 40

4.3 Esquema de um corte transversal da montagem do modelo no tanque de testes do laboratório de engenharia naval e oceânica da Escola Politécnica. . . . . . . 41

4.4 Medição do momento de inércia do modelo de bojo arredondado. . . . . . . . . . 42

4.5 Diferentes proporções de $B / T$ ensaiadas. . . . . . . . . . . . . . . . . . . 42

4.6 Vistas lateral (à esquerda) e superior (à direita) da configuração de lastro para o calado máximo com centro de gravidade mais baixo na vertical. . . . . . . . 43

4.7 Vistas lateral (à esquerda) e superior (à direita) da configuração de lastro para o calado máximo com centro de gravidade mais alto na vertical. . . . . . . . .

4.8 Foto da montagem do ensaio de decaimento com o dispositivo para abandono do modelo em destaque (linha branca). . . . . . . . . . . . . . . . 45

4.9 Redução dos dados do ensaio com bojo arredondado no calado maior. . . . . . 48

4.10 Redução dos dados do ensaio com bolina maior no calado maior. . . . . . . . . 49

4.11 Redução dos dados do ensaio com bolina menor no calado maior. . . . . . . . . 50

4.12 Redução dos dados do ensaio com bojo quinado no calado maior. . . . . . . . . 51

4.13 Massas adicionadas adimensionais para as diferentes geometrias no calado médio. 52

4.14 Comparação entre os coeficientes de amortecimento linear médio para as diferentes geometrias no calado médio. . . . . . . . . . . . . . . 53

4.15 Comparação entre as massas adicionadas adimensionais para as diferentes geometrias no calado máximo. . . . . . . . . . . . . . . . . . . . . .

4.16 Comparação entre os coeficientes de amortecimento linear médio para as diferentes geometrias no calado máximo. . . . . . . . . . . . . . 
4.17 Comparação entre as massas adicionadas adimensionais para as diferentes geometrias no calado mínimo . . . . . . . . . . . . . . . . 56

4.18 Comparação entre os coeficientes de amortecimento linear médio para as diferentes geometrias no calado mínimo . . . . . . . . . . . . . 57

4.19 Modelagens de amortecimento e restauração e a série temporal para a geometria bojo arredondado. . . . . . . . . . . . . . . . . .

4.20 Modelagens de amortecimento e restauração e a série temporal para a geometria bojo arredondado com bolina menor. . . . . . . . . . . . . . . . .

4.21 Modelagens de amortecimento e restauração e a série temporal para a geometria bojo arredondado com bolina maior. . . . . . . . . . . . . . . . .

4.22 Modelagens de amortecimento e restauração e a série temporal para a geometria bojo quinado. . . . . . . . . . . . . . . . . . . . .

4.23 Espectro de potência da onda gerada pelo modelo na condição bojo arredondado no calado médio. . . . . . . . . . . . . . . . . . . . .

4.24 Comparação entre registro temporal e simulação com coeficientes obtidos através de análise por ciclos médio para o caso bojo arredondado. . . . . . . . . . . . .

4.25 Comparação entre registro temporal e simulação com coeficientes obtidos através de análise por ciclos médio para o caso bojo arredondado. . . . . . . . . . . . .

4.26 Comparação entre registro temporal e simulação com coeficientes obtidos através de análise por ciclos médio para o caso bojo arredondado. . . . . . . . . . . . .

B.1 Geometria confeccionado na bancada do Laboratório do Departamento de Engenharia Naval e Oceânica. . . . . . . . . . . . . . . . . . .

B.2 Calibração da seção no laboratório. Medição do momento de inércia por meio de ensaio bifilar. . . . . . . . . . . . . . . . . . 83

B.3 Foto da tampa e da calha utilizadas na confecção da seção cilíndrica. . . . . . . 84

B.4 Geometria bojo arrendondado com bolina maior. . . . . . . . . . . . . . . 84

B.5 Detalhe da fixação da geometria bojo arrendondado com bolina maior. . . . . 85

B.6 Geometria bojo quinado com o sistema de pivotamento em primeiro plano. . . 85

B.7 Setup do ensaio em posição inicial. . . . . . . . . . . . . . . . . 86

B.8 Liberação do corpo para oscilar livremente. . . . . . . . . . . . . . . . . . . . . 86 


\section{Lista de Tabelas}

4.1 Matriz de ensaios . . . . . . . . . . . . . . . . . . . . . . . 46

4.2 Inércia adicionada adimensional em função da geometria da seção para o calado

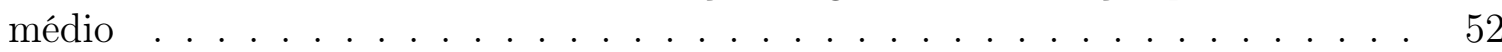

4.3 Inércia adicionada adimensional em função da geometria da seção para o calado médio . . . . . . . . . . . . . . . . . . . . 53

4.4 Inércia adicionada adimensional em função da geometria para o calado máximo 54

4.5 Inércia adicionada adimensional em função da geometria da seção para o calado máximo . . . . . . . . . . . . . . . . . . 55

4.6 Inércia adicionada adimensional em função da geometria para o calado mínimo 56

4.7 Amortecimento linear médio em função da geometria da seção para o calado mínimo . . . . . . . . . . . . . . . . . . . . . 57

4.8 Efeito do ângulo inicial na inércia adicionada . . . . . . . . . . . . . 58

4.9 Efeito do ângulo inicial no amortecimento linear . . . . . . . . . . . . 58

4.10 Influência no amortecimento linear pela alteração das condições de inércia . . . 59

4.11 Influência na inércia adicionada pela alteração das condições de inércia . . . 59

4.12 Estimativa da energia carregada pela onda irradiada e sua participação na energia potencial no início do decaimento . . . . . . . . . . . . . 65

A.1 Relação dos ensaios com bojo quinado. . . . . . . . . . . . . . 78

A.2 Relação dos ensaios com bolina grande. . . . . . . . . . . . . . . . . . . . . . 79

A.3 Relação dos ensaios com bolina pequena. . . . . . . . . . . . . . . . . . . 80

A.4 Relação dos ensaios com bojo quinado. . . . . . . . . . . . . . . . . . 81 


\section{Lista de Símbolos}

V

$\rho$

$t$

$\mu$

i

k

$\Phi$

$x$

$z$

$p_{a t m}$

$p_{\text {superfcie }}$

$\eta$

$\omega$

$v$

A

$\phi$

$k$

$\lambda$

$g$

u

$w$

V

$E_{\text {mecanica }}$

$E_{\text {cinetica }}$

$E_{\text {potencial }}$

$h$

$\dot{\phi}$

$\ddot{\phi}$

I

c

$k$

$\alpha$

A

$B$

$c_{c}$

$\zeta$ velocidade vetorial de uma partícula fluida ....................... 11

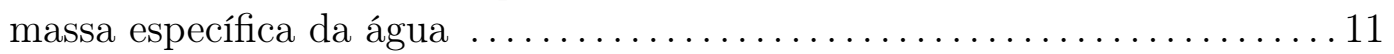

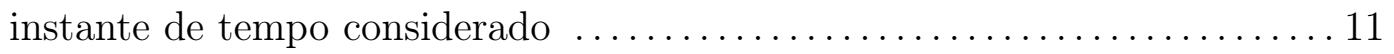

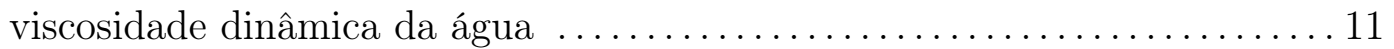

vetor unitário orientado na direção de propagação da onda $\ldots \ldots \ldots \ldots \ldots 11$

vetor unitário orientado na direção vertical à propagação da onda $\ldots \ldots 16$

potencial de um campo de velocidades $\ldots \ldots \ldots \ldots \ldots \ldots \ldots \ldots \ldots \ldots \ldots \ldots$

eixo coordenado orientado na direção horizontal $\ldots \ldots \ldots \ldots \ldots \ldots \ldots \ldots \ldots \ldots$

eixo coordenado orientado na direção direção vertical $\ldots \ldots \ldots \ldots \ldots \ldots \ldots 12$

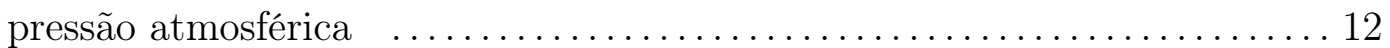

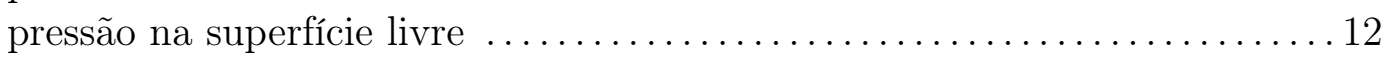

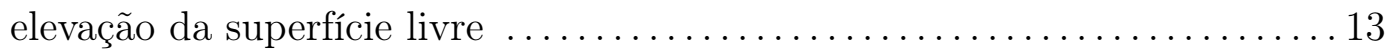

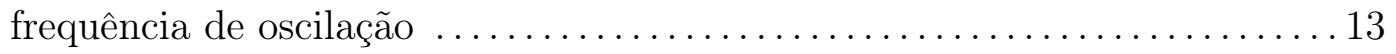

velocidade de fase de uma onda progressiva $\ldots \ldots \ldots \ldots \ldots \ldots \ldots \ldots \ldots \ldots$

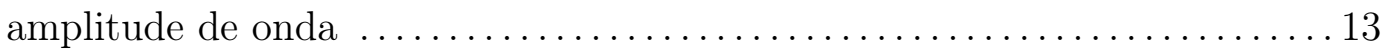

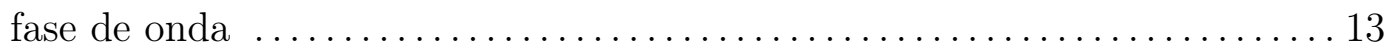

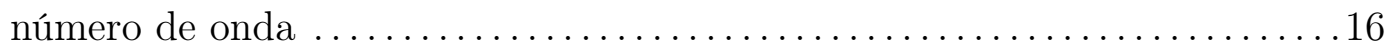

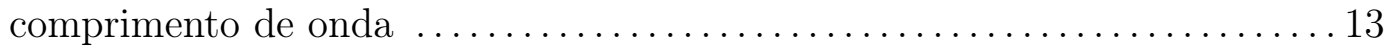

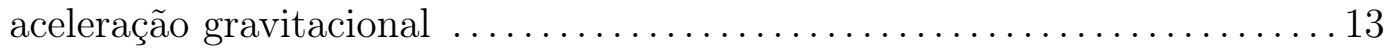

velocidade de partícula fluida na direção horizontal $\ldots \ldots \ldots \ldots \ldots \ldots \ldots 14$

velocidade de partícula fluida na direção vertical $\ldots \ldots \ldots \ldots \ldots \ldots \ldots \ldots . \ldots 14$

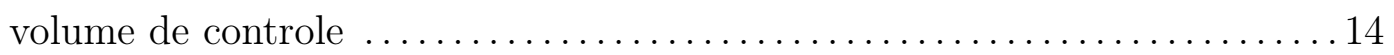

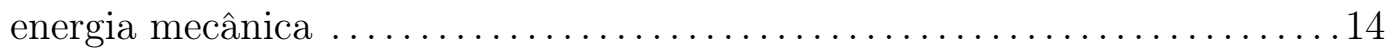

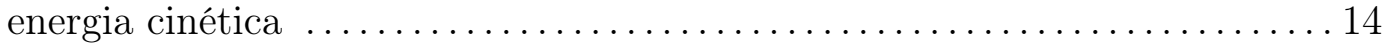

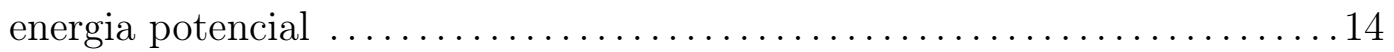

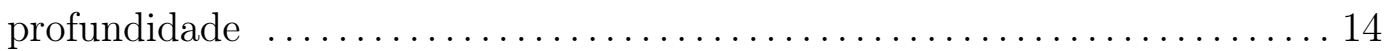

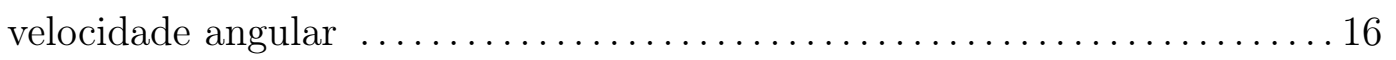

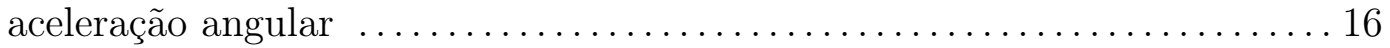

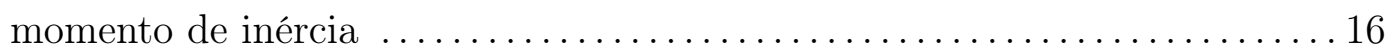

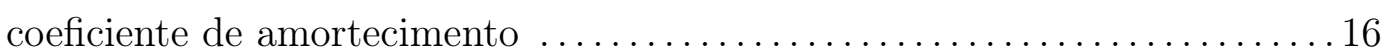

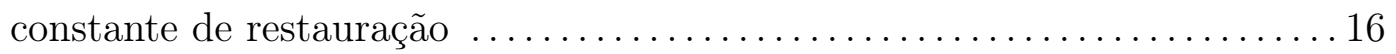

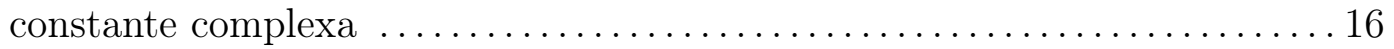

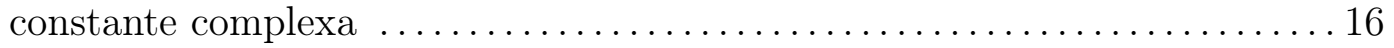

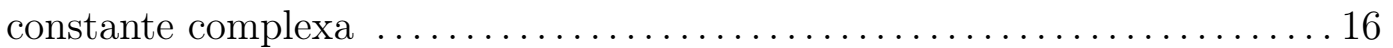

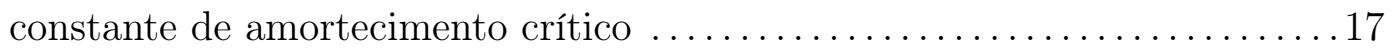

coeficiente adimensional de amortecimento linear $\ldots \ldots \ldots \ldots \ldots \ldots \ldots \ldots$ 


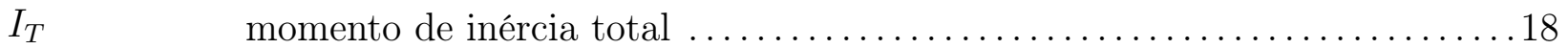

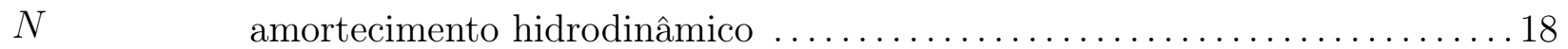

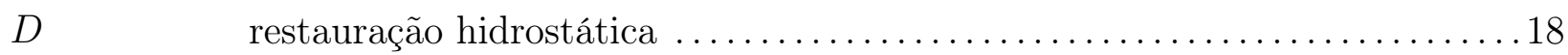

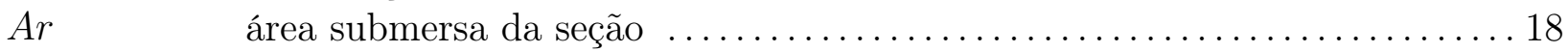

$B_{1} \quad$ constante de amortecimento linear com a velocidade $\ldots \ldots \ldots \ldots \ldots \ldots \ldots$

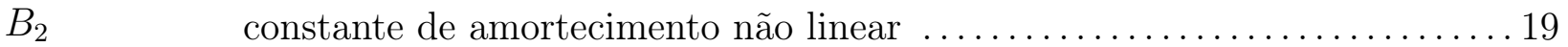

$\Delta \quad$ deslocamento volumétrico de corpo imerso $\ldots \ldots \ldots \ldots \ldots \ldots \ldots \ldots \ldots$

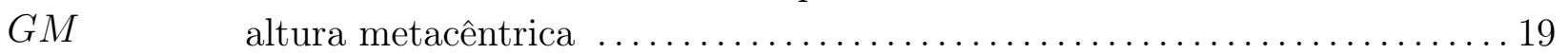

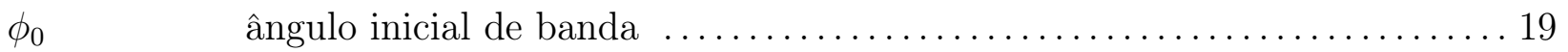

$B_{e} q \quad$ constante de amortecimento linear equivalente $\ldots \ldots \ldots \ldots \ldots \ldots \ldots \ldots \ldots$

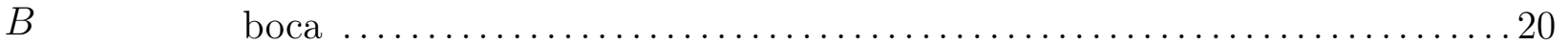

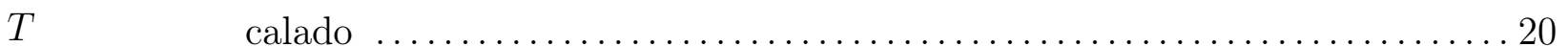

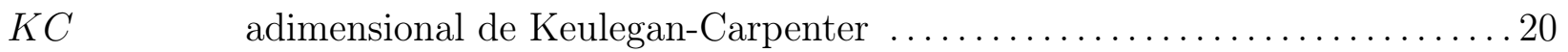

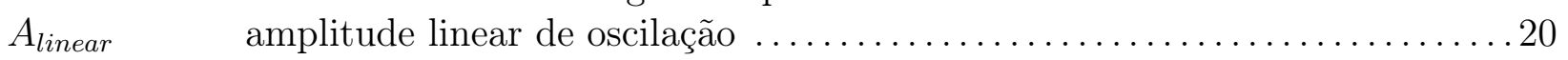

$T_{\text {contorno }}$ tempo que uma partícula leva para contornar a geometria da seção . . ...21

$T_{\text {reverso }} \quad$ tempo necessário para reversão do movimento de oscilação $\ldots \ldots \ldots \ldots 21$

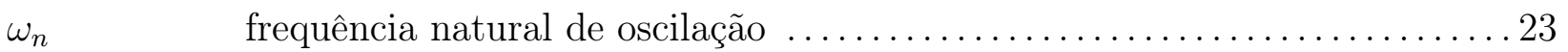

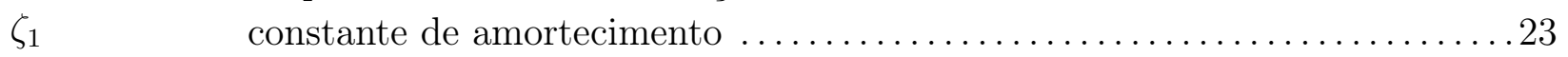

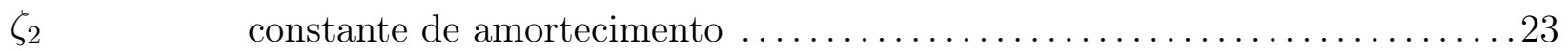

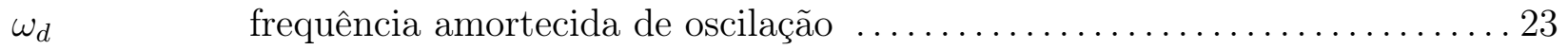

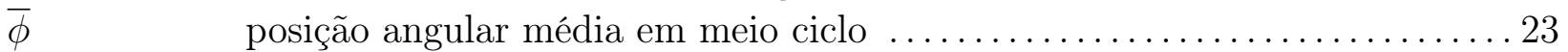

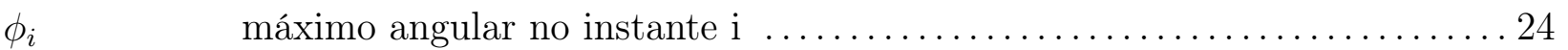

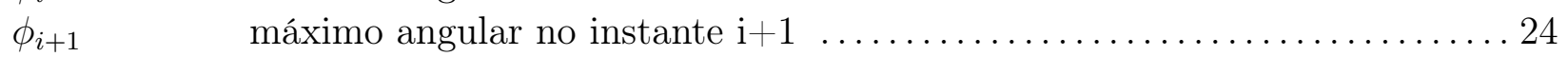

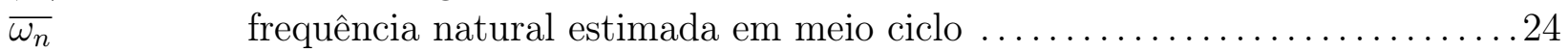

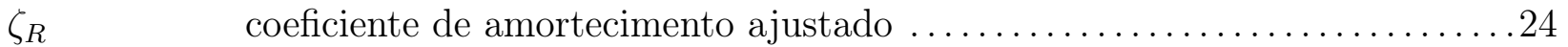

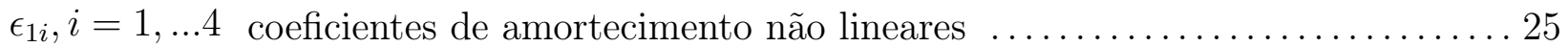

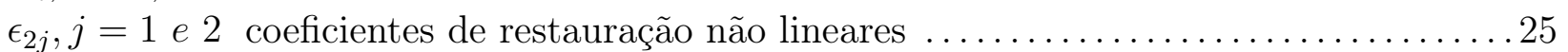

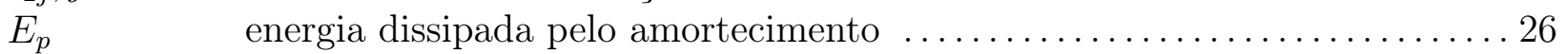

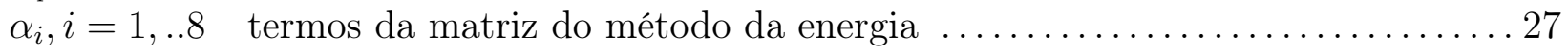

$\hat{\alpha}_{i} \quad$ estimativas dos termos da matriz do método da energia $\ldots \ldots \ldots \ldots \ldots 27$

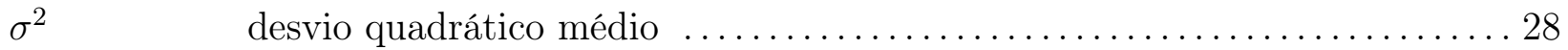

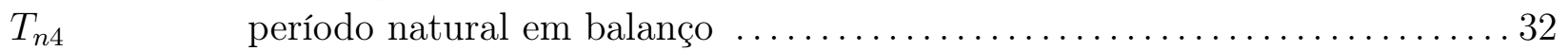

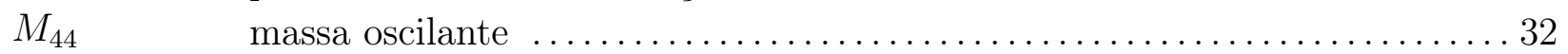

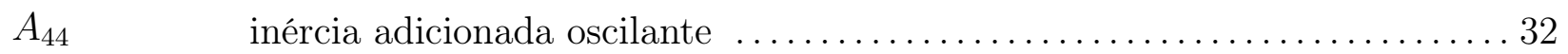

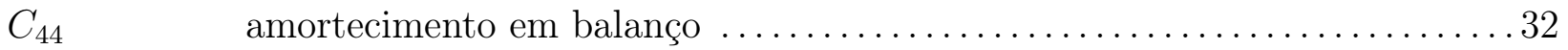

$r_{44}$

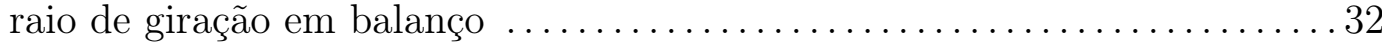




\section{Sumário}

Dedicatória $\quad$ iv

Agradecimentos $\quad$ v

Resumo vi vi vis

$\begin{array}{lll}\text { Abstract } & \text { vii }\end{array}$

Lista de Figuras $\quad$ viii

Lista de Tabelas $\quad$ x

Lista de Símbolos $\quad$ xi

Sumário $\quad$ xiii

1 Introdução $\quad 1$

1.1 Contexto . . . . . . . . . . . . . . . . . . . . . 1

1.2 Revisão bibliográfica . . . . . . . . . . . . . . . . . . . . . . . . . . . . . . . . . . . . . . .

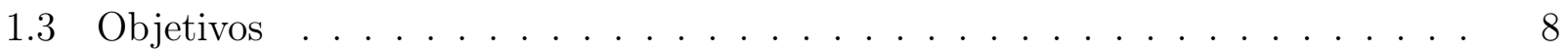

1.4 Conteúdo do trabalho . . . . . . . . . . . . . . . . . . 8

2 Fundamentos 10

2.1 Introdução . . . . . . . . . . . . . . . . . . . . . . . . . . 10

2.2 Energia de onda monocromática linear . . . . . . . . . . . . . . . 10

2.2.1 Modelo linear de ondas . . . . . . . . . . . . . . . . . . 11

2.3 Densidade de energia da onda por unidade de área . . . . . . . . . . . . . . . 14

2.4 Modelo analítico do oscilador livre amortecido de grau um de liberdade . . . . 16

2.5 Modelo analítico para uma seção em balanço . . . . . . . . . . . . . . . 18

2.6 Análise dimensional e similaridade para ensaios de balanço . . . . . . . . . . . 20

2.6.1 Caracterização de escoamentos oscilatórios - o adimensional de Keulegan

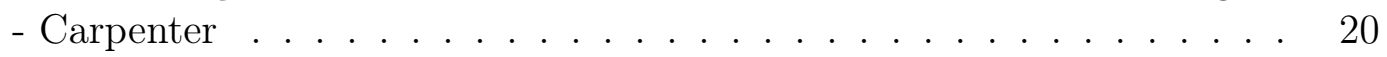

2.7 Modelos experimentais de estimativa de inércia e amortecimento hidrodinâmicos em balanço . . . . . . . . . . . . . . . . . . . . . . . . 23

2.7.1 Método do amortecimento linear equivalente pela energia média entre

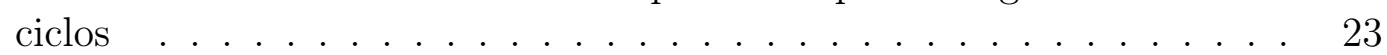

2.7.2 Método do balanço da energia . . . . . . . . . . . . 25 
2.8 Obtenção da inércia hidrodinâmica à partir dos resultados experimentais . . . 32

2.9 Determinação experimental de momento de inércia pelo método bifilar . . . . . 33

3 Proposta

3.1 Determinação de Inércia Adicionada e de Amortecimento de Seções 2D Oscilando em Balanço em Ensaios de Decaimento . . . . . . . . . . . . . . . . 36

4 Desenvolvimento da proposta $\quad 39$

4.1 Descrição . . . . . . . . . . . . . . . . . . . . . . . . . . . . . . . . . 39

4.1 .1 Planejamento . . . . . . . . . . . . . . . . . . . . . . . . . . . 39

4.1.2 Ajuste das características de inércia das seções . . . . . . . . . . . . . . 43

4.1 .3 Instrumentação . . . . . . . . . . . . . . . . . . . . . . . . . . . . . . . . . . .

4.2 Os ensaios . . . . . . . . . . . . . . . . . . . . . . . . . . 45

4.3 Resultados . . . . . . . . . . . . . . . . . . . . 47

4.3.1 Processamento dos dados experimentais . . . . . . . . . . . . 47

4.3.2 Amortecimento linear médio e coeficiente de massa adicionada . . . . . 52

4.3.3 Verificação da influência do ângulo inicial . . . . . . . . . . . . . . 58

4.3.4 Efeito do momento de inércia e centro de gravidade no amortecimento e inércia adicionada . . . . . . . . . . . . . . . 59

4.3.5 Método da energia: estudo de termos não-lineaes de amortecimento e inércia adicionada empregados para cada geometria . . . . . . . . . . . 60

4.3.6 Energia das ondas irradiadas em balanço . . . . . . . . . . . . . . 64

4.4 Análise: obtenção do amortecimento e da inércia adicionada . . . . . . . . . . 65

4.4.1 Seleção de Modelo . . . . . . . . . . . . . . . . . . . . . 65

4.4 .2 Análise dos resultados . . . . . . . . . . . . . . . . . . . . 69

$\begin{array}{lll}5 & \text { Conclusões e recomendações } & \mathbf{7 0}\end{array}$

5.1 Conclusões . . . . . . . . . . . . . . . . . . . . . . 70

5.2 Recomendações . . . . . . . . . . . . . . . . . . . . . . 71

$\begin{array}{ll}\text { Referências Bibliográficas } & 72\end{array}$

$\begin{array}{ll}\text { A Relação de ensaios } & 77\end{array}$

B Registro fotográfico dos ensaios $\quad 82$ 


\section{Capítulo 1}

\section{Introdução}

\subsection{Contexto}

Observa-se a expansão das fronteiras petrolíferas brasileiras para águas de profundidades superiores a três mil metros, dentro da qual cresce o trânsito de embarcações como rebocadores em operações offshore, navios aliviadores, navios plataforma tipo FPSO, navios sondas e navegação de cabotagem, com possível enfrentamento de condições severas de amplitude de ondas.

A segurança da navegação por estas áreas, principalmente pelo comportamento em ondas do navio durante seu trajeto, deve ser objeto de estudo para se evitar grandes amplitudes de movimento e acelerações que podem causar danos à embarcação e provocar a perda de vidas humanas.

Um dos objetivos da hidrodinâmica desde pelo menos o século XIX [22] tem sido avaliar a probabilidade de ocorrência de respostas indesejáveis do navio às solicitações do meio ambiente . Estes estudos têm-se valido de investigação analítica, testes com modelos reduzidos e, mais recentemente, análises numérico-computacionais. O conjunto destas disciplinas são ferramentas importantes no projeto de embarcações e sistemas oceânicos, que podem ser úteis no desenvolvimento de soluções para sistemas que possam apresentar movimento excessivo.

Dentre os movimentos do navio, o movimento de balanço ou roll apresenta-se como um dos mais importantes no que se refere à segurança da embarcação; geralmente, é o que apre- 
senta maiores amplitudes de movimento e que apresenta maiores dificuldades de modelagem analítico-numérica devido à variedade de regimes de escoamento envolvidos.

Recentemente, o emprego de grandes navios petroleiros como navios plataforma estacionários na costa brasileira, especialmente quando amarrados na condição de torre ou turret implicando no enfrentamento de grandes ondas incidindo transversalmente ao casco durante certas condições de mar. Para estas embarcações, são registradas importantes amplitudes de oscilação que podem ser minimizadas por meio do emprego de grandes bolinas.

O movimento de balanço é influenciado pela geometria da seção oscilante e pelas suas propriedades de inércia. Tal influência pode ser verificada por meio de duas propriedades hidrodinâmicas fundamentais: massa adicionada e amortecimento.

Para uma investigação focada no movimento de balanço, opta-se pela situação de balanço puro, onde somente é possível o movimento ao redor de um eixo paralelo ao comprimento da embarcação. Para este tipo de movimento e para cada geometria ensaiada são estimados a inércia adicionada e o amortecimento .

O ensaio adotado para estudar a dinâmica da embarcação com foco nos parâmetros acima descritos é o decaimento livre para um grau de liberdade com seções bidimensionais, largamente empregado para a determinação destes atributos hidrodinâmicos.

Para este ensaio, são necessários recursos para registro da velocidade angular, ângulo inicial de ensaio medição da geometria e das propriedades inerciais do modelo (raio de giração e centro de gravidade). O dispositivo empregado, neste caso, foi um girômetro ou rate-gyro de estado sólido. Este dispositivo, acoplado a um condicionador eletrônico e equipamento para aquisição de sinais, é suficiente para a obtenção do registro temporal da velocidade e, por meio de métodos numéricos de integração, da posição angular durante o decaimento.

As seções bidimensionais eliminam outros fatores geométricos que podem afetar os atributos hidrodinâmicos do corpo, como uma assimetria entre proa e popa.

Para avaliar diferenças qualitativas e quantitativas no movimento são testadas quatro seções com características geométricas diferentes.

Uma das seções ensaiadas é com bojo arredondado, com pode ser encontrado em embar- 
cações. Também são ensaiadas duas alturas de bolina posicionadas sobre o bojo arredondado, solução comumente utilizada como dispositivo mitigador de movimentos. Este dispositivo pode alcançar tamanhos relativamente maiores que os convencionais para sistemas offshore, como os navios plataforma. Emprega-se também, para a mesma geometria, quinas com efeitos semelhantes aos da presença de bolinas.

Outros parâmetros que podem influir são as condições de inércia, momento de inércia e centro de gravidade do modelo. Testa-se a sensibilidade da dinâmica do modelo relativas a estas mudanças.

São empregados três variações de calados, denominados médio, mínimo e máximo, para verificar sua influência nos atributos hidrodinâmicos do sistema.

Pode-se, utilizando-se os resultados dos ensaios, avaliar a variação dos parâmetros de inércia adicionada e do amortecimento para as geometrias ensaiadas, por meio de métodos de análise propostos em literatura.

O trabalho é parte da linha de pesquisa sobre identificação de atributos hidrodinâmicos do movimento de balanço de navios, relevante para a verificação da segurança e conforto das embarcações.

\subsection{Revisão bibliográfica}

Seguem os registros de alguns trabalhos correlatos de predição dos atributos hidrodinâmicos de interesse, em ordem cronológica.

Froude (1955) [22],no século XIX, realiza ensaios pioneiros na investigação da dinâmica do movimento em balanço. Promove experimentos de decaimento livre com modelos pinados em escala reduzida de embarcações e registra a sua evolução temporal. Propõe a substituição dos termos não-lineares do amortecimento por um termo linear equivalente em termos da energia dissipada por ciclo.

Bass e Haddara (1988) [3] propõem a aplicação de método de balanço de energia para ensaios de decaimento em balanço. Modelam as funções de amortecimento e restauração por 
termos lineares e não-lineares.

Haddara e Bennett (1989) [24] analisam funcionalmente o amortecimento de modelos em ensaios de decaimento em balanço. Consideram embarcações com e sem bolina e com e sem velocidade de avanço. Aplicam o método do balanço de energia, verificando a forte dependência da posição angular nas estimativas.

Faltinsen (1990) [13] apresenta técnicas experimentais para determinação de massa adicionada e amortecimento por meio do modelo de amortecimento linear equivalente a energia média dissipada por ciclo. Chakrabarti (1995) [7] apresenta a mesma modelagem por meio da identificação dos extremos dos movimentos e posterior análise do amortecimento por meio do decremento logarítmico. Ambos os casos são derivações do metodologia introduzida por Froude (1955) [22], que estima a energia média por ciclo, com a hipótese do movimento ser um oscilador harmônico com amortecimento subcrítico.

Contento et al (1995) [10] analisaram o balanço de navios Ro-Ro sob ondas regulares de través, usando modelo quadrático para o amortecimento e de quinto grau para a restauração. Indicam a importância da consideração de não linearidades na representação do fenômeno.

Chan et al (1995) [9] comparam dois métodos para identificação de propriedades hidrodinâmicas do navio em balanço a partir de curvas de decaimento. No primeiro simulam o balanço com valores adotados para o amortecimento e a restauração. No segundo aplicam método assintótico e método de energia para recuperar os coeficientes hidrodinâmicos, comparando os resultados com os valores anteriormente adotados. Admitem representações quadrática e cúbica para o amortecimento, e polinomial para a restauração compatível com a condição de limite de emborcamento.

Souza Jr et al (1998) [39] investigam numérica e empiricamente o movimento não linear de um FPSO ancorado. Foram utilizados dois procedimentos para determinação do amortecimento. Um deles baseou-se no amortecimento linear equivalente por média entre ciclos proposto por Froude (1955) [22]; outro método sugere a correlação de n-ciclos. É descartada a hipótese de que o amortecimento seja constante ao longo da trajetória de decaimento. Desse modo, é necessário levar-se em conta a região do decaimento para estimar o decai- 
mento. Maiores valores de amortecimento ocorrem no início do decaimento devido às grandes amplitudes de deslocamento. O amortecimento nos últimos ciclos é pequeno, sendo considerado linear. Considera-se a não-linearidade na dependência do amortecimento de um ciclo em relação aos ciclos e amplitudes anteriores.

Taylan (2000) [42] simula o balanço de diferentes tipos de navios, aplicando método assintótico para obter os picos espectrais da resposta. Conclui que a adequação dos modelos empregados dependem do tipo de embarcação.

Chakrabarti (2001) [8] apresenta método baseado em coeficientes empíricos para estimar as contribuições das diversas componentes do amortecimento. O amortecimento é modelado em termos não-lineares até a ordem cúbica. Ele divide o amortecimento em diversas parcelas, relacionadas a fenômenos distintos: atrito viscoso com a superfície do casco, emissão de vorticidade pelo casco, efeitos de superfície livre, força de sustentação e presença de bolinas. São expressas formulações para testes estacionários e testes com velocidades de avanço. Efeitos de escoamento tridimensional podem alterar os valores dos coeficientes. Cada parcela de amortecimento é considerada isoladamente, não sendo considerados os efeitos de interação entre os termos. Uma vez que as expressões foram derivadas de ensaios em modelos reduzidos, os efeitos de escala, ainda que possivelmente pequenos, podem ocorrer nos coeficientes acima.

Ferrari e Ferreira (2002) [18] aborda a modelagem por amortecimento linear equivalente para modelos de navios FPSO em três calados e diversas combinações de bolina com variações de altura e de comprimento ao longo do casco. Os coeficientes de amortecimento linear e não-linear são aferidos para cada caso constatando-se uma diminuição das amplitudes de oscilação em balanço para tamanhos crescentes de bolina. Ocorre um aumento na frequência de oscilação conforme a ampliação da dimensão das bolinas, condizente com o aumento da inércia adicionada.

Moinuddin et al (2003) [33] aborda por meio de um estudo experimental em escoamento confinado a separação ao redor de uma seção quinada e o impacto do desenvolvimento da camada limite turbulenta sobre o arrasto. Conclui que as velocidades que se formam no entorno da quina estão associadas à presença de vorticidade. A direção destes vórtices é 
contrária à direção bissetora da quina e o escoamento retorna e atinge as paredes da seção.

Ueno et al (2003) [43] identificam para pesqueiros em balanço atributos hidrodinâmicos por meio de decaimento livre, adotando representações puramente quadrática, quadrática mais linear, e racional quadrática para o amortecimento, e cúbica para a restauração. Aplicam o método da energia aos valores dos picos da curva de decremento do balanço, e o método do algoritmo genético. Comparam resultados numéricos com experimentais.

Irvine el al (2004) [27] realizam experimentos de decaimento livre em balanço puro em tanque de provas com um modelo de embarcação rápida com e sem a presença de bolinas. Também são verificados os movimentos acoplados de arfagem e caturro. São avaliados os períodos de oscilação e coeficientes de amortecimentos para diferentes números de Froude com e sem a presença de bolina. Médias de fase das velocidades no entorno das bolinas são avaliadas por meio de velocimetria de imagens por partículas PIV (particle image velocimetry).

Lewandowski (2004) [30] apresenta técnicas semi-empíricas de amortecimento em balanço equivalente linear, como proposto por Froude (1955) [22] e a técnica proposta por Himeno (1981) [25]. Tal formulação origina-se de resultados empíricos combinados com uma modelagem da distribuição da pressão ao longo do casco durante o balanço para velocidade de avanço nula. Adota-se nesse trabalho coeficientes de arrasto para o casco liso e para as bolinas, o que torna a formulação mais conveniente para a estimativa do termo de amortecimento quadrático. O método proposto é formulado somente para casos de navios convencionais e nas vizinhanças da frequência natural.

Jung el al (2005) [29] apresenta medições de características do escoamento no entorno de seções bidimensional em balanço puro devido à excitação de ondas em um canal de testes bidimensional. A técnica PIV é utilizada para medir o campo de velocidades ao redor da estrutura. Investigam o amortecimento devido à geração de vorticidade por meio da observação do campo de velocidades. A interação do escoamento gerado pela oscilação com a onda e a investigação da escala de turbulência e do balanço da energia cinética turbulenta são relacionados ao movimento da seção. Observa-se que a fase de emissão de vorticidade pelas quinas da seção é invertida caso as ondas incidentes estejam próximas à ressonância do modelo 
relativamente à fase de emissão de vorticidade caso as ondas incidentes estejam afastadas da ressonância.

Surendran et al (2005) [40] realizam simulação numérica com coeficientes hidrodinâmicos adotados para um navio Ro-Ro hipotético. Admitem representação quadrática para o amortecimento e de quinto grau para a restauração. Analisa a influência dos coeficientes admitidos na resposta .

Asghari et al (2007) [1] analisam o balanço de um navio graneleiro sob um momento excitador tipo degrau, em que a resposta oscilatória tende a um valor limite. Resultados experimentais são comparados com previsões analítico-numéricas pelos métodos da energia e da simulação no domínio do tempo. No caso do método da energia não se considera o amortecimento; na simulação considera-se amortecimento linear.

Fernandes e Ferreira (2009) [17] propõem outra abordagem para a análise da curva de decaimento de modelos em escala reduzida de cascos com fundo chato de navios tipo VLCC com bolina em dois trechos. Afirma-se que o método de ajuste da curva de amortecimento para obtenção do coeficiente de amortecimento linear equivalente não consegue apreender adequadamente o comportamento não linear do movimento para este tipo de geometria. Por este motivo, é proposto o método bilinear que ajusta um amortecimento linear diferente para cada trecho do decaimento. A primeira parte, região de grande amplitude de movimento, o amortecimento é significativamente maior, associado à grandes vórtices gerados nas bolinas e atraídos em direção ao fundo durante o movimento. A segunda região caracteriza-se por uma mudança no regime do escoamento, com pares de vórtices de menor tamanho sendo emitidos na direção em que a bolina aponta que geram um amortecimento de menor monta.

Jang et al (2010) [28] transformam o problema de decaimento em balanço em um problema com integral de Volterra de primeira espécie, visando a identificação da forma funcional do amortecimento. Aplicam o procedimento a resultados experimentais do decaimento em balanço para um modelo de navio pesqueiro. Comparam a forma funcional do amortecimento obtida pelo procedimento proposto com modelo quadrático de amortecimento.

Asghari et al (2010) [2] avaliam o amortecimento em balanço de um navio graneleiro por 
meio de ensaios de decaimento livre. Simulações numéricas indicam que a adoção de representação polinomial de quinta potência no ângulo de balanço para a restauração e de terceira potência na velocidade de balanço para o amortecimento levam a uma melhor aderência com os resultados experimentais.

\subsection{Objetivos}

Objetiva-se verificar a influência de propriedades geométricas e inerciais de seções bidimensionais na inércia adicionada e no amortecimento de balanço.

\subsection{Conteúdo do trabalho}

O conteúdo do trabalho está dividido, além desta seção introdutória, nas seguintes seções: 2 Fundamentos; 3 - Proposta; 4 Desenvolvimento da Proposta; 5 Conclusões e recomendações; 6 Referências bibliográficas; 7-Anexos.

- seção 1: Introdução

Nesta seção é o trabalho é introduzido.

- seção 2: Fundamentos

Expõe-se aqui os fundamentos teóricos utilizados na tratamento analítico dos dados experimentais.

- seção 3: Proposta

O conteúdo desta seção é composto pelo detalhamento da proposta de determinação de atributos hidrodinâmicos do casco, em geometrias semelhantes àquelas ensaiadas.

Estabelece-se orientações para avaliação da influência das propriedades geométricas e inerciais no comportamento do casco em balanço. 
- seção 4: Desenvolvimento da Proposta

A seção apresenta a descrição do arranjo experimental e os resultados experimentais.

É apresentada a redução dos resultados experimentais, e a aplicação do método de coeficiente linear médio. Também foi realizada uma aplicação do método que leva em conta o balanço de energia do movimento elaborado por Haddara [24].

Com elementos fornecidos pelas análises acima mencionadas, são apresentados os resultados comparativos dos métodos empregados para os quatro casos de geometria de seção, os três calados e as duas variações de momento de inércia e centro de gravidade. São avaliadas a sensibilidade dos atributos em relação ao calado e ao ângulo inicial de banda.

Considerações são apresentadas, sobre a adequação dos métodos utilizados. A massa adicionada e o amortecimento são analisados para cada tipo de geometria e seus resultados são apresentados. É verificada a influência de outros parâmetros com respeito aos resultados obtidos.

- seção 5: Conclusões e Recomendações

Apresenta-se nesta seção a conclusão do trabalho realizado. Em seguida, são apresentadas recomendações para a aplicação dos métodos utilizados na análise de ensaios hidrodinâmicos de decaimento com modelos em escala reduzida.

- Anexos

Em anexo apresenta-se a documentação fotográfica do arranjo experimental. Informações relevantes das geometrias ensaiadas, como as condições de inércia, estão documentadas. 


\section{Capítulo 2}

\section{Fundamentos}

\subsection{Introdução}

Neste capítulo apresentam-se o modelamento da energia de onda monocromática linear. Em seguida, apresentam-se o modelo analítico para o oscilador livre amortecido com um grau de liberdade e sua aplicação para uma seção em balanço.

Consideram-se a análise dimensional e a similaridade para os ensaios de balanço e modelos experimentais de estimativa de inércia e amortecimento hidrodinâmicos.

\subsection{Energia de onda monocromática linear}

Apresenta-se a formulação da propagação de onda monocromática e das correspondentes energias cinética e potencial. Admite-se escoamento potencial e linearização da condição de contorno na superfície livre.

Considera-se aqui ondas de superfície, ou seja, ondas que ocorrem na interface ar-água. São ignoradas os outros tipo de propagação ondulatória na água como ondas capilares devido à efeitos de tensão superficial. 


\subsubsection{Modelo linear de ondas}

\section{Hipóteses}

Considera-se ondas de superfície, ou seja, ondas que ocorrem na interface ar-água. São ignorados outros tipos de propagação ondulatória na água como ondas capilares devido à efeitos de tensão superficial.

São assumidas as seguintes hipóteses:

fluido incompressível: $\frac{\partial \rho}{\partial t}=0$, sendo $\rho$ a massa específica no volume de controle e $t$ o tempo;

massa específica uniforme: $\nabla \rho=0$, sendo $\nabla \rho$ o divergente da massa específica;

fluido invíscido: $\mu=0$, sendo $\mu$ a viscosidade dinâmica;

irrotacional: $\nabla \times \mathbf{V}=0$, sendo $\mathbf{V}$ o campo de velocidades e $\nabla \times \mathbf{V}$ o rotacional do campo de velocidades ;

\section{escoamento bidimensional}

Sejam um referencial inercial de eixos ortonormais x,z, de versores $\mathbf{i}$ e $\mathbf{k}$, respectivamente, e um campo de velocidades $\mathbf{V}$, definido em dado volume de controle, e uma onda bidimensional conforme a figura 2.1 .

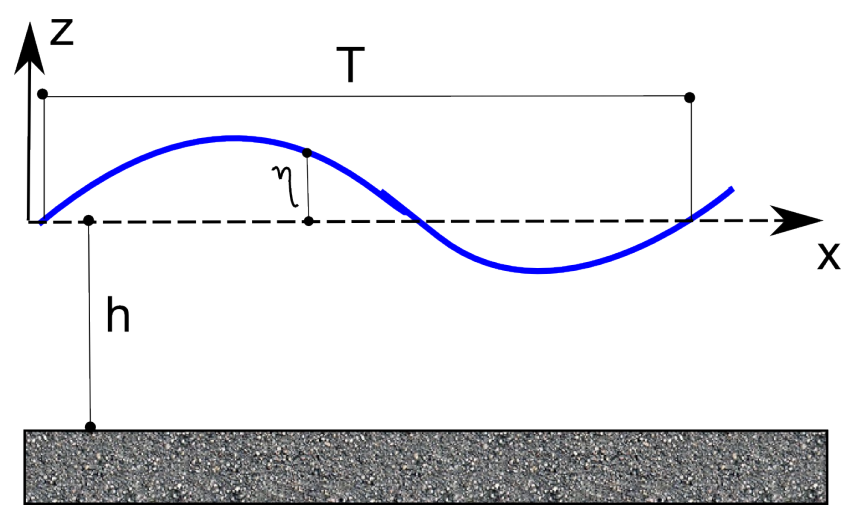

Figura 2.1: Sistema de coordenadas para uma onda progressiva.

Considera-se que o campo de velocidades é descrito por um potencial $\Phi$ tal que $\overrightarrow{\mathbf{V}}=\nabla \Phi$ 
$\Phi$ é denominado potencial de velocidades, portanto:

$$
\mathbf{V}=\nabla \Phi \equiv \frac{\partial \Phi}{\partial x} \mathbf{i}+\frac{\partial \Phi}{\partial z} \mathbf{k}
$$

Assumindo-se as hipóteses acima, o potencial de velocidades $\boldsymbol{\Phi}$ satisfaz a equação de Laplace:

$$
\frac{\partial^{2} \Phi}{\partial x^{2}} \mathbf{i}+\frac{\partial^{2} \Phi}{\partial z^{2}} \mathbf{k}=0
$$

Para a descrição analítica da onda monocromática, deve-se obter a solução da equação de Laplace, com linearização de termos para a obtenção das condições de contorno.

Considere-se agora a equação de Bernoulli :

$$
p+\rho g z+\rho \frac{\partial \Phi}{\partial t}+\rho \mathbf{V} \cdot \mathbf{V}=C_{t e}
$$

onde $C_{t e}$ assume o mesmo valor para todo o campo podendo variar no tempo.

Considere-se ainda que a única força de campo atuante é o a gravitacional.

Deste modo, sem perda de generalidade $C_{t e}=p_{a t m}$ e a pressão pode ser determinada.

Faz-se $z=0$ como o nível médio da superfície livre.

Para estas condições, ficam estabelecidas duas condições de contorno: uma delas de caráter cinemático e a outra de caráter dinâmico.

A condição cinemática linearizada na posição média da superfície livre, $z=0$, impõe que uma partícula fluida na superfície livre fique confinada nesta superfície.

Define-se eta como a elevação da superfície livre.

$$
\frac{\partial \eta}{\partial t}=\frac{\partial \Phi}{\partial \eta}
$$

A condição dinâmica da superfície livre impõe a igualdade entre pressões, $p_{\text {atm }}=p_{\text {superfcie }}$. 


$$
g z+\frac{\partial \Phi}{\partial t}=0
$$

em $\mathrm{Z}=0$

$\eta$, definida como a elevação da superfície livre, pode ser encontrada através da linearização da condição dinâmica quando $\Phi$ é conhecida.

Combinando-se as duas expressões anteriores chega-se à:

$$
\frac{\partial^{2} \Phi}{\partial t^{2}}+g \frac{\partial \Phi}{\partial z}=0
$$

$\mathrm{em} \mathrm{z}=0$

Admitindo-se $\Phi$ harmônico, e $\omega$ a frequência, tem-se:

$$
-\omega^{2} \Phi+g \frac{\partial \Phi}{\partial z}=0
$$

$\mathrm{em} \mathrm{z}=0$

\section{Ondas planas progressivas}

Considerando-se ondas bidimensionais, harmônicas com frequência $\omega$ e velocidade de fase $v$, as ondas progressiva podem ser expressas por 2.8 .

$$
\eta(x, t)=A \cos (k x-\omega t+\phi)
$$

$A$ é a amplitude de onda , $\phi$ a fase da onda, $k=\frac{2 \pi}{\lambda}$ o número de onda e $\lambda$ o comprimento de onda.

A solução da equação da superfície livre para onda plana progressiva resulta:

$$
\Phi=\frac{g A}{\omega} e^{k z} \sin (k x-\omega t)
$$

onde g é a aceleração gravitacional. 
Vale a relação de dispersão para águas infinitamente profundas $k=\frac{\omega^{2}}{g}$.

As componentes da velocidade resultam:

$$
\begin{aligned}
& u=\frac{\partial \Phi}{\partial x}=\omega A e^{k z} \cos (k x-w t) \\
& w=\frac{\partial \Phi}{\partial z}=\omega A e^{k z} \sin (k x-w t)
\end{aligned}
$$

Com u e w, velocidades de uma partícula fluida, respectivamente, nas direções horizontal e vertical.

\subsection{Densidade de energia da onda por unidade de área}

A energia mecânica média $\left(E_{\text {mecanica }}\right)$ de uma onda gravitacional propagando-se é caracterizada pela troca entre energia cinética $\left(E_{\text {cinetica }}\right)$ e energia potencial $\left(E_{\text {potencial }}\right)$.

A energia mecânica associada para um volume de controle $V$ é expressa por:

$$
E_{\text {mecanica }}=E_{\text {cinetica }}+E_{\text {potencial }}=\rho \iiint_{V}\left(\frac{1}{2} V \cdot V+g z\right) d V
$$

Considere-se uma onda progressiva deslocando-se em um meio com profundidade $\mathrm{h}$, e tome-se uma coluna deste fluido conforme figura 2.2 .

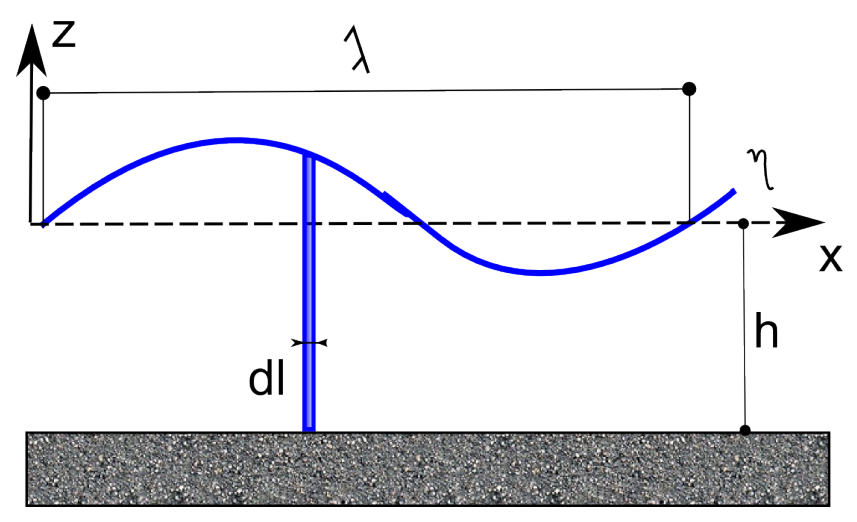

Figura 2.2: Coluna de fluido considerada no equacionamento da densidade de energia superficial da onda por unidade de área. 
Nesta coluna, a energia mecânica por unidade de área superficial é calculada por :

$$
E_{\text {mecanica }}=\rho \int_{-\infty}^{\eta}\left(\frac{V^{2}}{2}+g z\right) d z=\frac{1}{2} \rho \int_{-h}^{\eta} V^{2} d z+\frac{1}{2} \rho g\left(\eta^{2}-h^{2}\right)
$$

Pode-se desconsiderar $h$, uma vez que a cota de referência $z=0$ é a superfície livre.

Aplicando-se os resultados de 2.10 e 2.11 em 2.13, obtém-se :

$$
E_{\text {mecanica }}=E_{\text {cinetica }}+E_{\text {potencial }}=\frac{\rho \omega^{2} A^{2}}{4 k} e^{2 k \eta}+\frac{1}{2} \rho g \eta^{2}
$$

Com a hipótese de $\eta$ pequeno, devido à teoria linear, tem-se que $E_{\text {mecanica }} \propto A^{2}$. Usando-se a relação de dispersão $k$ e $\eta(x, t)$, obtém-se a expressão para energia potencial média por ciclo:

$$
E_{\text {potencial }}=\frac{1}{4} \rho g A^{2}
$$

Pela equação 2.14, verifica-se que o termo associado à energia cinética é uma multiplicação de $\frac{\rho \omega^{2} A^{2}}{4 k}$ pela exponencial $e^{2 k \eta}$. Expandindo-se este termo em série de Taylor, resulta:

$$
\frac{\rho \omega^{2} A^{2}}{4 k} e^{2 k \eta} \equiv \frac{\rho \omega^{2} A^{2}}{4 k}+\frac{\rho \omega^{2} A^{2} 2 k \eta}{4 k}
$$

A energia cinética associada à coluna de fluido considerada pode ser expressa por:

$$
E_{\text {cinetica }}=\frac{1}{2} \rho g A^{2}
$$

Como $\eta=A \cos (k x-\omega t)$, o segundo termo é proporcional a $A^{3}$. Como são consideradas amplitudes pequenas, o segundo termo de 2.16 é desprezado.

Resulta, que a densidade de energia mecânica por unidade de área superficial projetada se reduz a energia cinética exclusivamente. Assim:

$$
E_{\text {mecanica }}=\frac{1}{2} \rho g A^{2}
$$




\subsection{Modelo analítico do oscilador livre amortecido de grau um de liberdade}

Considere-se um sistema livre com amortecimento linear e grau um de liberdade:

$$
I \ddot{\phi}+c \dot{\phi}+k \phi=0
$$

onde $I$ é o momento de inércia em relação ao ponto de pivotamento do corpo, $c$ é o coeficiente de amortecimento proporcional a velocidade, e $k$ a constante de restauração.

A solução da equação acima é da forma $e^{\alpha t}$, com $\alpha$ complexo, que aplicada em 2.19 resulta

$$
\left(I \alpha^{2}+c \alpha+k\right) e^{\alpha t}=0
$$

Como $e^{\alpha t} \neq 0$, a solução 2.20 são as raízes do polinômio do segundo grau entre parênteses,

$$
\alpha=\frac{\left(-c \pm \sqrt{c^{2}-4 I k}\right)}{2 I}
$$

isto é:

$$
\alpha=-\frac{c}{2 I} \pm \sqrt{\left(\frac{c}{2 I}\right)^{2}-\frac{k}{I}}
$$

A solução de 2.19 é:

$$
\phi=A e^{\alpha_{1} t}+B e^{\alpha_{2} t}
$$

com A e B constantes complexas arbitrárias.

O caso $\frac{c}{2 I}>\sqrt{\frac{k}{I}}$ é o de amortecimento supercrítico e o de $\frac{c}{2 I}=\frac{k}{I}$ é o de amortecimento crítico. Ambos correspondem a soluções na forma exponencial real e decrescente.

O caso $\frac{c}{2 I}=\sqrt{\frac{k}{I}}$ é um caso particular da solução anterior, sendo o limiar entre o comporta- 
mento não oscilatório e o surgimento de oscilações, por este motivo denominado amortecimento crítico. Define-se $c_{c}=2 I \sqrt{\frac{K}{I}}$, como o amortecimento limite entre comportamentos distintos do oscilador e a razão $\frac{c}{c_{c}}$ indica a proximidade deste limiar.

Quanto o amortecimento é pequeno o suficiente, com $\frac{c}{2 I}<\sqrt{\frac{k}{I}}$, a equação 2.20 apresenta raízes complexas:

$$
\alpha_{1,2}=-\frac{c}{2 I} \pm i \sqrt{\frac{k}{I}-\left(\frac{c}{2 I}\right)^{2}}
$$

Substituindo-se em 2.20, segue:

$$
\phi=A e^{\left(-\frac{c}{2 I}+i \sqrt{\frac{K}{I}-\left(\frac{c}{2 I}\right)^{2}}\right) t}+B e^{\left(-\frac{c}{2 I}-i \sqrt{\frac{K}{I}-\left(\frac{c}{2 I}\right)^{2}}\right) t}
$$

e tomando-se a parte real:

$$
\phi=R e\left\{A e^{\left(-\frac{c}{2 I}+i \sqrt{\frac{K}{I}-\left(\frac{c}{2 I}\right)^{2}}\right) t}+B e^{\left(-\frac{c}{2 I}-i \sqrt{\frac{k}{I}-\left(\frac{c}{2 I}\right)^{2}}\right) t}\right\}
$$

No caso de A e B complexos, leva a:

$$
\phi=e^{-\left(\frac{c}{2 I}\right) t} \cdot\left(C \cdot \cos \left[\sqrt{\frac{k}{I}-\frac{c^{2}}{4 I^{2}} t}\right]+D \cdot \sin \left[\sqrt{\frac{k}{I}-\frac{c^{2}}{4 I^{2}}}\right] t\right)
$$

Esta solução implica em um movimento oscilatório modulado por uma curva exponencial decrescente. A taxa de amortecimento é $\zeta \equiv \frac{c}{2 \sqrt{I k}}$, denominado coeficiente de amortecimento.

O coeficiente de amortecimento $\zeta$ está relacionado com a intensidade do amortecimento. Maiores valores de $\zeta$ implicam em uma maior taxa de decréscimo da curva de amortecimento e menos ciclos observáveis. 


\subsection{Modelo analítico para uma seção em balanço}

O balanço de seções bidimensionais sob decaimento é modelado por um oscilador livre amortecido de um grau de liberdade, conforme a figura 2.3 .

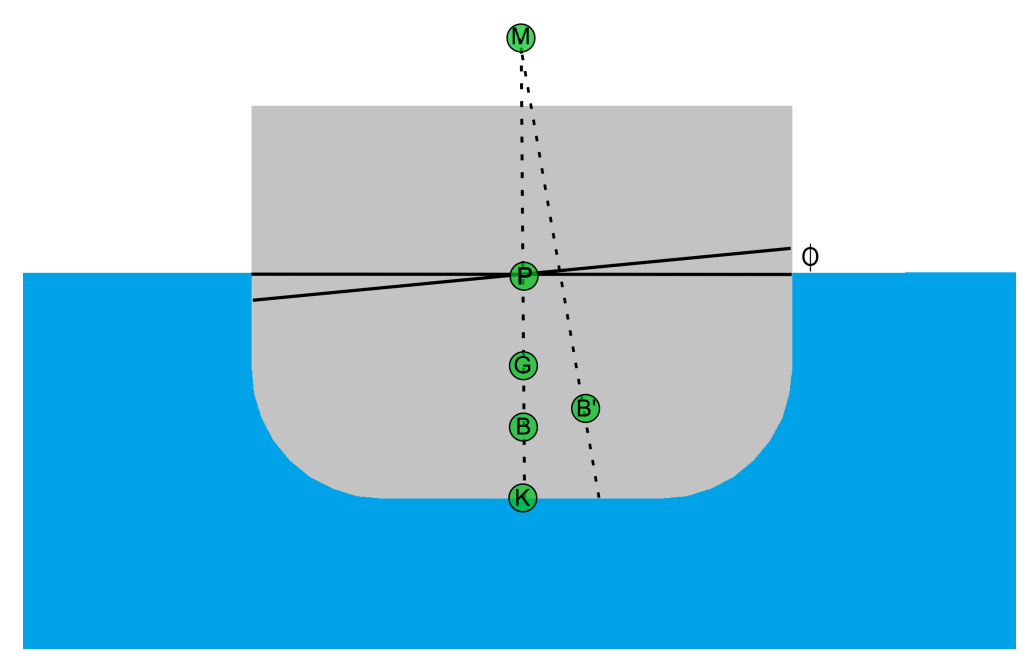

Figura 2.3: Diagrama do equilíbrio hidrostático de uma seção bidimensional.

Equação para o decaimento livre em balanço com um grau de liberdade:

$$
I_{T} \ddot{\phi}+N(\phi, \dot{\phi})+D(\phi)=0
$$

em que $I_{T}$ representa a inércia total (inércia do corpo mais parcela proveniente da reação do fluido $), N(\phi, \dot{\phi})$ representa o amortecimento hidrodinâmico, $D(\phi)$ representa a restauração hidrostática e $\phi$ o ângulo de balanço.

A restauração para ângulos de balanço restritos à imersão e emersão de partes verticais do costado pode ser representada linearmente como função da altura metacêntrica GZ:

$$
N(\phi)=\rho g A r \phi
$$

em que Ar é a área submersa da seção.

Froude (1955) [22] propõe que o amortecimento seja representado por um termo linear e 
um termo proporcional ao quadrado da velocidade:

$$
D(\dot{\phi})=B_{1} \dot{\phi}+B_{2} \dot{\phi}|\dot{\phi}|
$$

Dessa maneira, a equação 2.28 pode ser reescrita como:

$$
I_{T}(\ddot{\phi})+B_{1} \dot{\phi}+B_{2} \dot{\phi}|\dot{\phi}|+\Delta G M \phi=0
$$

na qual,

$$
D(\phi)=B_{1} \dot{\phi}+B_{2} \dot{\phi}|\dot{\phi}|
$$

e

$$
N(\phi, \dot{\phi})=\Delta G M \phi
$$

que no caso do decaimento livre, é submetida às condições iniciais $\dot{\phi}=0$ e $\phi(0)=\phi_{0}$.

É possível definir $B_{e q}$ para se obter um sistema linear equivalente, considerando-se a mesma quantidade de energia dissipada por ciclo:

$$
\int_{t}^{t+\frac{\pi}{\omega}}\left(B_{1} \dot{\phi}+B_{2} \dot{\phi}|\dot{\phi}|\right) \dot{\phi} d t=\int_{t}^{t+\frac{\pi}{\omega}} B_{e q} \dot{\phi} \dot{\phi} d t
$$

Considera-se $\phi$ harmônico da forma:

$$
\phi=\phi_{0} \sin (\omega t)
$$

obtém-se: 


$$
\int_{t}^{t+\frac{\pi}{\omega}}\left(\phi_{0} B_{1} \omega \cos (\omega t)+\phi_{0}^{2} B_{2} \omega^{2} \cos (\omega t)|\cos (\omega t)|\right) \phi_{0} \omega \cos (\omega t) d t=\int_{t}^{t+\frac{\pi}{\omega}} B_{e q} \phi_{0}^{2} \omega^{2} \cos ^{2}(\omega t) d t
$$

que resulta:

$$
\frac{1}{2} \phi_{0}^{2} \omega^{2} B_{1}+\phi_{0}^{2} \omega^{2} B_{2} \frac{16}{3 \pi} \omega \bar{\phi}=\frac{1}{2} \phi_{0}^{2} \omega^{2} B_{e} q
$$

A expressão acima permite obter $B_{e q}$, que é equivalente em termos de energia média por ciclo:

$$
B_{e q}=B_{1}+\frac{8}{3 \pi} \omega \bar{\phi}
$$

\subsection{Análise dimensional e similaridade para ensaios de balanço}

\subsubsection{Caracterização de escoamentos oscilatórios - o adimensional de Keulegan - Carpenter}

Caracteriza-se o escoamento oscilatório, de maneira a verificar se ocorre descolamento da trajetória da partícula fluida em relação a um movimento oscilatório de uma seção bidimensional em balanço.

Considere-se a seção com dimensões características B e T, e amplitude de oscilação angular $\phi_{a}$, representada na figura 2.4 .

A amplitude linear média de oscilação $A_{\text {linear }}$ da partícula fluida é composta pelo deslocamento da partícula ao longo do costado e ao longo do bojo, que podem ser de magnitudes 


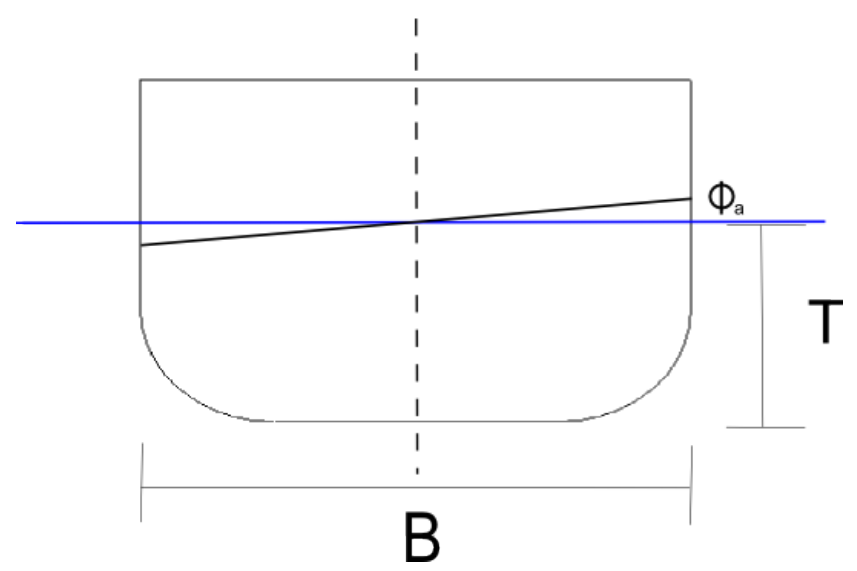

Figura 2.4: Esquema das dimensões consideras nas seções ensaiadas para caracterização do escoamento oscilatório.

diferentes. Para equiparar o efeito da mudança de amplitude nos dois tipos de deslocamento, calcula-se média geométrica entre a distância percorrida na lateral do casco $\phi_{a} \cdot T$ e a distância percorrida no bojo $\phi_{a} \cdot \sqrt{T^{2}+\frac{B}{2}^{2}}$.

Caracteriza-se o escoamento oscilatório como a relação entre o tempo que uma partícula leva para contornar a geometria da seção $T_{\text {contorno }}$ e o tempo necessário para reversão do movimento de oscilação $T_{\text {reverso }}$.

Considera-se $\omega$ a frequência de oscilação da seção.

Os períodos característicos são definidos como:

$$
\begin{gathered}
T_{\text {reversao }}=\frac{\pi}{\omega} \\
T_{\text {contorno }}=\frac{\text { dim }_{\text {caracteristica }}}{\text { vel }_{\text {media }}}
\end{gathered}
$$

E o adimensional que caracteriza esta grandeza, o número de Keulegan-Carpenter para esta caso fica definido como a relação entre estes períodos:

$$
K C=\frac{T_{\text {contorno }}}{T_{\text {reversao }}}=\frac{\frac{\pi A_{\text {linear }}}{\omega \phi_{a}}}{\frac{\pi}{\omega}}
$$

A expressão de KC para seções bidimensionais oscilantes: 


$$
K C=\frac{\frac{B}{T}}{\pi \phi_{a}\left(1+\left(\frac{1}{2} \frac{B}{T}\right)^{2}\right)^{\frac{1}{4}}}
$$




\subsection{Modelos experimentais de estimativa de inércia e amor- tecimento hidrodinâmicos em balanço}

\subsubsection{Método do amortecimento linear equivalente pela energia mé- dia entre ciclos}

Pode-se dividir os termos da equação 2.28 pela inércia total, obtendo-se:

$$
\ddot{\phi}+2 \zeta_{1} \omega_{n} \dot{\phi}+2 \zeta_{2} \omega_{n} \dot{\phi}|\dot{\phi}|+\omega_{n}^{2} \phi=0
$$

onde:

$\omega_{n}$ é a frequência natural não amortecida;

$\zeta_{1}$ e $\zeta_{2}$ são os coeficientes de amortecimento. Cabe ressaltar que $\zeta_{2}$ não é adimensional.

Conforme equação 2.5, define-se $\zeta_{e}$, linear com a velocidade, equivalente em termos de energia dissipada por ciclo:

$$
\zeta_{e} \equiv \zeta_{2}|\bar{\phi}| \omega_{d} \frac{8}{3 \pi}
$$

onde $\omega_{d}=\omega_{n} \sqrt{1-\zeta^{2}}$

$\omega_{d}$ é a frequência natural amortecida. Para decaimento livre em balanço, este termo é assumido como $\omega_{d} \approx \omega_{n}$ uma vez que o termo $\zeta$ é pequeno. Com estas considerações, resulta na seguinte equação linearizada para decaimento livre em balanço:

$$
\ddot{\phi}+2\left(\zeta_{R}\right) \omega_{n} \dot{\phi}+\omega_{n}^{2}=0
$$

onde $\zeta$ é tal que : $\zeta_{R}=\zeta_{1}+\zeta_{e}$. 
Pode-se calcular o valor de $\zeta$ subtraindo-se dois valores extremos consecutivos de $\phi\left(\phi_{i}\right.$ e $\left.\phi_{i+1}\right)$, sendo estes extremos separados por intervalos de período $T=\frac{2 \pi}{\omega_{d}}$.

A identificação destes dois máximos locais consecutivos permite o cálculo de $\omega_{d}$ médio no intervalo delimitado.

obtém-se os valores de $\zeta$ e $\omega_{d}$ por ciclo através do decremento logarítmico entre máximos locais de mesmo sinal $\phi_{i}$ e $\phi_{i+1}$ consecutivos conforme figura 2.5 .

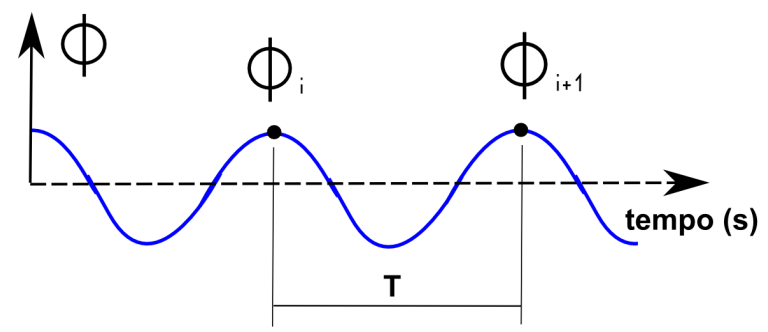

Figura 2.5: Máximos locais sucessivos entre ciclos durante o decaimento.

$$
\frac{\phi_{i+1}}{\phi_{i}}=e^{\zeta \omega_{d}}
$$

e dessa forma pode-se estimar o amortecimento médio no intervalo considerado através de:

$$
\ln \left(\phi_{i+1}\right)-\ln \left(\phi_{i}\right)=\zeta \omega_{d}
$$

Com os valores de $\omega_{n}$ obtidos para cada trecho analisado, $\overline{\omega_{n}}$ é obtido através da média $\operatorname{dos} \omega_{n i}, i=1, . ., j$.

Define-se o período entre cada $\phi_{i}$ e $\phi_{i+1}$ subsequente como $T=\frac{2 \pi}{\omega_{n}}$. T é suposto constante ao longo do movimento.

$\zeta_{R}=\zeta_{1}+\zeta_{e}$ é obtido através do ajuste de reta de $\zeta$ com a ordenada:

$$
\zeta=\zeta_{1}+\zeta_{2} \frac{16}{3} \frac{\bar{\phi}}{T}
$$




\subsubsection{Método do balanço da energia}

Considera-se aqui a equação 2.28, aqui reescrita por unidade de inércia:

$$
\frac{d^{2} \phi}{d t^{2}}+N(\phi, \dot{\phi})+D(\phi)=0
$$

Nesta seção, aplica-se uma representação mais geral que a da seção anterior, em que se consideram os efeitos da frequência $\omega_{n}$, conforme Haddara (1989) [24]:

$$
\begin{gathered}
N(\phi, \dot{\phi}) \equiv 2 \zeta \omega_{n} \dot{\phi}\left[1+\epsilon_{11}|\phi|+\epsilon_{12} \phi^{2}+\epsilon_{13} \frac{1}{\omega_{n}}|\dot{\phi}|+\epsilon_{14} \frac{1}{\omega_{n}^{2}} \dot{\phi}^{2}\right] \\
D(\phi) \equiv \omega_{n}^{2} \phi\left[1+\epsilon_{21} \phi^{2}+\epsilon_{22} \phi^{4}\right]
\end{gathered}
$$

em que $\epsilon_{11}, \epsilon_{12}, \epsilon_{13}$ e $\epsilon_{14}$ são coeficientes de amortecimento e $\epsilon_{21}$ e $\epsilon_{22}$ são coeficientes de restauração.

A energia mecânica do sistema, composta pela energia cinética e pela energia potencial, é dissipada por amortecimento da energia total do sistema, e pode ser expressa como:

$$
\frac{d}{d t}\left[E_{c}(t)+E_{p}(I)\right]=\frac{d}{d t}\left[E_{d}(t)\right]
$$

sendo $E_{c}$, a energia cinética por unidade de momento de inércia:

$$
E_{c}(t) \equiv \int_{0}^{t} \frac{d^{2} \phi}{d t^{2}} \dot{\phi} d t=\int_{t_{0}}^{t} \frac{d \dot{\phi}}{d t} \dot{\phi} d t=\left[\frac{1}{2} \dot{\phi}^{2}\right]_{t_{0}}^{t}
$$


$E_{p}$ a energia potencial por unidade de momento de inércia:

$$
\begin{gathered}
E_{p}(t) \equiv \int_{t_{0}}^{t} D(\phi) \dot{\phi} d t=\int_{t_{0}}^{t} \omega^{2}\left[\phi+\epsilon_{21} \phi^{3}+\epsilon_{22} \phi^{5}\right] d \phi= \\
=\left[\frac{1}{2} \omega_{n}^{2} \phi^{2}\left(1+\frac{1}{2} \epsilon_{21} \phi^{2}+\frac{1}{3} \epsilon_{22} \phi^{4}\right)\right]_{t_{0}}^{t}
\end{gathered}
$$

$E_{p}$ a energia dissipada por unidade de momento de inércia:

$$
\begin{gathered}
E_{d}(t) \equiv \int_{t_{0}}^{t} N(\phi, \dot{\phi}) \dot{\phi} d t=\int_{t_{0}}^{t} 2 \zeta \omega_{n} \dot{\phi}^{2}\left[1+\epsilon_{11}|\phi|+\epsilon_{12} \phi^{2}+\epsilon_{13} \frac{1}{\omega_{n}}|\dot{\phi}|+\epsilon_{14} \frac{1}{\omega_{n}^{2}} \dot{\phi}^{2}\right] d t \\
=2 \zeta \omega_{n}\left[\int_{t_{0}}^{t} \dot{\phi}^{2} d t+\epsilon_{11} \int_{t_{0}}^{t}|\phi| \dot{\phi}^{2} d t+\epsilon_{13} \frac{1}{\omega_{n}} \int_{t_{0}}^{t}|\dot{\phi}| \dot{\phi}^{2} d t+\epsilon_{14} \frac{1}{\omega_{n}^{2}} \int_{t_{0}}^{t} \dot{\phi}^{4} d t\right.
\end{gathered}
$$

Aplica-se o método para os registros discretizados dos ensaios de decaimento; o equacionamento é, assim, expresso em termos de intervalos finitos de tempo $\Delta t=t_{i+1}-t_{i}$ :

Tem-se:

$$
\left[E_{c}(t)+E_{p}(t)\right]_{t_{i}}^{t_{i}+1} \simeq\left[E_{d}\right]_{t i}^{t_{i+1}}
$$

Nos casos estudados, foram consideradas as seguintes combinações de representações de amortecimento e restauração:

- amortecimento linear com a velocidade ; restauração linear com a posição: $N(\phi)=2 \zeta \omega_{n} \dot{\phi}$ e $D(\phi)=\omega_{n}^{2} \phi$ 
- amortecimento linear e quadrático com a velocidade ; restauração linear com a posição: $N(\phi)=2 \zeta \omega_{n} \dot{\phi}\left[1+\epsilon_{13} \frac{1}{\omega_{n}}|\dot{\phi}|\right]$ e $D(\phi)=\omega_{n}^{2} \phi$

- representação não linear mais completa para amortecimento e restauração: $N(\phi, \dot{\phi})$ e $D(\phi)$, conforme as equações 2.44 .

Buscam-se estimativas que atendam a 2.49 para os $(n+1)$ pontos do intervalo $0 \leq i \leq N$. Por conveniência, definem-se os seguintes termos, para $j=1,2, . .8$ :

- $\alpha_{1} \equiv \hat{\omega}_{n}^{2}$

- $\alpha_{2} \equiv \hat{\epsilon_{21}} \omega_{n}^{2}$

- $\alpha_{3} \equiv \hat{\epsilon_{22} \omega_{n}^{2}}$

- $\alpha_{4} \equiv \hat{\zeta} \omega_{n}$

- $\alpha_{5} \equiv \hat{\zeta} \omega_{n} \epsilon_{11}$

- $\alpha_{6} \equiv \hat{\zeta} \omega_{n} \epsilon_{12}$

- $\alpha_{7} \equiv \hat{\zeta} \epsilon_{13}$

- $\alpha_{8} \equiv \hat{\zeta} \epsilon_{14} \frac{1}{\hat{\omega_{n}}}$

O critério adotado para o ajuste dos coeficientes à série temporal é a minimização dos desvios quadráticos no balanço de energia, ou seja:

$$
\sigma^{2}\left(\hat{\alpha}_{1}, \hat{\alpha}_{2}, \hat{\alpha}_{3}, \hat{\alpha}_{4}, \hat{\alpha}_{5}, \hat{\alpha}_{6}, \hat{\alpha}_{7}, \hat{\alpha}_{8}\right)=\frac{1}{N} \sum_{j=0}^{N-1}\left[\left[E_{c}(t)+E_{p}(t)\right]_{t_{i}}^{t_{i}+1}\right]
$$

onde $\hat{\alpha_{j}}$ são estimativas para os correspondentes $\alpha_{j}, j=1, \ldots, 8$.

Os termos de energia cinética e potencial são numericamente calculados instante a instante por: 


$$
\begin{gathered}
E_{c}\left(t=t_{i}\right)=\left[\frac{1}{2} \dot{\phi}^{2}\right]_{t_{i}}^{t_{i+1}} \\
E_{p}\left(t=t_{i}\right)=\left[\frac{1}{2} \phi^{2}\left(\hat{\alpha_{1}}+\frac{1}{2} \hat{\alpha_{2}} \phi^{2}+\frac{1}{3} \hat{\alpha_{3}} \phi^{4}\right)\right]_{t_{i}}^{t_{i+1}}
\end{gathered}
$$

e o termo de energia dissipado é integrado numericamente entre instantes sucessivos através de aproximação por trapézios:

$$
\begin{gathered}
E_{d}\left(t=t_{i}\right)=2 \frac{t_{i+1}-t_{i}}{2}\left[\hat{\alpha_{4}} \dot{\phi}^{2}+\hat{\alpha_{5}}|\phi| \dot{\phi}^{2}+\hat{\alpha_{6}} \phi^{2} \dot{\phi}^{2}+\hat{\alpha_{7}}|\dot{\phi}| \dot{\phi}^{2}+\hat{\alpha_{8}} \dot{\phi}^{4}\right]_{t=t_{i}} \\
+\left[\hat{\alpha_{4}} \dot{\phi}^{2}+\hat{\alpha_{5}}|\phi| \dot{\phi}^{2}+\hat{\alpha_{6}} \phi^{2} \dot{\phi}^{2}+\hat{\alpha_{7}}|\dot{\phi}| \dot{\phi}^{2}+\hat{\alpha_{8}} \dot{\phi}^{4}\right]_{t=t_{i+1}}
\end{gathered}
$$

O termo $\sigma^{2}$ pode ser minimizado através da resolução do seguinte sistema de equações:

$$
\frac{\partial \sigma^{2}}{\partial \hat{\alpha}_{j}}=0, j=1, \ldots, 8
$$

Desenvolvendo-se as derivadas acima, obtém-se:

$$
\frac{\partial \sigma^{2}}{\partial \hat{\alpha_{1}}}=\frac{2}{N} \sum_{i=0}^{N-1}\left\{\left[\frac{1}{2} \dot{\phi}^{2}+\frac{1}{2} \phi^{2}\left(\hat{\alpha_{1}}+\frac{1}{2}{\hat{\alpha_{2}}}^{2}+\frac{1}{3}{\hat{\alpha_{3}}}^{3}\right)\right]_{t_{i}}^{t_{i+1}}\right.
$$




$$
\begin{aligned}
& -2 \frac{t_{i+1}-t_{i}}{2}\left[\left[\alpha_{4} \dot{\phi}^{2}+\alpha_{5}|\phi| \dot{\phi}^{2}+\alpha_{6} \phi^{2} \dot{\phi}^{2}+\alpha_{7}|\dot{\phi}| \dot{\phi}^{2}+\alpha_{8} \dot{\phi}^{4}\right]_{t=t_{i}}\right. \\
& \left.\left.+\left[\alpha_{4} \dot{\phi}^{2}+\alpha_{5}|\phi| \dot{\phi}^{2}+\alpha_{6} \phi^{2} \dot{\phi}^{2}+\alpha_{7}|\dot{\phi}| \dot{\phi}^{2}+\alpha_{8} \dot{\phi}^{4}\right]_{t=t_{i+1}}\right]\left[\frac{1}{2} \phi^{2}\right]_{t_{i}}^{t_{i+1}}\right\} \\
& \frac{\partial \sigma^{2}}{\partial \hat{\alpha_{2}}}=\frac{2}{N} \sum_{i=0}^{N-1}\left\{\left[\frac{1}{2} \dot{\phi}^{2}+\frac{1}{2} \phi^{2}\left(\hat{\alpha_{1}}+\frac{1}{2}{\hat{\alpha_{2}}}^{2}+\frac{1}{3}{\hat{\alpha_{3}}}^{3}\right)\right]_{t_{i}}^{t_{i+1}}\right. \\
& -2 \frac{t_{i+1}-t_{i}}{2}\left[\left[\alpha_{4} \dot{\phi}^{2}+\alpha_{5}|\phi| \dot{\phi}^{2}+\alpha_{6} \phi^{2} \dot{\phi}^{2}+\alpha_{7}|\dot{\phi}| \dot{\phi}^{2}+\alpha_{8} \dot{\phi}^{4}\right]_{t=t_{i}}\right. \\
& \left.\left.+\left[\alpha_{4} \dot{\phi}^{2}+\alpha_{5}|\phi| \dot{\phi}^{2}+\alpha_{6} \phi^{2} \dot{\phi}^{2}+\alpha_{7}|\dot{\phi}| \dot{\phi}^{2}+\alpha_{8} \dot{\phi}^{4}\right]_{t=t_{i+1}}\right]\left[\frac{1}{4} \phi^{2}\right]_{t_{i}}^{t_{i+1}}\right\} \\
& \frac{\partial \sigma^{2}}{\partial \hat{\alpha_{3}}}=\frac{2}{N} \sum_{i=0}^{N-1}\left\{\left[\frac{1}{2} \dot{\phi}^{2}+\frac{1}{2} \phi^{2}\left(\hat{\alpha_{1}}+\frac{1}{2}{\hat{\alpha_{2}}}^{2}+\frac{1}{3}{\hat{\alpha_{3}}}^{3}\right)\right]_{t_{i}}^{t_{i+1}}\right. \\
& -2 \frac{t_{i+1}-t_{i}}{2}\left[\left[\alpha_{4} \dot{\phi}^{2}+\alpha_{5}|\phi| \dot{\phi}^{2}+\alpha_{6} \phi^{2} \dot{\phi}^{2}+\alpha_{7}|\dot{\phi}| \dot{\phi}^{2}+\alpha_{8} \dot{\phi}^{4}\right]_{t=t_{i}}\right.
\end{aligned}
$$




$$
\begin{gathered}
\left.\left.+\left[\alpha_{4} \dot{\phi}^{2}+\alpha_{5}|\phi| \dot{\phi}^{2}+\alpha_{6} \phi^{2} \dot{\phi}^{2}+\alpha_{7}|\dot{\phi}| \dot{\phi}^{2}+\alpha_{8} \dot{\phi}^{4}\right]_{t=t_{i+1}}\right]\left[\frac{1}{6} \phi^{2}\right]_{t_{i}}^{t_{i+1}}\right\} \\
\frac{\partial \sigma^{2}}{\partial \hat{\alpha_{4}}}=\frac{2}{N} \sum_{i=0}^{N-1}\left\{\left[\frac{1}{2} \dot{\phi}^{2}+\frac{1}{2} \phi^{2}\left(\hat{\alpha_{1}}+\frac{1}{2}{\hat{\alpha_{2}}}^{2}+\frac{1}{3} \hat{\alpha}^{3}\right)\right]_{t_{i}}^{t_{i+1}}\right. \\
-2 \frac{t_{i+1}-t_{i}}{2}\left[\left[\alpha_{4} \dot{\phi}^{2}+\alpha_{5}|\phi| \dot{\phi}^{2}+\alpha_{6} \phi^{2} \dot{\phi}^{2}+\alpha_{7}|\dot{\phi}| \dot{\phi}^{2}+\alpha_{8} \dot{\phi}^{4}\right]_{t=t_{i}}\right.
\end{gathered}
$$

$\left.\left.+\left[\alpha_{4} \dot{\phi}^{2}+\alpha_{5}|\phi| \dot{\phi}^{2}+\alpha_{6} \phi^{2} \dot{\phi}^{2}+\alpha_{7}|\dot{\phi}| \dot{\phi}^{2}+\alpha_{8} \dot{\phi}^{4}\right]_{t=t_{i+1}}\right]\left(-2 \frac{t_{i+1}-t_{i}}{2}\right)\left[\left[\dot{\phi}^{2}\right]_{t_{i}}+\left[\dot{\phi}^{2}\right]_{t_{i+1}}\right]\right\}$

$$
\begin{gathered}
\frac{\partial \sigma^{2}}{\partial \hat{\alpha_{5}}}=\frac{2}{N} \sum_{i=0}^{N-1}\left\{\left[\frac{1}{2} \dot{\phi}^{2}+\frac{1}{2} \phi^{2}\left(\hat{\alpha_{1}}+\frac{1}{2}{\hat{\alpha_{2}}}^{2}+\frac{1}{3}{\hat{\alpha_{3}}}^{3}\right)\right]_{t_{i}}^{t_{i+1}}\right. \\
-2 \frac{t_{i+1}-t_{i}}{2}\left[\left[\alpha_{4} \dot{\phi}^{2}+\alpha_{5}|\phi| \dot{\phi}^{2}+\alpha_{6} \phi^{2} \dot{\phi}^{2}+\alpha_{7}|\dot{\phi}| \dot{\phi}^{2}+\alpha_{8} \dot{\phi}^{4}\right]_{t=t_{i}}\right.
\end{gathered}
$$

$\left.\left.+\left[\alpha_{4} \dot{\phi}^{2}+\alpha_{5}|\phi| \dot{\phi}^{2}+\alpha_{6} \phi^{2} \dot{\phi}^{2}+\alpha_{7}|\dot{\phi}| \dot{\phi}^{2}+\alpha_{8} \dot{\phi}^{4}\right]_{t=t_{i+1}}\right]\left(-2 \frac{t_{i+1}-t_{i}}{2}\right)\left[\left[|\phi| \dot{\phi}^{2}\right]_{t_{i}}+\left[|\phi| \dot{\phi}^{2}\right]_{t_{i+1}}\right]\right\}$ 


$$
\begin{gathered}
\frac{\partial \sigma^{2}}{\partial \hat{\alpha_{6}}}=\frac{2}{N} \sum_{i=0}^{N-1}\left\{\left[\frac{1}{2} \dot{\phi}^{2}+\frac{1}{2} \phi^{2}\left(\hat{\alpha_{1}}+\frac{1}{2}{\hat{\alpha_{2}}}^{2}+\frac{1}{3}{\hat{\alpha_{3}}}^{3}\right)\right]_{t_{i}}^{t_{i+1}}\right. \\
-2 \frac{t_{i+1}-t_{i}}{2}\left[\left[\alpha_{4} \dot{\phi}^{2}+\alpha_{5}|\phi| \dot{\phi}^{2}+\alpha_{6} \phi^{2} \dot{\phi}^{2}+\alpha_{7}|\dot{\phi}| \dot{\phi}^{2}+\alpha_{8} \dot{\phi}^{4}\right]_{t=t_{i}}\right.
\end{gathered}
$$

$\left.\left.+\left[\alpha_{4} \dot{\phi}^{2}+\alpha_{5}|\phi| \dot{\phi}^{2}+\alpha_{6} \phi^{2} \dot{\phi}^{2}+\alpha_{7}|\dot{\phi}| \dot{\phi}^{2}+\alpha_{8} \dot{\phi}^{4}\right]_{t=t_{i+1}}\right]\left(-2 \frac{t_{i+1}-t_{i}}{2}\right)\left[\left[\phi^{2} \dot{\phi}^{2}\right]_{t_{i}}+\left[\phi^{2} \dot{\phi}^{2}\right]_{t_{i+1}}\right]\right\}$

$$
\frac{\partial \sigma^{2}}{\partial \hat{\alpha_{7}}}=\frac{2}{N} \sum_{i=0}^{N-1}\left\{\left[\frac{1}{2} \dot{\phi}^{2}+\frac{1}{2} \phi^{2}\left(\hat{\alpha_{1}}+\frac{1}{2}{\hat{\alpha_{2}}}^{2}+\frac{1}{3}{\hat{\alpha_{3}}}^{3}\right)\right]_{t_{i}}^{t_{i+1}}\right.
$$

$$
-2 \frac{t_{i+1}-t_{i}}{2}\left[\left[\alpha_{4} \dot{\phi}^{2}+\alpha_{5}|\phi| \dot{\phi}^{2}+\alpha_{6} \phi^{2} \dot{\phi}^{2}+\alpha_{7}|\dot{\phi}| \dot{\phi}^{2}+\alpha_{8} \dot{\phi}^{4}\right]_{t=t_{i}}\right.
$$

$\left.\left.+\left[\alpha_{4} \dot{\phi}^{2}+\alpha_{5}|\phi| \dot{\phi}^{2}+\alpha_{6} \phi^{2} \dot{\phi}^{2}+\alpha_{7}|\dot{\phi}| \dot{\phi}^{2}+\alpha_{8} \dot{\phi}^{4}\right]_{t=t_{i+1}}\right]\left(-2 \frac{t_{i+1}-t_{i}}{2}\right)\left[\left[|\dot{\phi}| \dot{\phi}^{2}\right]_{t_{i}}+\left[|\dot{\phi}| \dot{\phi}^{2}\right]_{t_{i+1}}\right]\right\}$

$$
\frac{\partial \sigma^{2}}{\partial \hat{\alpha_{8}}}=\frac{2}{N} \sum_{i=0}^{N-1}\left\{\left[\frac{1}{2} \dot{\phi}^{2}+\frac{1}{2} \phi^{2}\left(\hat{\alpha_{1}}+\frac{1}{2}{\hat{\alpha_{2}}}^{2}+\frac{1}{3}{\hat{\alpha_{3}}}^{3}\right)\right]_{t_{i}}^{t_{i+1}}\right.
$$




$$
\begin{gathered}
-2 \frac{t_{i+1}-t_{i}}{2}\left[\left[\alpha_{4} \dot{\phi}^{2}+\alpha_{5}|\phi| \dot{\phi}^{2}+\alpha_{6} \phi^{2} \dot{\phi}^{2}+\alpha_{7}|\dot{\phi}| \dot{\phi}^{2}+\alpha_{8} \dot{\phi}^{4}\right]_{t=t_{i}}\right. \\
\left.\left.+\left[\alpha_{4} \dot{\phi}^{2}+\alpha_{5}|\phi| \dot{\phi}^{2}+\alpha_{6} \phi^{2} \dot{\phi}^{2}+\alpha_{7}|\dot{\phi}| \dot{\phi}^{2}+\alpha_{8} \dot{\phi}^{4}\right]_{t=t_{i+1}}\right]\left(-2 \frac{t_{i+1}-t_{i}}{2}\right)\left[\left[\dot{\phi}^{4}\right]_{t_{i}}+\left[\dot{\phi}^{4}\right]_{t_{i+1}}\right]\right\}
\end{gathered}
$$

Obtém-se o sistema linear:

$$
A \hat{\alpha}=B
$$

Cuja resolução fornece os parâmetros aproximados de interesse.

\subsection{Obtenção da inércia hidrodinâmica à partir dos resul- tados experimentais}

Os ensaios de decaimento permitem que o modelo oscile na sua frequência amortecida $\omega_{d}$, sendo a energia do movimento dissipada pelo amortecimento. A frequência natural pode ser então estimada através de $\omega_{d}=\omega_{n} \sqrt{1-\zeta^{2}}$, onde $\zeta=c / c_{c} \cdot c_{c}$ corresponde ao amortecimento crítico e $c$ corresponde ao amortecimento linear do sistema. Pode ser determinado através dos ensaios.

O período natural do sistema desacoplado e não-amortecido pode ser expresso por:

$$
T_{n 4}=2 \pi\left(\frac{M_{44}+A_{44}}{C_{44}}\right)^{\frac{1}{2}}
$$

O ensaio de decaimento fornece informações que permitem a determinação do período 
natural e do amortecimento do sistema. Com o período natural, é possível a determinação da inércia adicionada em balanço $A_{44}$, uma vez que a restauração $C_{44}$ do sistema pode ser determinada. Considerando-se que o raio de giração em roll seja $r_{44}$ e a restauração do sistema $C_{44}=\rho g V G M_{T}$, a expressão do período natural em balanço fica:

$$
T_{n 4}=2 \pi\left(\frac{M r_{44}^{2}+A_{44}}{\rho g V G M_{T}}\right)^{\frac{1}{2}}
$$

A altura metacêntrica transversal $G M_{T}$ e o raio de giração $r_{44}$ dependem da condição de carregamento.

A inércia adicionada pode então ser estimada através dos parâmetros medidos.

\subsection{Determinação experimental de momento de inércia pelo método bifilar}

Considere-se um corpo de massa $M$ e momento de inércia $I$. Este corpo está suspenso verticalmente por dois fios em torno da posição do centro de gravidade vertical e encontra-se em equilíbrio.

Uma rotação $\beta \leq 10^{\circ}$ é imposta ao corpo em relação ao seu plano horizontal, conforme figura 2.6. Esta figura apresenta as direções das forças em resposta à rotação em torno do seu centro de gravidade. O corpo é liberado e oscila com período $T_{p}$.

Estabelece-se uma relação entre $I$ e o $T_{p}$.

O ângulo $\alpha$ é o ângulo do fio com a vertical. São conhecidos $a$, distância entre fios e $L$, comprimento dos fios.

A força de restauração que surge da restauração gravitacional projetada no plano horizontal é esquematizada na figura 2.7 .

$$
F=\frac{M g}{2} \sin (\alpha)
$$




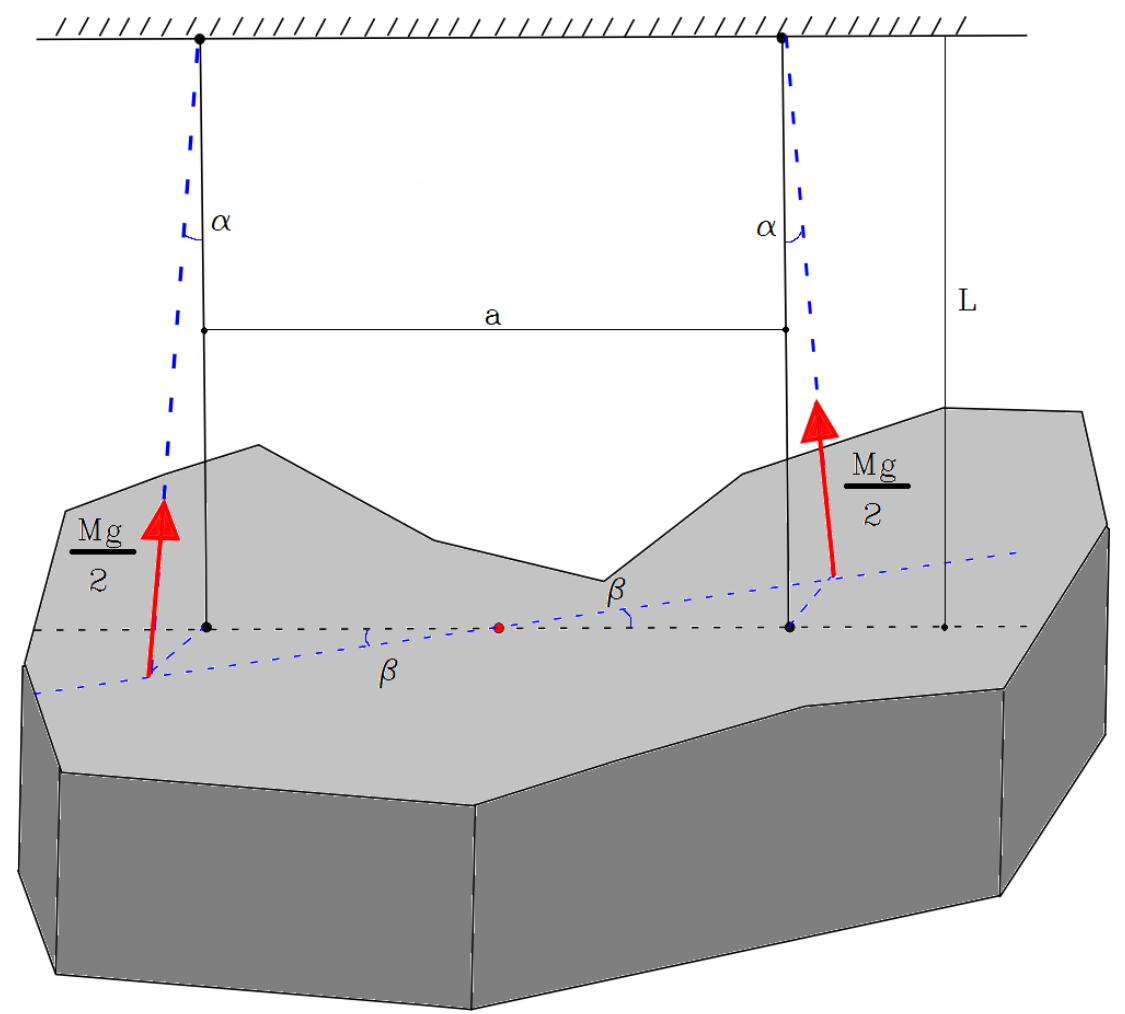

Figura 2.6: Diagrama de um corpo suspenso por dois fios equilibrado em torno de seu centro de gravidade.

O momento $M_{z}$ atuante no plano horizontal é:

$$
M_{z}=2\left(\frac{M g}{2} \frac{a}{2} \sin (\alpha)\right)
$$

A seguinte relação geométrica é obtida por meio da figura 2.7.

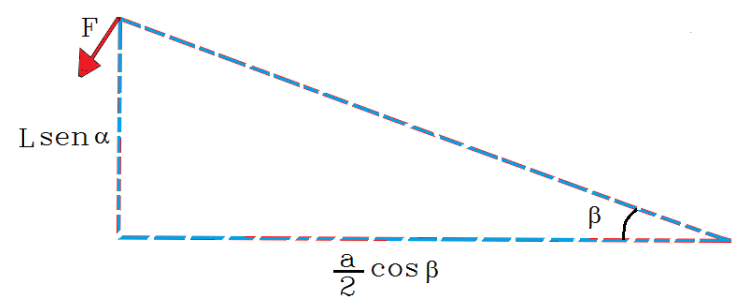

Figura 2.7: Projeção da força exercida pelo fio no plano horizontal.

$$
L \sin (\alpha) \frac{a}{2} \sin (\beta)
$$


O momento resulta:

$$
M_{z}=2\left(\frac{M g}{2} \frac{a}{2}\left(\frac{a}{2} \frac{\sin (\beta)}{L}\right)\right)
$$

Para $\beta<10 \mathrm{deg}, \sin (\beta) \simeq \beta$ e o momento resulta:

$$
M_{z}=\frac{M g}{L}\left(\frac{a}{2}\right)^{2} \beta
$$

A equação do movimento é expressa por:

$$
\ddot{\beta}+\frac{M g}{I L}\left(\frac{a}{2}\right)^{2} \beta=0
$$

A equação 2.65 é da forma $\ddot{\beta}+\omega_{n}^{2} \beta=0$. Com $\omega_{n}=2 \frac{\pi}{T_{p}}$, obtém-se:

$$
\frac{2 \pi}{T_{p}}=\sqrt{\frac{M}{I} \frac{g}{L}} \frac{a}{2}
$$

Define-se o raio de giração $r_{g}$ :

$$
r_{g}=\sqrt{\frac{I}{M}}
$$

A relação entre o período de oscilação $T_{p}$ e o raio de giração $r_{g}$ fica:

$$
r_{g}=\frac{T_{p}}{4 \pi} a \sqrt{\frac{g}{L}}
$$




\section{Capítulo 3}

\section{Proposta}

\subsection{Determinação de Inércia Adicionada e de Amorteci- mento de Seções 2D Oscilando em Balanço em Ensaios de Decaimento}

Os coeficientes de amortecimento (linear e não lineares) e de inércia adicionada são recuperados de séries temporais das oscilações, obtidas experimentalmente, mediante sua análise por método de energia (ver capítulo 2).

São parâmetros associados aos resultados experimentais:

- forma do bojo: arredondado ou quinado;

- presença ou ausência de bolinas; quando presentes, sua altura é um parâmetro;

- altura do centro de gravidade e raio de giração;

- proporção entre boca e calado (por meio do ajuste do calado, mantendo a boca fixa).

São atributos associados aos resultados experimentais:

- coeficientes de amortecimento linear e não-lineares; 
- coeficiente de inércia adicionada.

Constróem-se na análise dos ensaios relações entre os atributos e parâmetros, com vistas a demonstrar um método de estimativa desses atributos para embarcações reais.

As condições de teste são idealizadas com simplificações com relação às situações práticas; por exemplo:

- os modelos oscilam segundo um único grau de liberdade (balanço), com restrição de movimento nos demais graus de liberdade;

- não há velocidade de avanço e nem correnteza nos testes;

- a geometria do modelo é cilíndrica, o que, nas situações práticas, somente se configura para a região central do corpo paralelo médio;

- no canal de testes, há a presença de limitações laterais e nas extremidades, como paredes e absorvedor de ondas.

A proposta do presente trabalho é:

1. considerar métodos analítico-numéricos de estimativa de amortecimento potencial e de inércia adicionada;

2. estimar, para o conjunto de parâmetros de ensaio, por meio dos métodos acima, os correspondentes atributos (amortecimento potencial e inércia adicionada), e comparálos com os atributos correlatos obtidos experimentalmente;

3. estimar, para os parâmetros cabíveis de ensaio, por meio dos métodos em (1), os correspondentes atributos (amortecimento linear), e compará-los com os atributos correlatos obtidos experimentalmente;

A figura 3.1 esquematiza a sequência de trabalho da proposta aqui desenvolvida. 


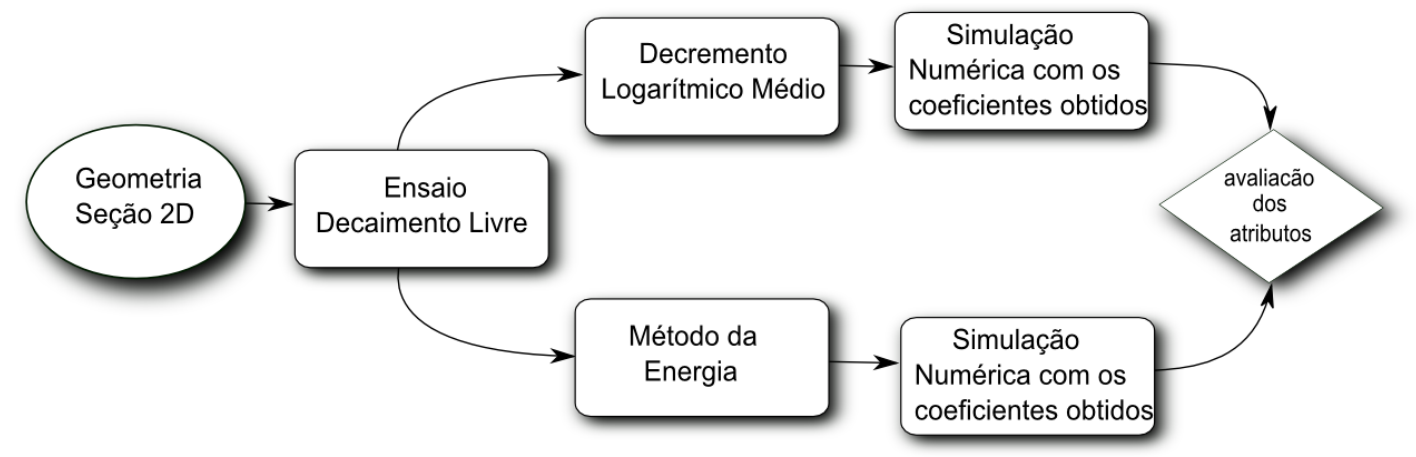

Figura 3.1: Diagrama da proposta do trabalho. 


\section{Capítulo 4}

\section{Desenvolvimento da proposta}

\subsection{Descrição}

\subsubsection{Planejamento}

Optou-se por quatro seções distinguidas pelas seguintes características: bojo arredondado, bojo com bolina maior, bojo com bolina menor e bojo quinado. As bolinas são dispositivos utilizados para diminuição do jogo das embarcações, resultando em alterações na inércia adicionada e amortecimento. Segue esboço destas seções na figura 4.1.
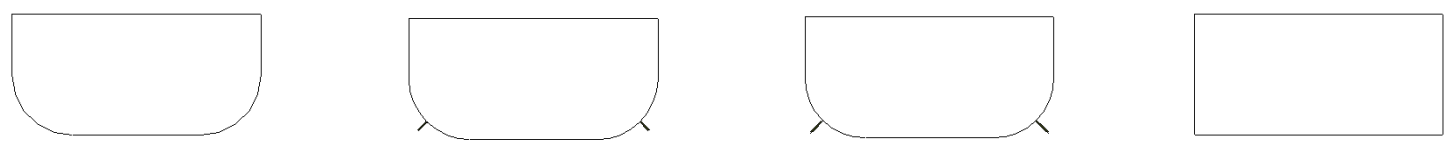

Figura 4.1: Diferentes geometrias testadas.

A instalação utilizada nos ensaios é o canal de testes do Laboratório de Engenharia Naval e Oceânica da EPUSP. Com 1 metro de largura por 1 metro de altura por 25 metros de comprimento; com uma lâmina d'agua de 0.8 metros. A figura 4.2 mostra um esboço da geometria do canal. 


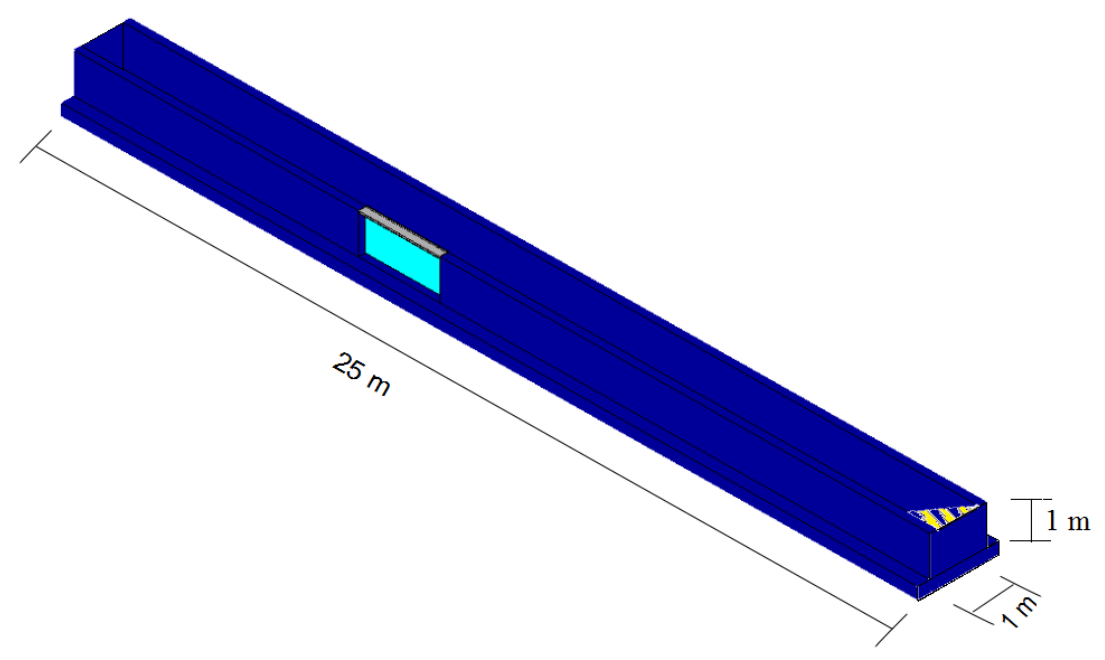

Figura 4.2: Desenho esquemático do canal de testes.

Os modelos têm formato cilíndrico, com seção transversal correspondente a cada geometria de interesse. A fixação do modelo no tanque é transversal com eixo de rotação na altura da superfície livre de repouso.

O diagrama da seção transversal é apresentado na figura 4.3.

No ensaio de decaimento livre, parte-se de um ângulo de banda com o modelo em repouso. Um cabo amarrado a um suporte externo mantém o modelo na posição inicial. Com o rompimento do cabo o modelo inicia o seu movimento.

O comprimento do canal permite a execução do decaimento livre do modelo até o repouso, antes que ocorra o retorno das ondas refletidas pela extremidade do canal.

Executando-se a montagem no centro do canal, a onda irradiada pelo modelo será refletida e irá percorrer 25 metros até atingir o modelo novamente.

As seções cilíndricas foram compostas por uma calha de instalações pluviais de PVC, com seção constante de formato retangular, e por tampas nas laterais. As quinas desta calha possuem um raio de arredondamento de $50 \mathrm{~mm}$ ou $30 \%$ da boca. A figura 4.4 traz uma foto do modelo usado para o caso de bojo arredondado durante a medição do momento de inércia. 


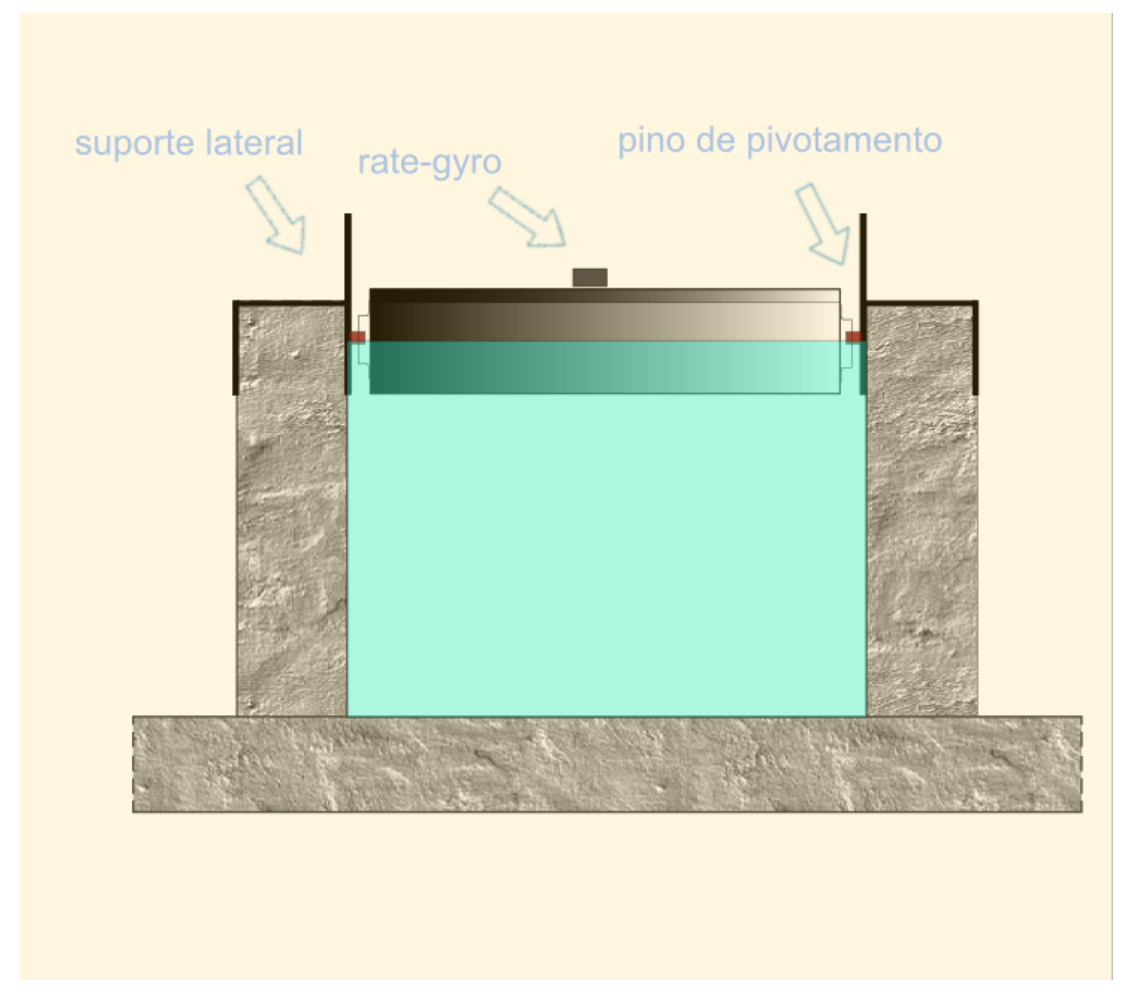

Figura 4.3: Esquema de um corte transversal da montagem do modelo no tanque de testes do laboratório de engenharia naval e oceânica da Escola Politécnica.

Consideram-se três condições de calado, em que as relações de $B / T$ são: 2.5 para o calado médio, 5.0 para o calado maior e 1,67 para o calado menor. (Ver figura 4.5). 


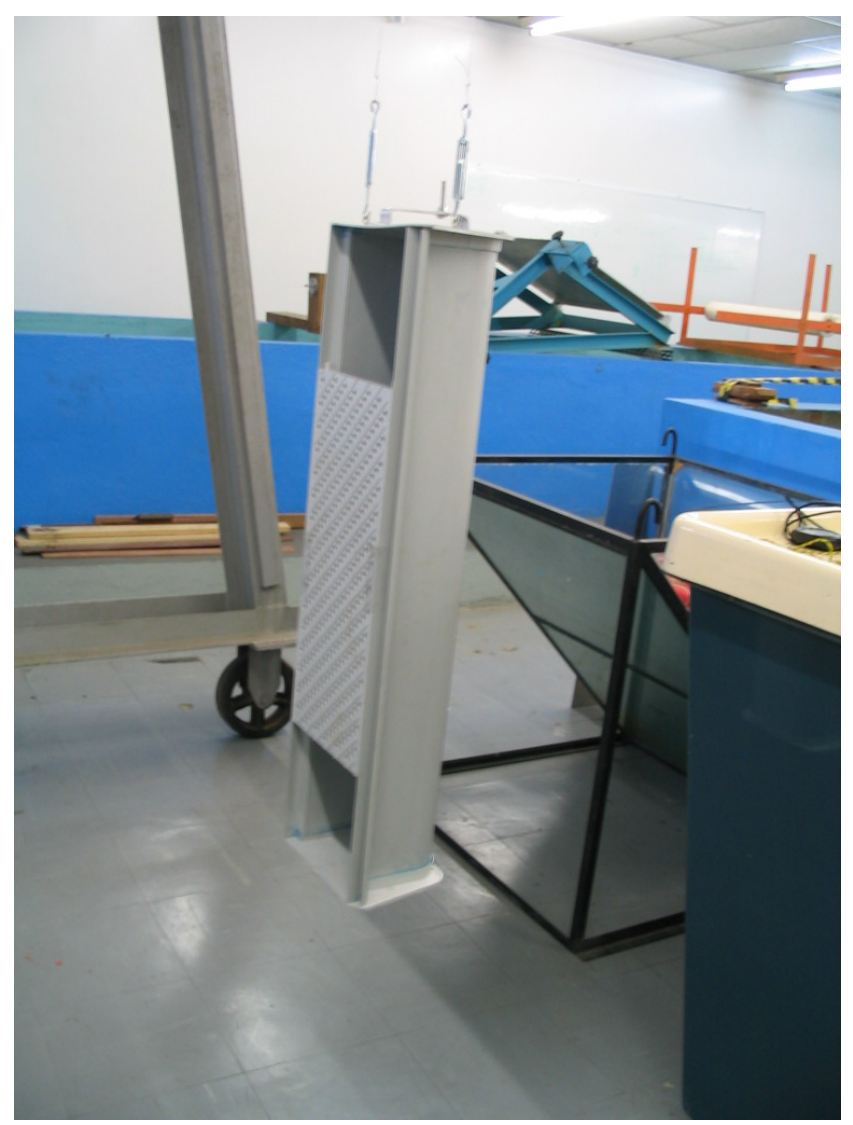

Figura 4.4: Medição do momento de inércia do modelo de bojo arredondado.
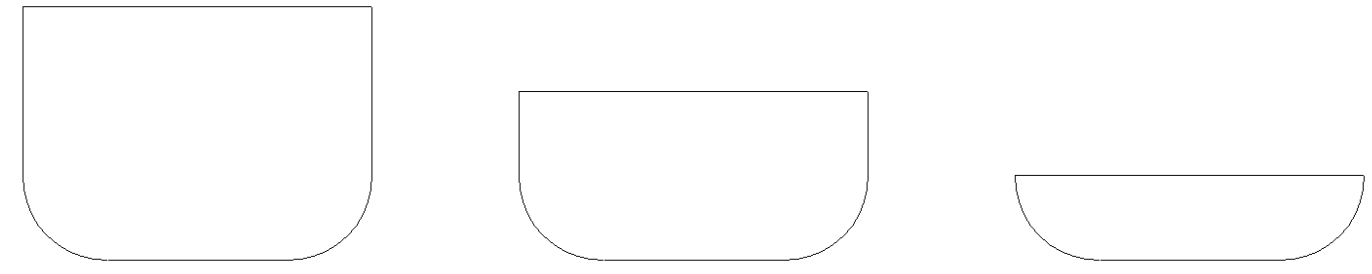

Figura 4.5: Diferentes proporções de $B / T$ ensaiadas. 


\subsubsection{Ajuste das características de inércia das seções}

Calibra-se a massa, momento de inércia e posição vertical do centro de gravidade das seções cilíndricas.

Para medir o momento de inércia em balanço das seções sem lastro emprega-se o método bifilar.

Mede-se a posição vertical do centro de gravidade por meio do equilíbrio do modelo em um fulcro.

Emprega-se paralelepípedos de chumbo com geometria conhecida posicionados internamente ao modelo para estabelecer as condições de inércia a serem ensaiadas.

As figuras 4.6 e 4.7 ilustram duas condições de lastro de mesma massa e centros de gravidade, e momentos de inércia diferentes.

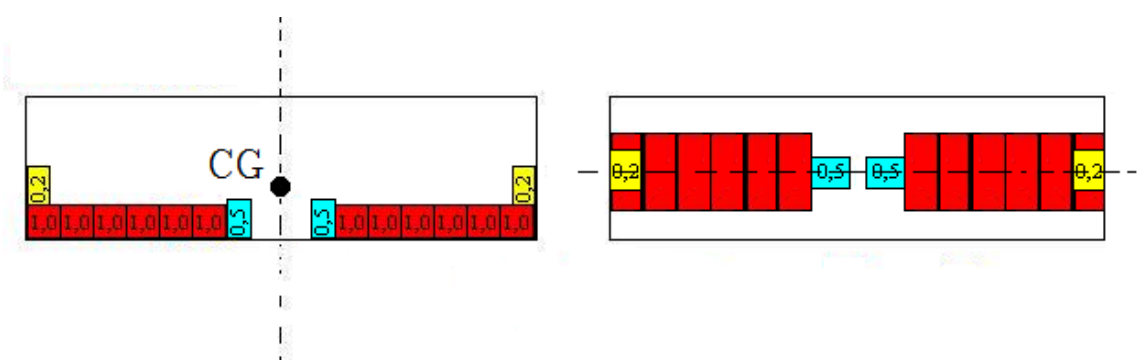

Figura 4.6: Vistas lateral (à esquerda) e superior (à direita) da configuração de lastro para o calado máximo com centro de gravidade mais baixo na vertical.

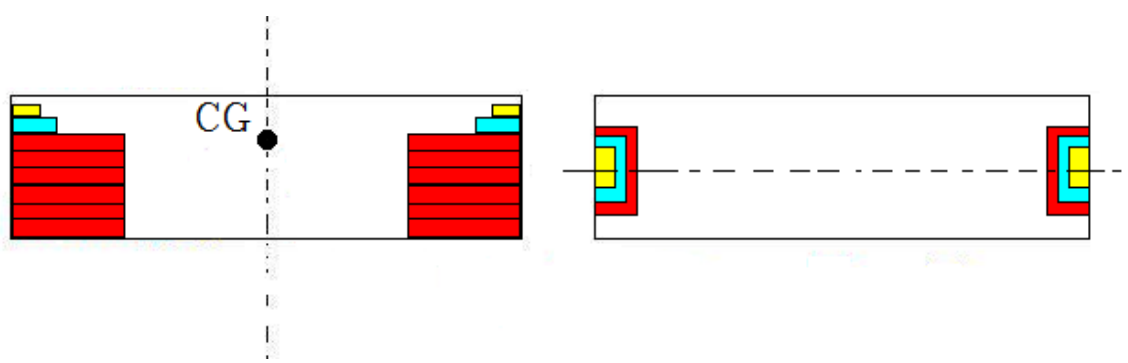

Figura 4.7: Vistas lateral (à esquerda) e superior (à direita) da configuração de lastro para o calado máximo com centro de gravidade mais alto na vertical. 


\subsubsection{Instrumentação}

A instrumentação do ensaio consistiu em três transdutores:

1. rate-gyro;

2. ondômetro;

3. inclinômetro de precisão digital;

4. condicionador e amplificador de sinais elétricos.

O rate-gyro consiste em um transdutor de velocidade angular para tensão elétrica. Um elemento vibratório triangular de cristal piezoelétrico é sensibilizado pela rotação. A variação de tensão elétrica correspondente a uma determinada rotação é então registrada.

O ondômetro resistivo ou wave-probe é um transdutor de nível de água para variação de resistência elétrica, medida por meio de ponte de Wheatstone.

Ambos os transdutores são concebidos para operar linearmente na faixa de interesse.

O inclinômetro de precisão digital é usado para a medição do ângulo inicial no qual é iniciado o decaimento. Este medidor angular tem como sensor um acelerômetro eletrônico que detecta a componente da aceleração gravitacional projetada na direção de inclinação.

Um condicionador de sinais foi empregado para amplificar e filtrar a tensão elétrica proveniente dos transdutores.

Todos os sinais condicionados são armazenados digitalmente com uma frequência de amostragem de $50 \mathrm{~Hz}$. Com o sinal do rate-gyro obtem-se através por meio de integração numérica a posição angular. O inclinômetro digital fornece o ângulo a partir do qual o modelo é liberado para o decaimento. A leitura angular é usada como constante de integração para o sinal do rate-gyro.

O arranjo do ensaio é apresentado na figura 4.8. O modelo está mantido em sua posição inicial de decaimento mantida pelo cabo utilizado. Nesta posição é realizada a leitura do ângulo inicial. 


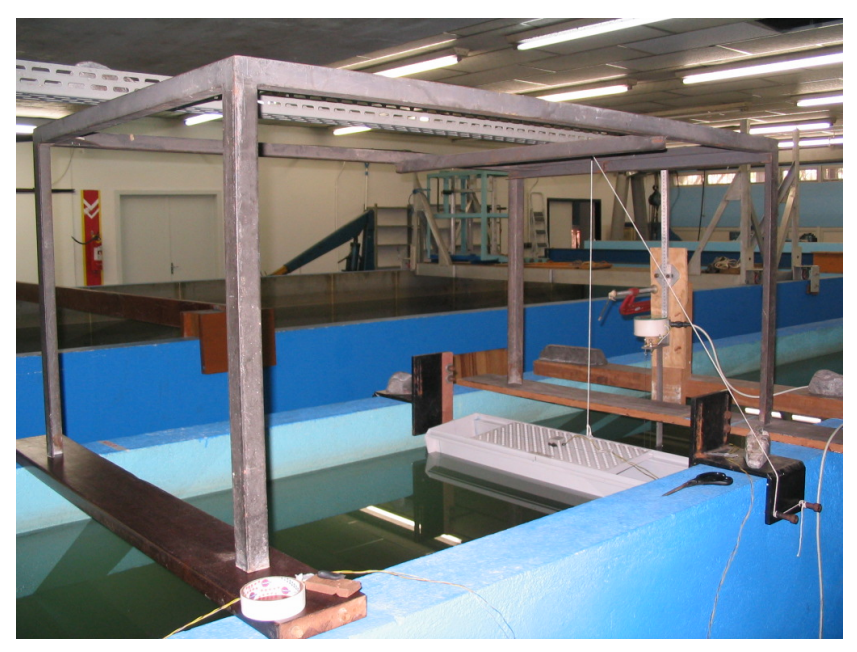

Figura 4.8: Foto da montagem do ensaio de decaimento com o dispositivo para abandono do modelo em destaque (linha branca).

\subsection{Os ensaios}

Os casos ensaiados para as várias geometrias de seção contemplam variações de calado e condições de inércia, e variações dos ângulos iniciais de balanço. As condições de inércia foram ajustadas por meio de paralelepípedos de chumbo e de medição da inércia da seção oscilante pelo método do pêndulo bifilar.

A tabela 4.1 apresenta a matriz de ensaios: geometria de seção, calado, raio de giração, centro de gravidade vertical.

No apêndice A são apresentados os parâmetros ensaiados para cada ensaio executado: geometria, ângulo inicial, lastro adicionado, condição de inércia, posição do KG, momento de inércia. 


\begin{tabular}{|c|c|c|c|}
\hline \multicolumn{4}{|c|}{ Ensaios de Decaimento - Matriz de Ensaios } \\
\hline Geometria da Seção & Calado $(\mathrm{mm})$ & Raio de Giração $(\mathrm{mm})$ & Centro de Gravidade Vertical (mm) \\
\hline \multirow{3}{*}{ Bojo Arredondado } & 80 & 68 & 38 \\
& 80 & 64 & 55 \\
& 40 & 84 & 68 \\
& 120 & 48 & 29 \\
& 120 & 59 & 66 \\
\hline \multirow{3}{*}{ Bojo com Bolina Altura 1 } & 80 & 68 & 38 \\
& 40 & 84 & 68 \\
& 120 & 48 & 29 \\
\hline \multirow{3}{*}{ Bojo com Bolina Altura 2} & 80 & 68 & 38 \\
& 40 & 84 & 68 \\
& 120 & 48 & 29 \\
\hline \multirow{3}{*}{ Bojo Quinado } & 80 & 68 & 36 \\
& 80 & 64 & 52 \\
& 40 & 83 & 60 \\
\hline
\end{tabular}

Tabela 4.1: Matriz de ensaios 


\subsection{Resultados}

\subsubsection{Processamento dos dados experimentais}

Os dados experimentais brutos fornecidos pelo sistema de coleta de dados foram inspecionados para identificação do início e do término de decaimento. O arquivo de dados contendo a série temporal foi verificado e o trecho de análise foi selecionado. Os registros temporais obtidos por meio dos transdutores são a velocidade angular e a altura de onda.

Separa-se trecho da série temporal selecionado em cada ensaio através de inspeção visual.

Gera-se novo arquivo de dados para a execução das operações de filtragem e integração numérica do registro do rate-gyro.

Para a operação de filtragem, utiliza-se filtro digital do tipo Butterworth passa-baixa em $15 \mathrm{~Hz}$, uma vez que a menor frequência de interesse é muito menor que a frequência de $7.5 \mathrm{~Hz}$ para este caso.

Integra-se o registro de velocidade angular para obter o registro de amplitude angular. Como constante de integração, utiliza-se a informação da amplitude inicial de cada ensaio medida pelo inclinômetro digital. Registra-se por meio de gráficos as operações para cada ensaio.

Nas figuras abaixo, apresenta-se a redução de dados para calado maior do modelo com bojo arredondado, bolina maior, bolina menor e bojo quinado, respectivamente. 


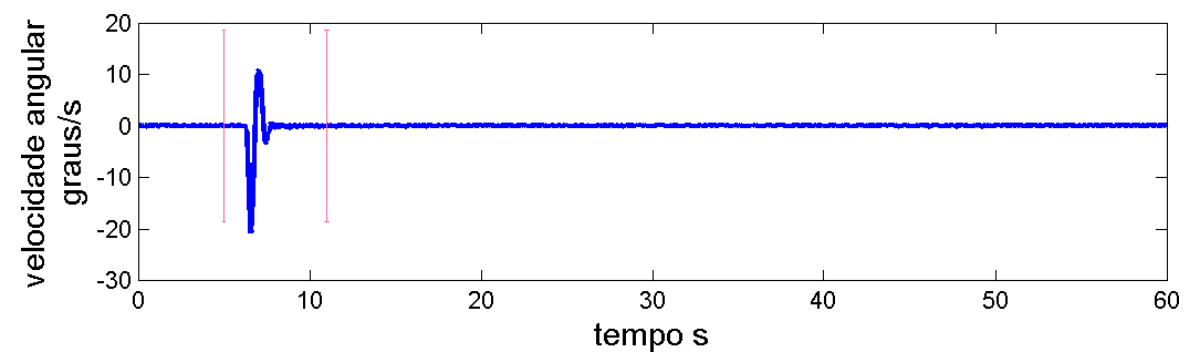

(a) Sinal original do rate-gyro .

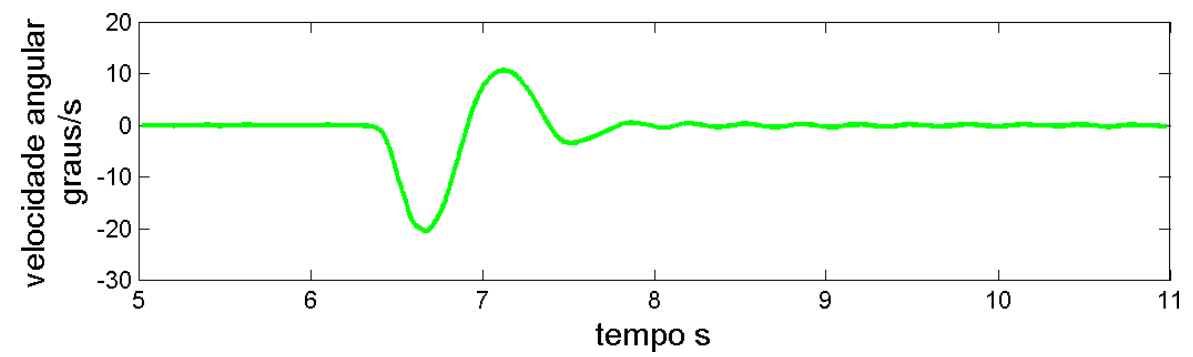

(b) Sinal separado e filtrado do rate-gyro.

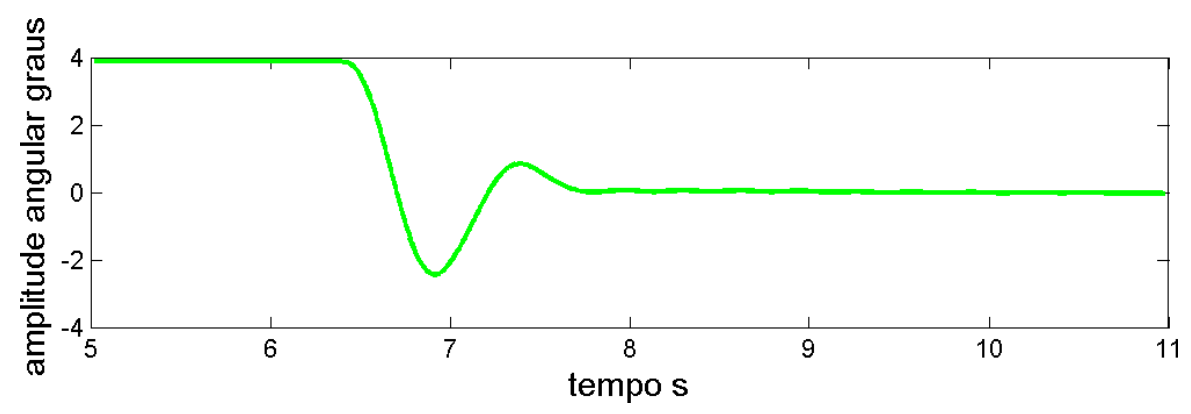

(c) Sinal integrado do rate-gyro.

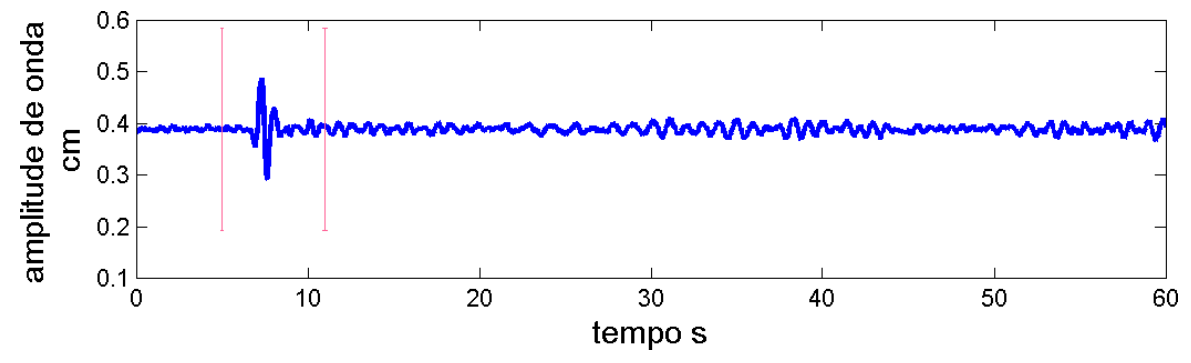

(d) Sinal original do ondômetro.

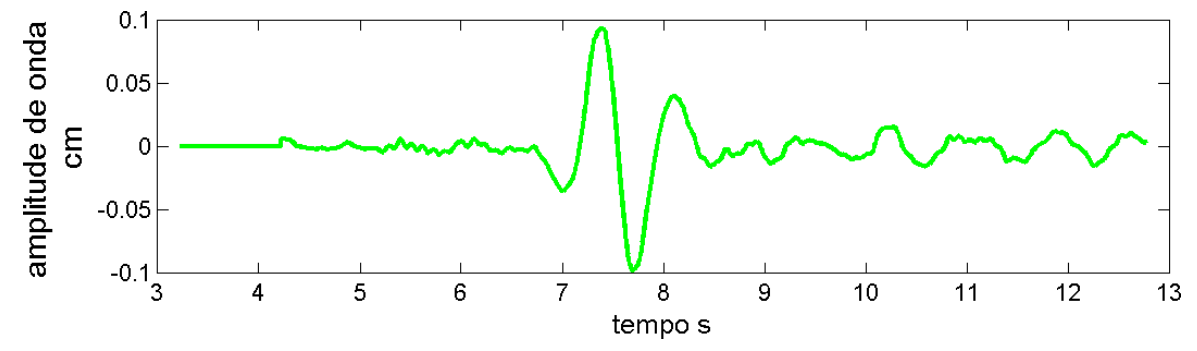

(e) Sinal separado e filtrado do ondômetro.

Figura 4.9: Redução dos dados do ensaio com bojo arredondado no calado maior. 


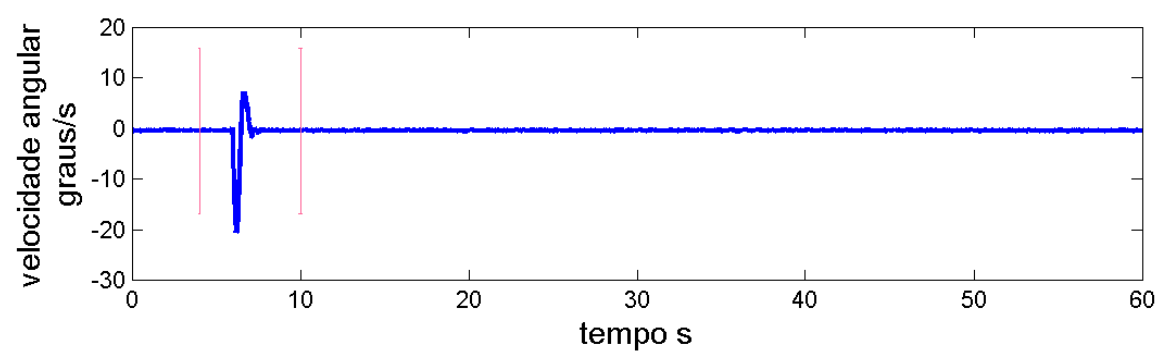

(a) Sinal original do rate-gyro .

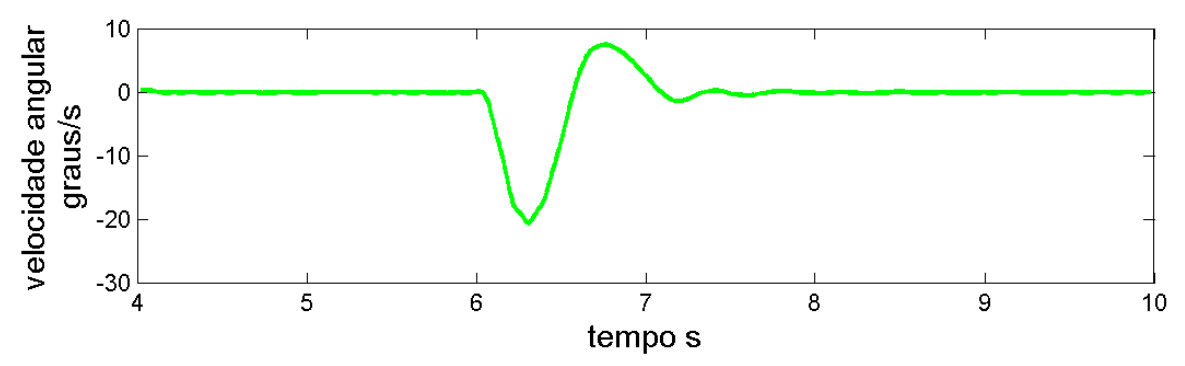

(b) Sinal separado e filtrado do rate-gyro.

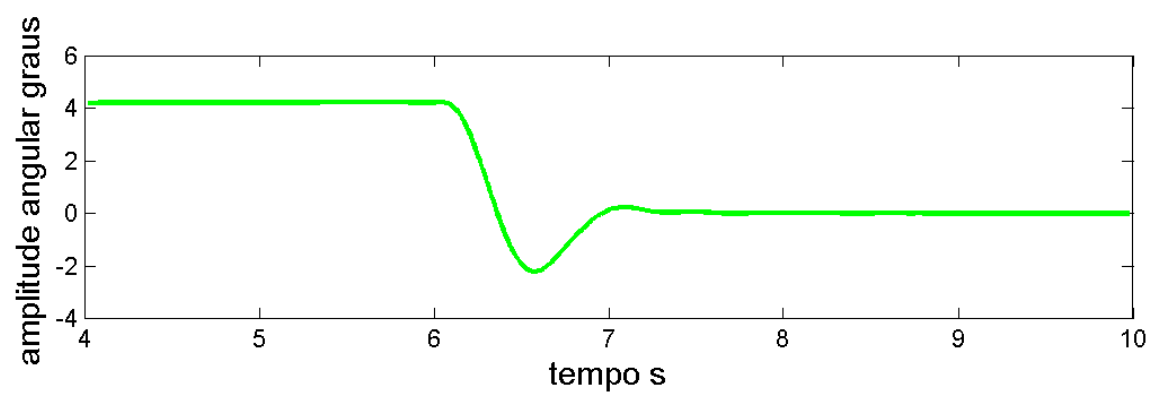

(c) Sinal integrado do rate-gyro.

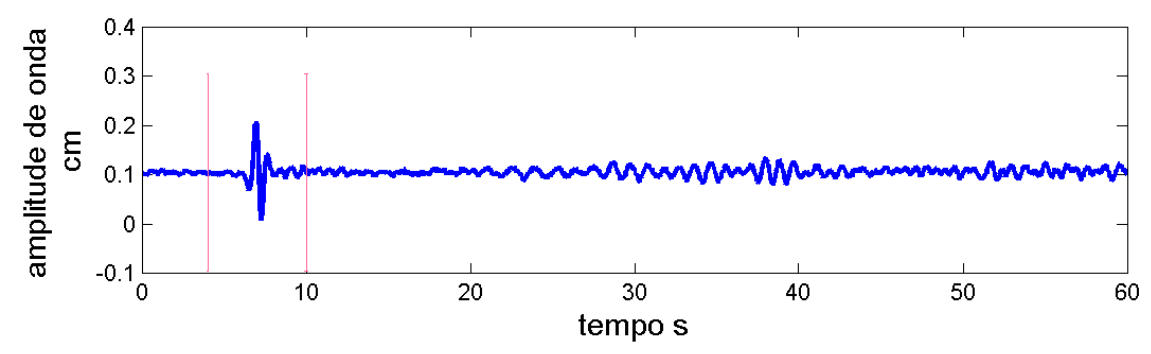

(d) Sinal original do ondômetro.

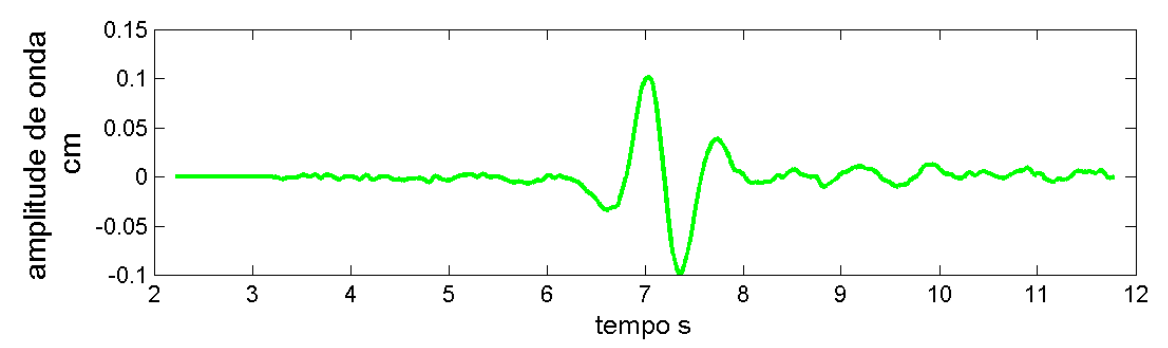

(e) Sinal separado e filtrado do ondômetro.

Figura 4.10: Redução dos dados do ensaio com bolina maior no calado maior. 


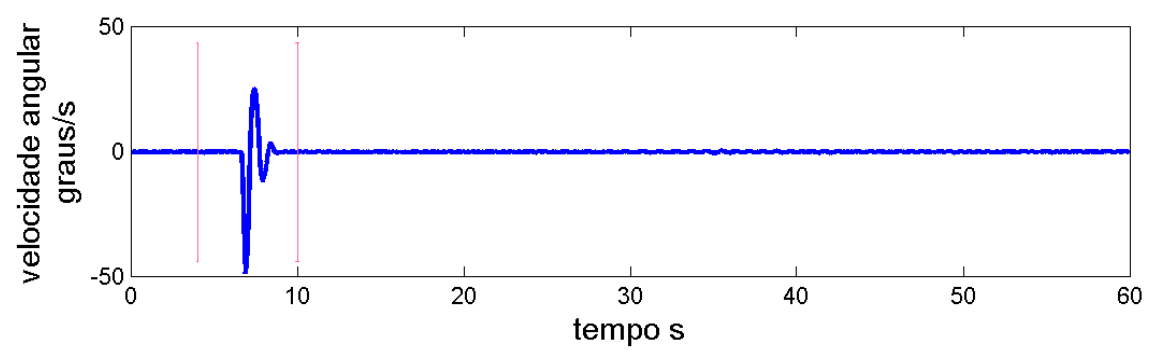

(a) Sinal original do rate-gyro .

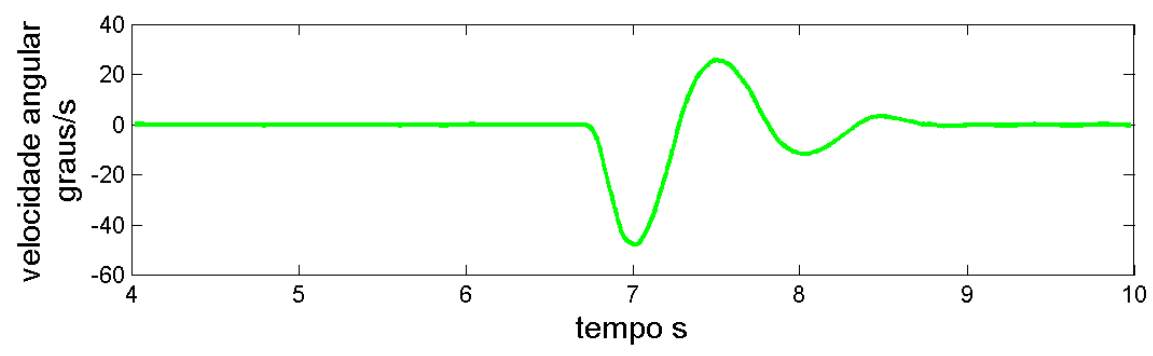

(b) Sinal separado e filtrado do rate-gyro.

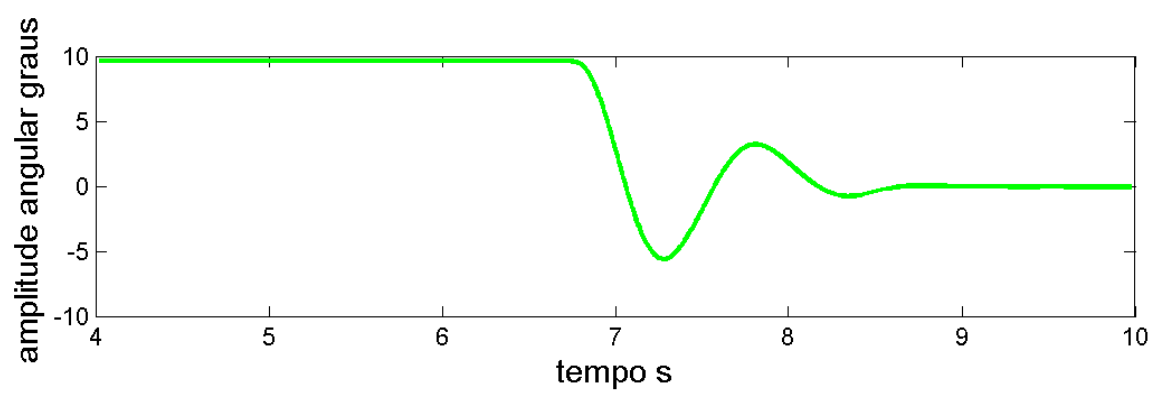

(c) Sinal integrado do rate-gyro.

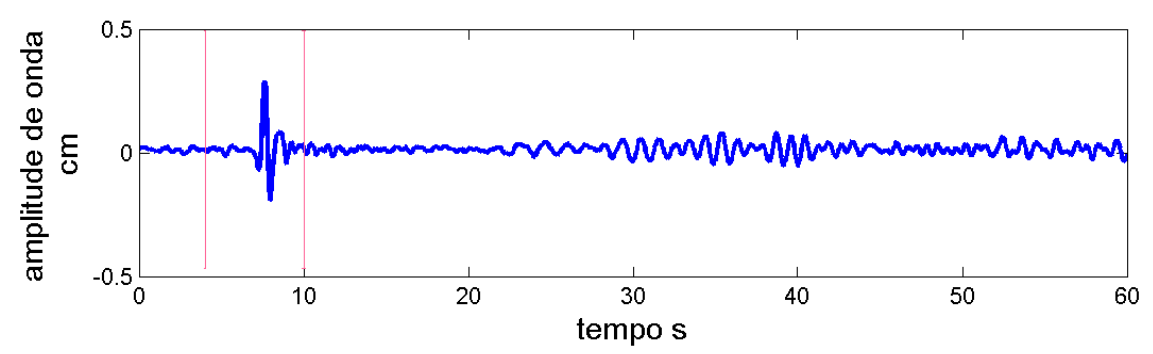

(d) Sinal original do ondômetro.

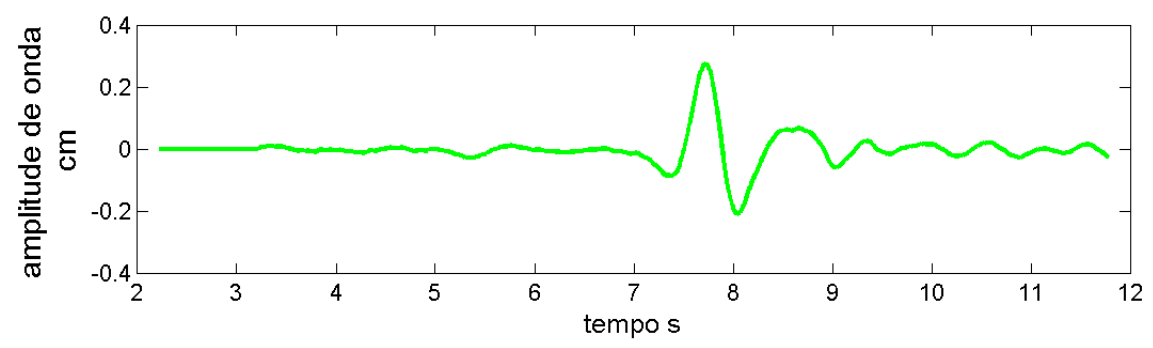

(e) Sinal separado e filtrado do ondômetro.

Figura 4.11: Redução dos dados do ensaio com bolina menor no calado maior. 


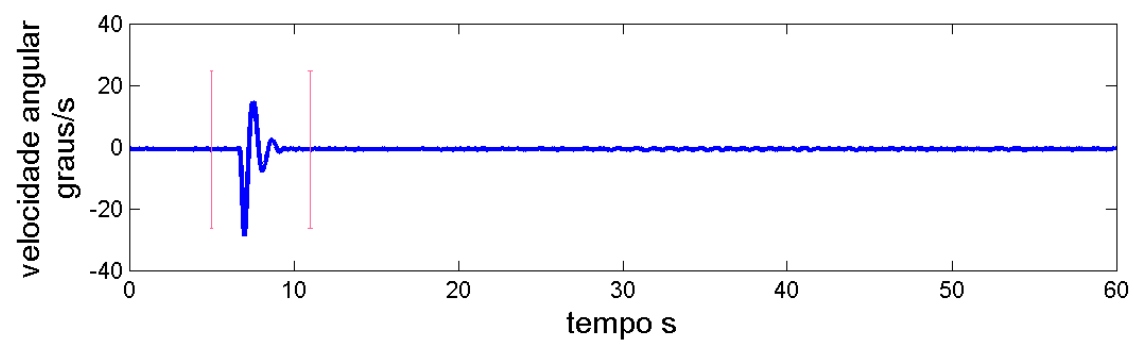

(a) Sinal original do rate-gyro .

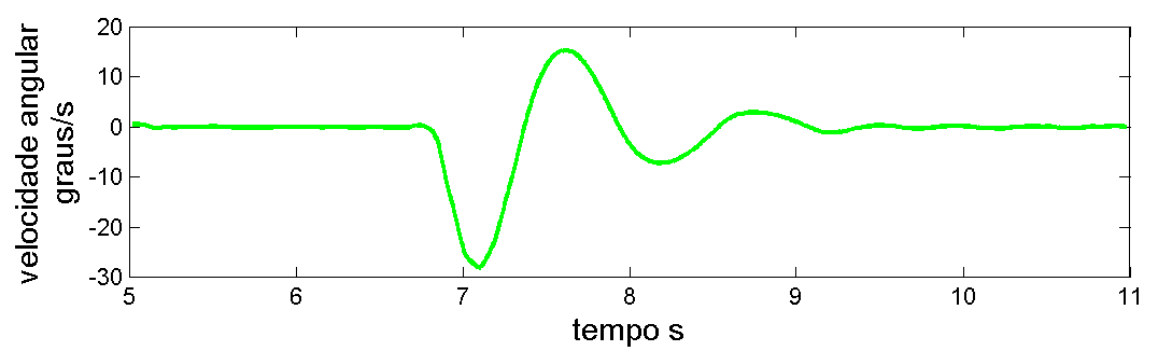

(b) Sinal separado e filtrado do rate-gyro.

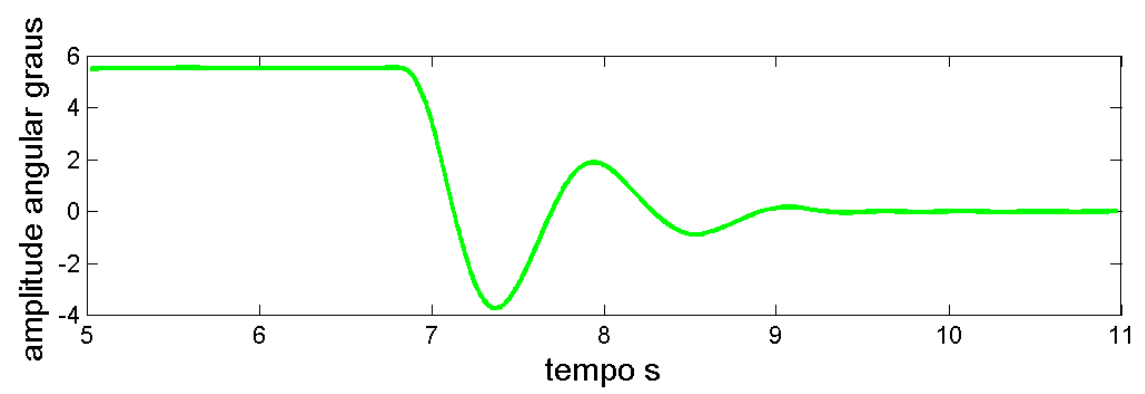

(c) Sinal integrado do rate-gyro.

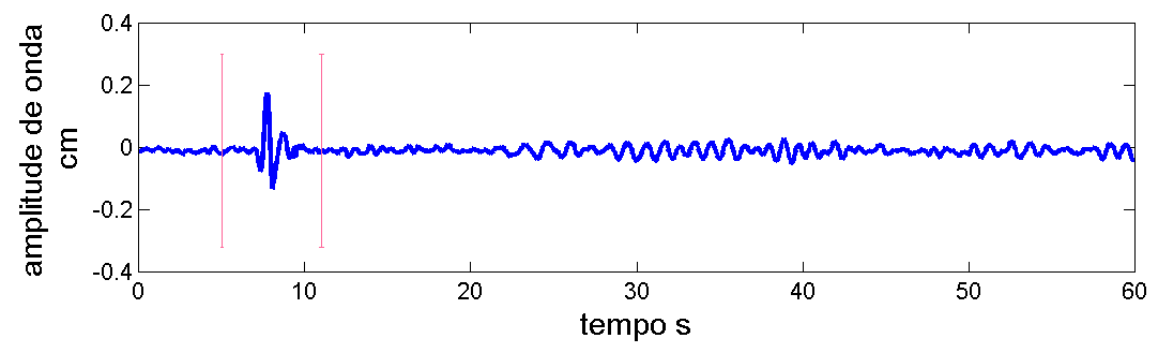

(d) Sinal original do ondômetro.

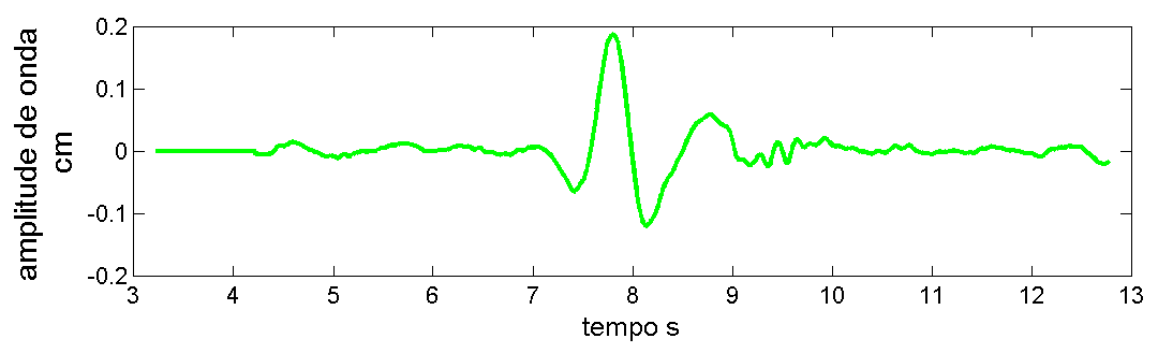

(e) Sinal separado e filtrado do ondômetro.

Figura 4.12: Redução dos dados do ensaio com bojo quinado no calado maior. 


\subsubsection{Amortecimento linear médio e coeficiente de massa adicionada}

São comparados os coeficientes de amortecimento linear e massa adicionada obtidos através da análise pelo método da energia para as diferentes seções no calado médio. Foram analisados os ensaios com ângulo inicial de banda de aproximadamente 10 graus.

\begin{tabular}{|c|c|}
\hline Geometria & Massa adicionada adimensional \\
\hline bojo arredondado & 0.9176 \\
\hline bolina menor & 1.0544 \\
\hline bolina maior & 0.9844 \\
\hline bojo quinado & 0.9956 \\
\hline
\end{tabular}

Tabela 4.2: Inércia adicionada adimensional em função da geometria da seção para o calado médio

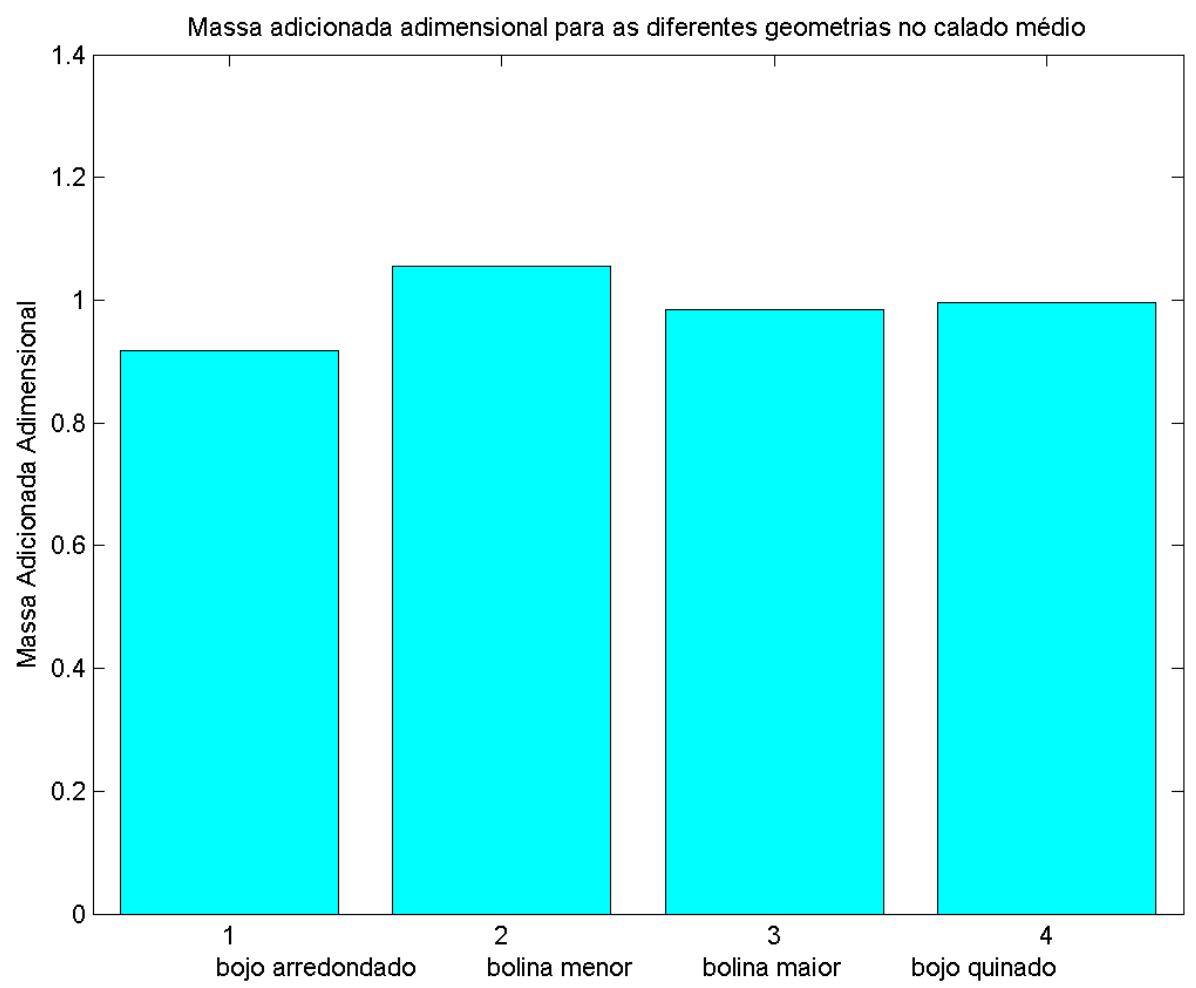

Figura 4.13: Massas adicionadas adimensionais para as diferentes geometrias no calado médio. 
Para o amortecimento linear médio, comparam-se as geometrias da seguinte forma:

\begin{tabular}{|c|c|}
\hline Geometria & Coeficiente de amortecimento linear médio \\
\hline bojo arredondado & 0.0168 \\
\hline bolina menor & 0.0656 \\
\hline bolina maior & 0.0505 \\
\hline bojo quinado & 0.0774 \\
\hline
\end{tabular}

Tabela 4.3: Inércia adicionada adimensional em função da geometria da seção para o calado médio

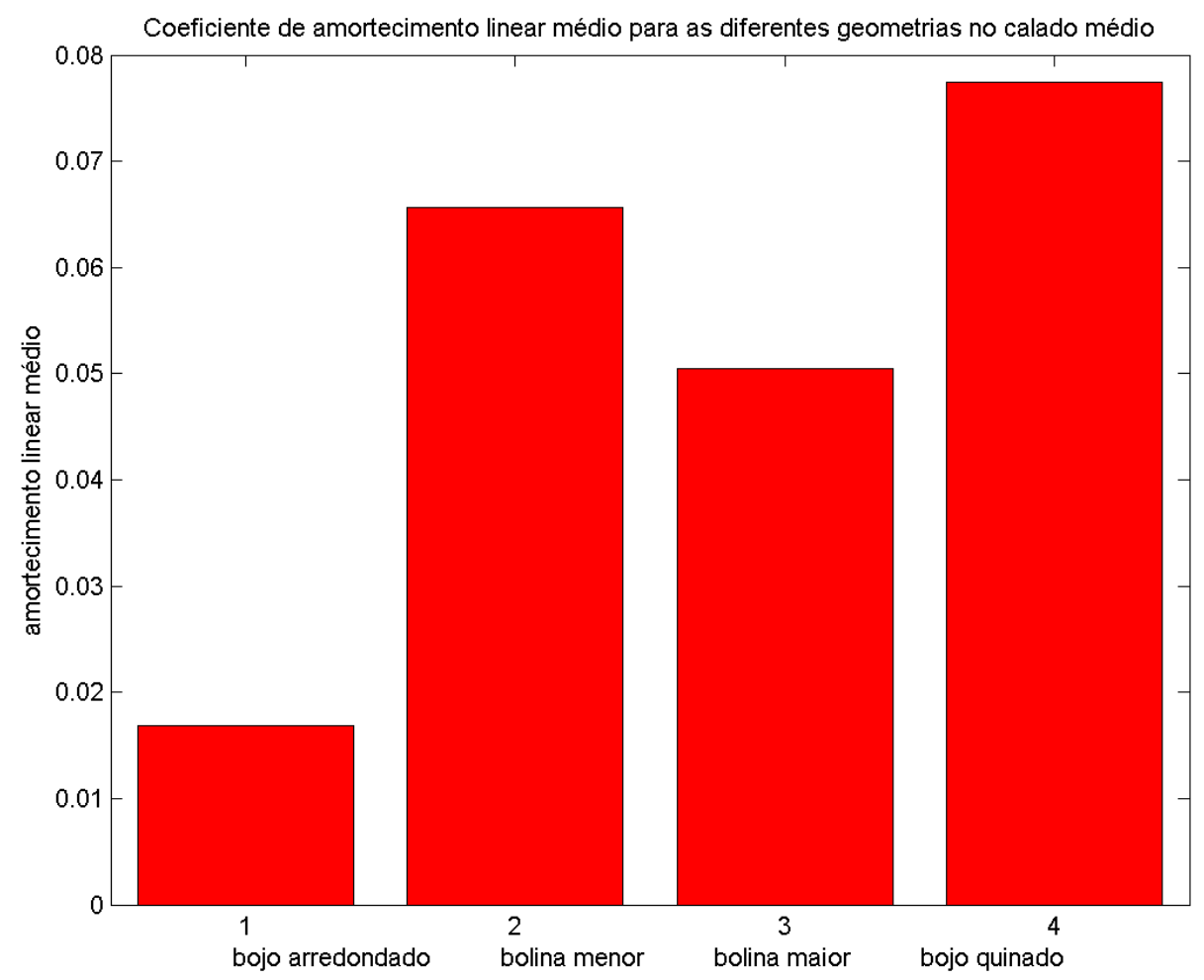

Figura 4.14: Comparação entre os coeficientes de amortecimento linear médio para as diferentes geometrias no calado médio. 
Procede-se à análise dos coeficientes de massa adicionada para o calado máximo.

\begin{tabular}{|c|c|}
\hline Geometria & Massa adicionada adimensional \\
\hline bojo arredondado & 1.0419 \\
\hline bolina menor & 1.1171 \\
\hline bolina maior & 1.1166 \\
\hline bojo quinado & 1.2257 \\
\hline
\end{tabular}

Tabela 4.4: Inércia adicionada adimensional em função da geometria para o calado máximo

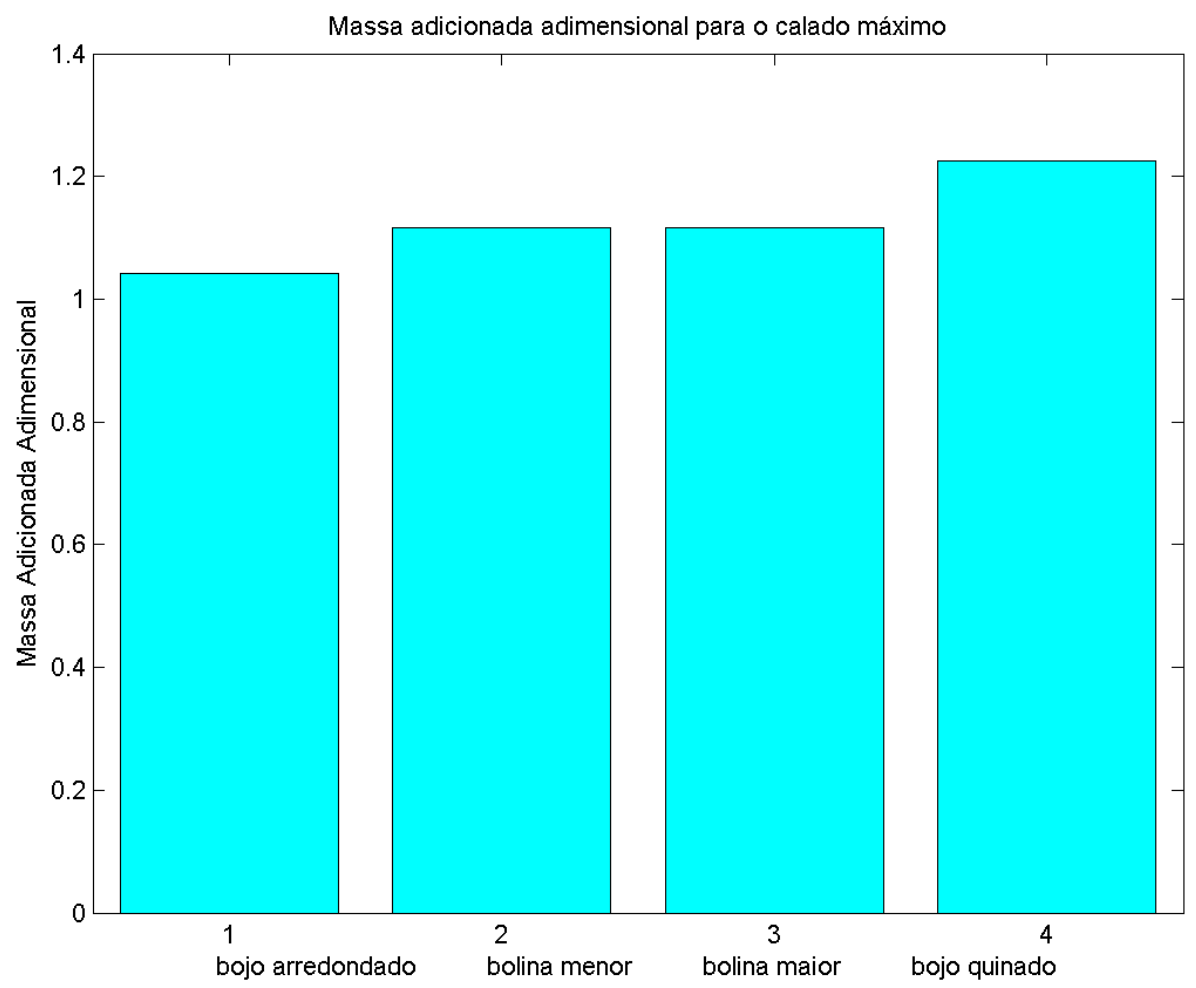

Figura 4.15: Comparação entre as massas adicionadas adimensionais para as diferentes geometrias no calado máximo. 
Examina-se o amortecimento linear médio para o calado máximo.

\begin{tabular}{|c|c|}
\hline Geometria & Coeficiente de amortecimento linear médio \\
\hline bojo arredondado & 0.1561 \\
\hline bolina menor & 0.1664 \\
\hline bolina maior & 0.1796 \\
\hline bojo quinado & 0.1473 \\
\hline
\end{tabular}

Tabela 4.5: Inércia adicionada adimensional em função da geometria da seção para o calado máximo

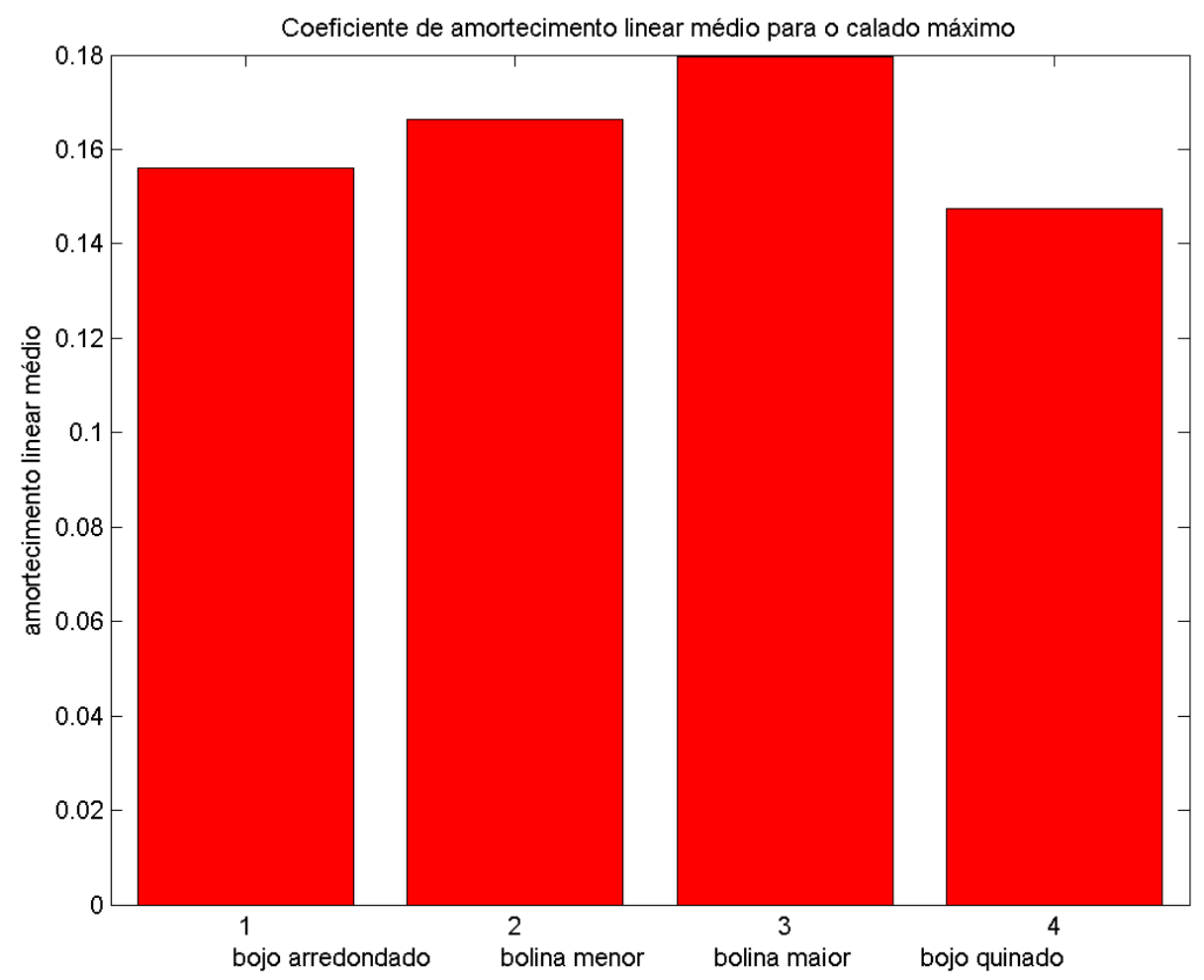

Figura 4.16: Comparação entre os coeficientes de amortecimento linear médio para as diferentes geometrias no calado máximo. 
Procede-se à análise dos coeficientes de massa adicionada para o calado mínimo.

\begin{tabular}{|c|c|}
\hline Geometria & Massa adicionada adimensional \\
\hline bojo arredondado & 0.8098 \\
\hline bolina menor & 0.8224 \\
\hline bolina maior & 0.8094 \\
\hline bojo quinado & 0.9217 \\
\hline
\end{tabular}

Tabela 4.6: Inércia adicionada adimensional em função da geometria para o calado mínimo

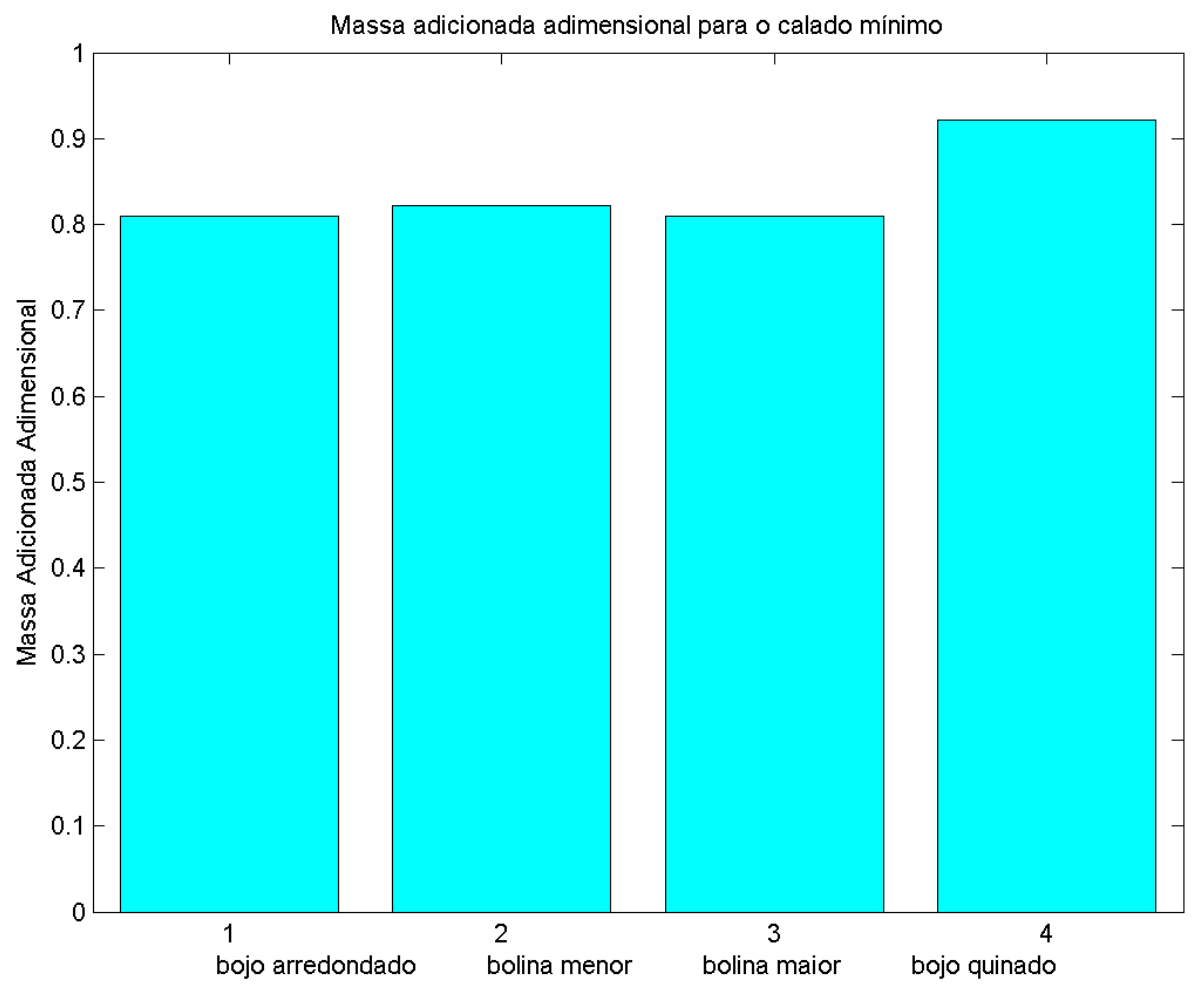

Figura 4.17: Comparação entre as massas adicionadas adimensionais para as diferentes geometrias no calado mínimo 
Examina-se o amortecimento linear médio para o calado mínimo.

\begin{tabular}{|c|c|}
\hline Geometria & Coeficiente de amortecimento linear médio \\
\hline bojo arredondado & 0.0395 \\
\hline bolina menor & 0.0540 \\
\hline bolina maior & 0.0432 \\
\hline bojo quinado & 0.0474 \\
\hline
\end{tabular}

Tabela 4.7: Amortecimento linear médio em função da geometria da seção para o calado mínimo

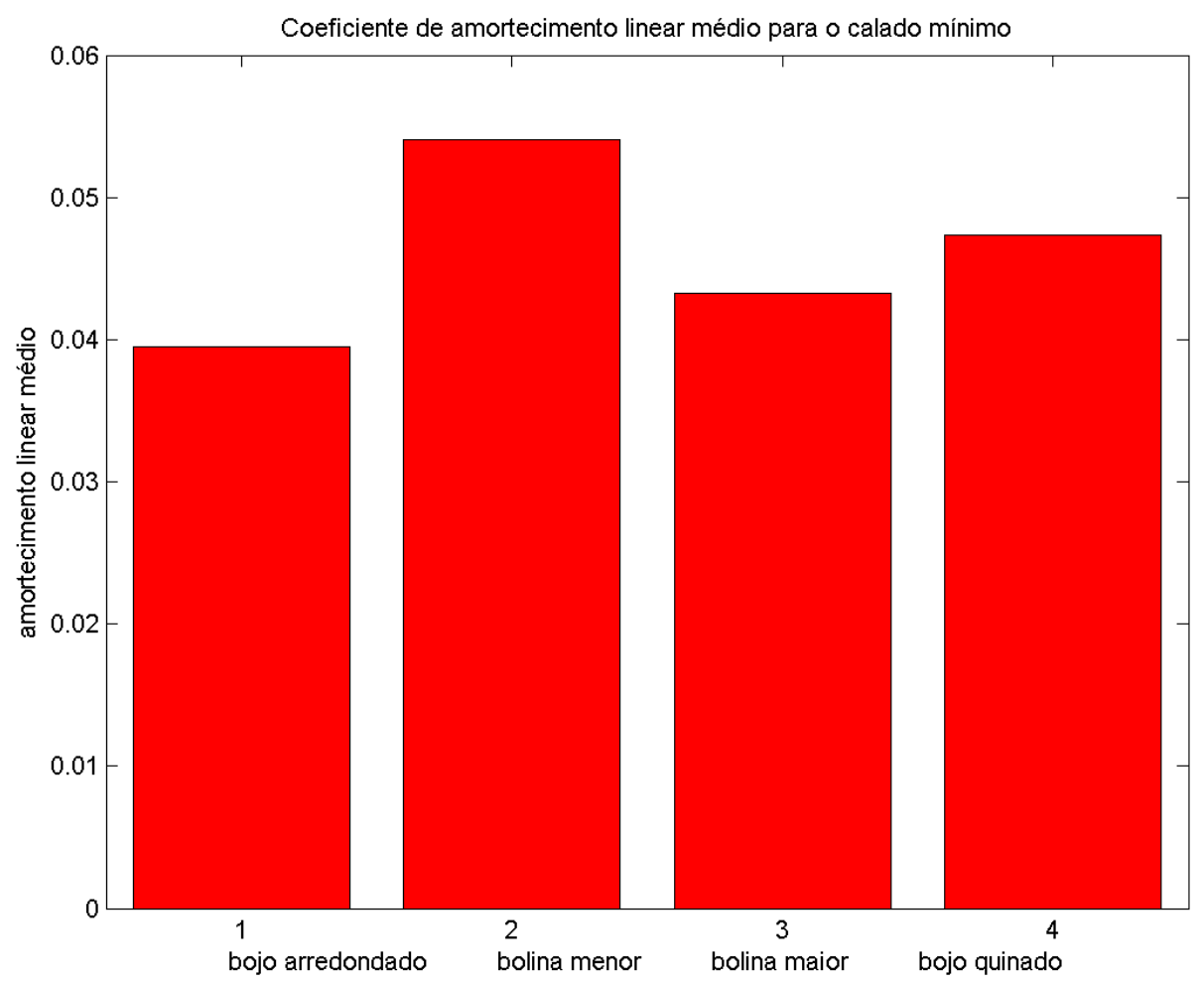

Figura 4.18: Comparação entre os coeficientes de amortecimento linear médio para as diferentes geometrias no calado mínimo 


\subsubsection{Verificação da influência do ângulo inicial}

O ângulo inicial determina a amplitude e a velocidade do movimento. Verifica-se a sua influência nos parâmetros de massa adicionada e de amortecimento linear. As tabelas 4.8 e 4.9 apresentam os valores de massa adicionada e amortecimento linear para as situações de ângulo inicial 5 e 10 graus.

\begin{tabular}{|c|c|c|}
\hline Geometria & Inércia adicionada para 5 graus & Inercia adicionada para 10 graus \\
\hline bojo arredondado & 1.5663 & 0.9176 \\
\hline bolina menor & 1.0496 & 1.0544 \\
\hline bolina maior & 1.0305 & 0.9840 \\
\hline
\end{tabular}

Tabela 4.8: Efeito do ângulo inicial na inércia adicionada

\begin{tabular}{|c|c|c|}
\hline Geometria & Amortecimento linear para 5 graus & Amortecimento linear para 10 graus \\
\hline bojo arredondado & 0.1016 & 0.0168 \\
\hline bolina menor & 0.0655 & 0.0656 \\
\hline bolina maior & 0.0671 & 0.0486 \\
\hline
\end{tabular}

Tabela 4.9: Efeito do ângulo inicial no amortecimento linear 


\subsubsection{Efeito do momento de inércia e centro de gravidade no amor- tecimento e inércia adicionada}

Foi testada uma variação nas condições de inércia referidas na seção 3.1.2, sendo a condição 1 da figura 4.6 e a condição 2 as da figura 4.7, respectivamente, para os casos de bojo arredondado e bojo quinado para o calado médio. Verificando-se a sua influência nos parâmetros de interesse.

\begin{tabular}{|c|c|c|}
\hline Geometria & Amortecimento linear Condição 1 & Amortecimento linear Condição 2 \\
\hline bojo arredondado & 0.0180 & 0.0297 \\
\hline bojo quinado & 0.0768 & 0.1011 \\
\hline
\end{tabular}

Tabela 4.10: Influência no amortecimento linear pela alteração das condições de inércia

\begin{tabular}{|c|c|c|}
\hline Geometria & Inércia adicionada Condição 1 & Inércia adicionada Condição 2 \\
\hline bojo arredondado & 0.9214 & 0.8593 \\
\hline bojo quinado & 0.9680 & 1.0591 \\
\hline
\end{tabular}

Tabela 4.11: Influência na inércia adicionada pela alteração das condições de inércia 


\subsubsection{Método da energia: estudo de termos não-lineaes de amorte- cimento e inércia adicionada empregados para cada geometria}

O estudo consiste no emprego dos modelos para inércia adicionada e amortecimento utilizados na análise pelo método da energia: termos lineares para amortecimento e restauração; termos dependentes da velocidade e do quadrado da velocidade angular para amortecimento e termos lineares para restauração; termos não-lineares para amortecimento e restauração, conforme equação 2.44 .

É selecionada para aplicação na geometria analisada o modelo com menor quantidade de termos não lineares que permite a recuperação dos série temporal através de simulação numérica .

Para a geometria de seção bojo arredondado, a modelagem de amortecimento linear permite a recuperação da série temporal.

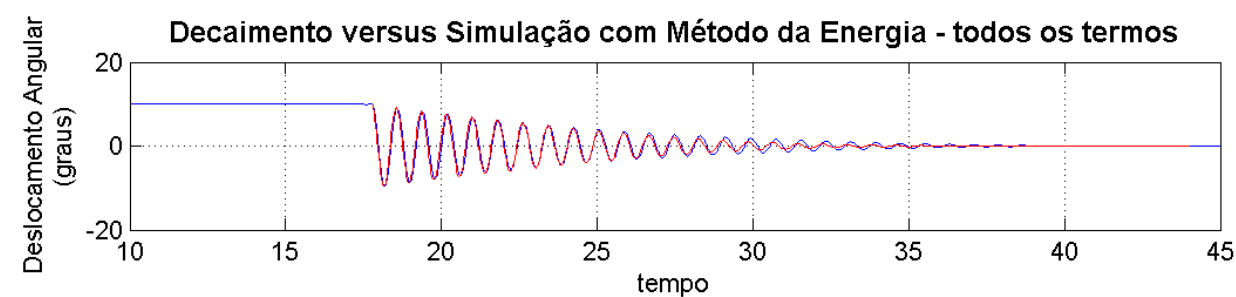

(s)

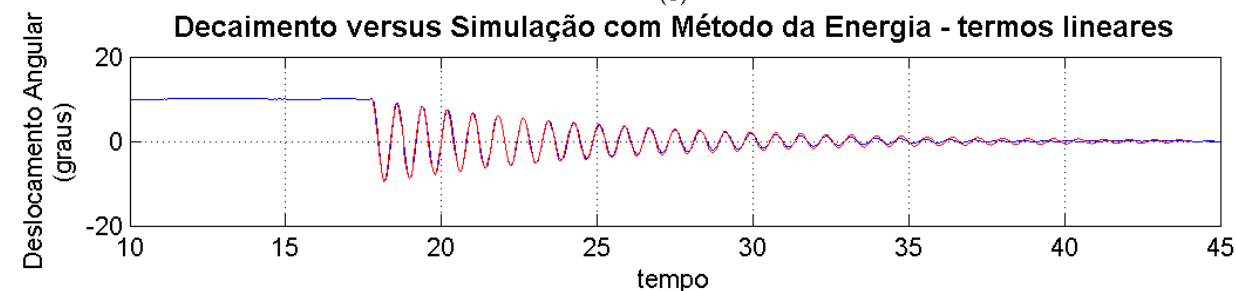

(s)

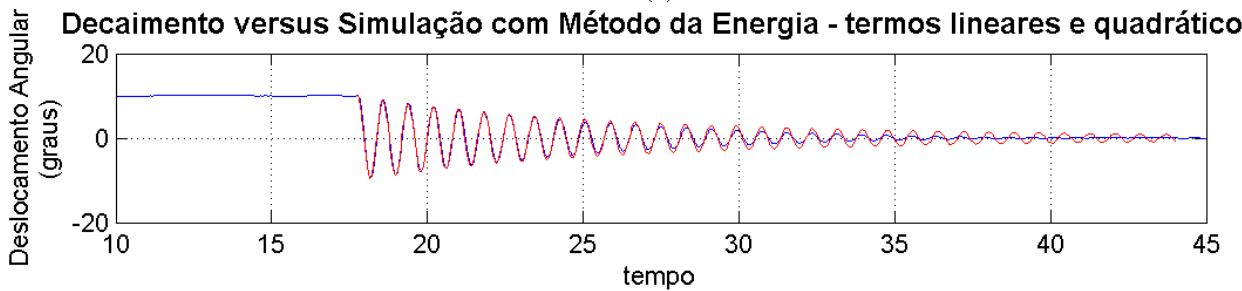

(s)

Figura 4.19: Modelagens de amortecimento e restauração e a série temporal para a geometria bojo arredondado. 
Para a geometria de seção bojo arredondado com bolina menor, a modelagem de amortecimento linear reconstitui a série temporal.

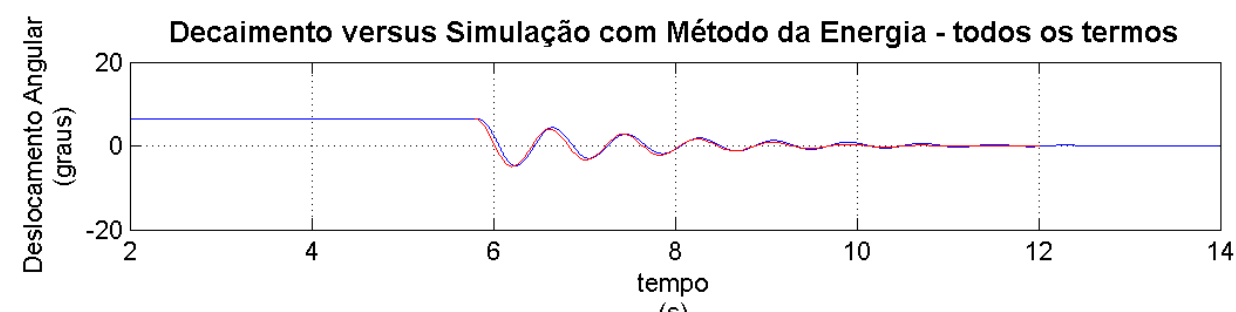

(s)

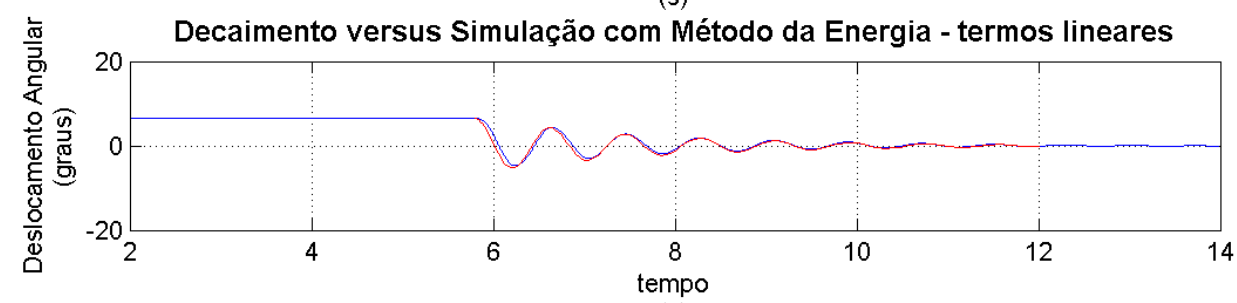

(s)

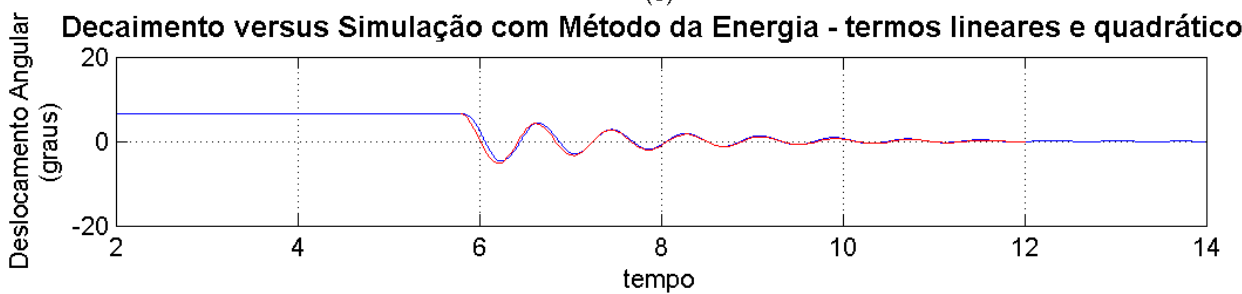

(s)

Figura 4.20: Modelagens de amortecimento e restauração e a série temporal para a geometria bojo arredondado com bolina menor. 
Com uma bolina maior, o amortecimento é maior do que nos casos anteriores. Verifica-se a redução do número de ciclos. A modelagem linear reproduz a série temporal.

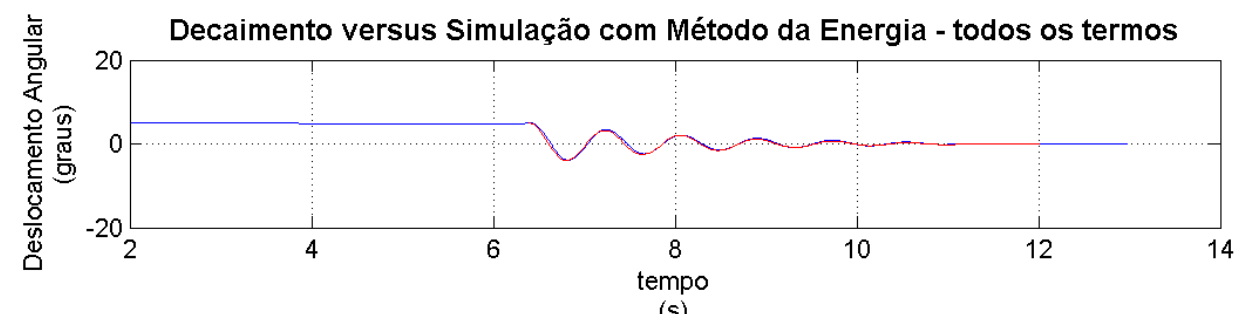

(s)

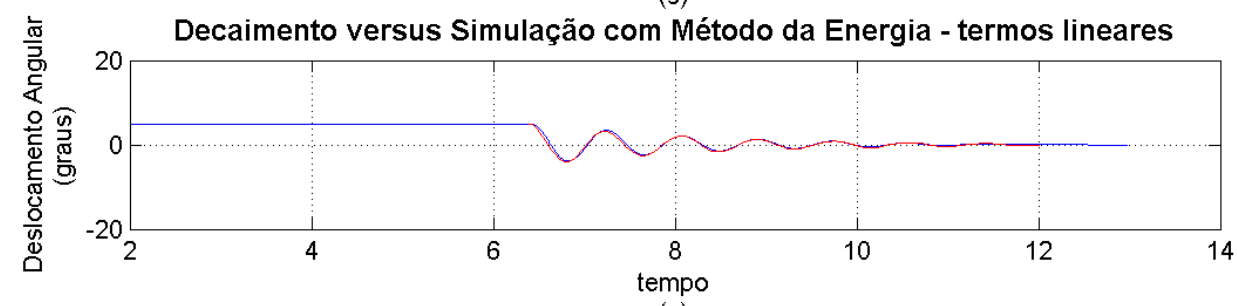

(s)

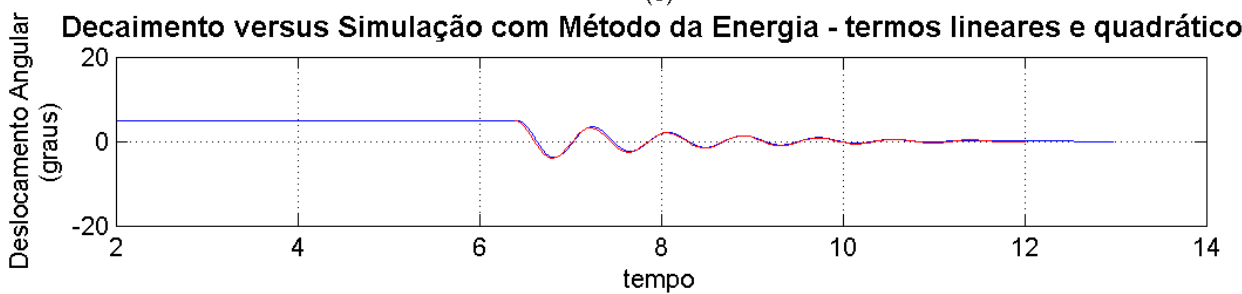

(s)

Figura 4.21: Modelagens de amortecimento e restauração e a série temporal para a geometria bojo arredondado com bolina maior. 
O bojo quinado impõe o amortecimento de maior magnitude. A simulação empregando-se somente os termos lineares é empregada.
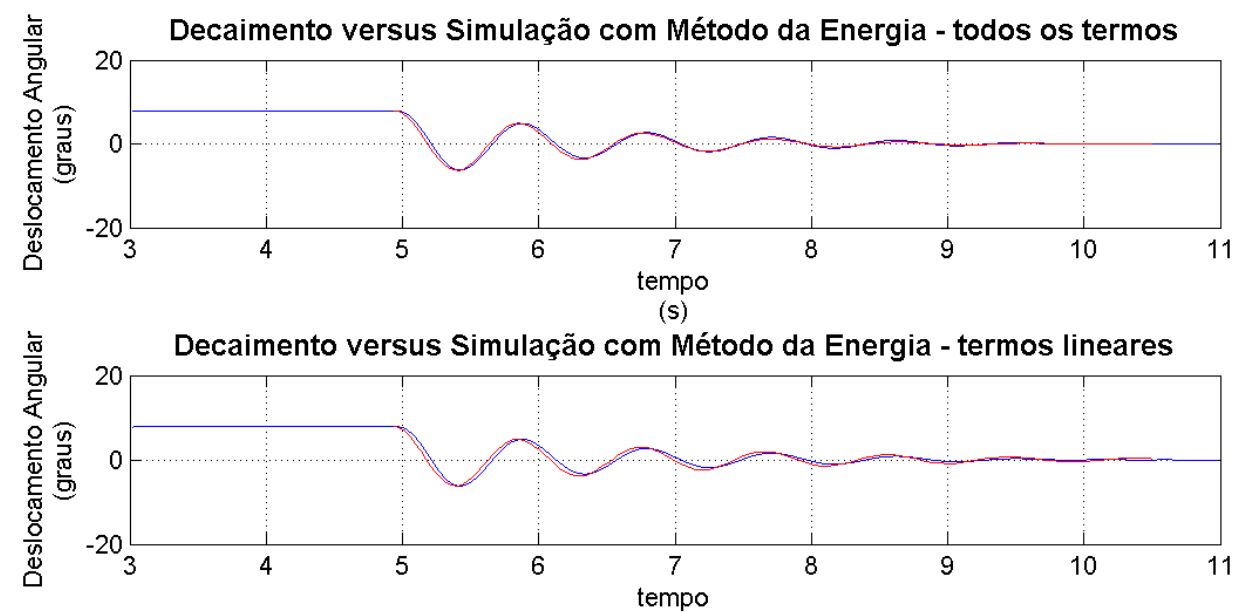

(s)

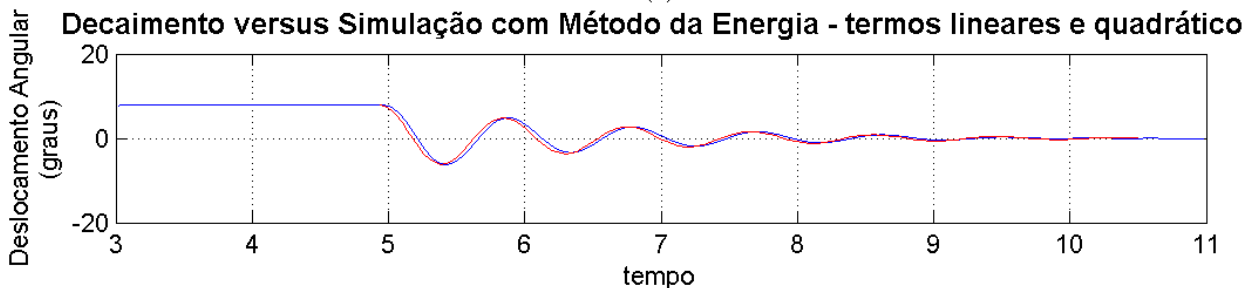

(s)

Figura 4.22: Modelagens de amortecimento e restauração e a série temporal para a geometria bojo quinado. 


\subsubsection{Energia das ondas irradiadas em balanço}

Analisa-se a energia transportada através das ondas irradiadas pelo corpo em balanço com relação à energia potencial relativa à posição inicial de banda. Estima-se a energia mecânica das ondas geradas pelo modelo através da equação 2.18 .

Apresenta-se a estimativa para a geometria bojo arredondado no calado médio, cujo espectro de potência é apresentado na figura 4.23.

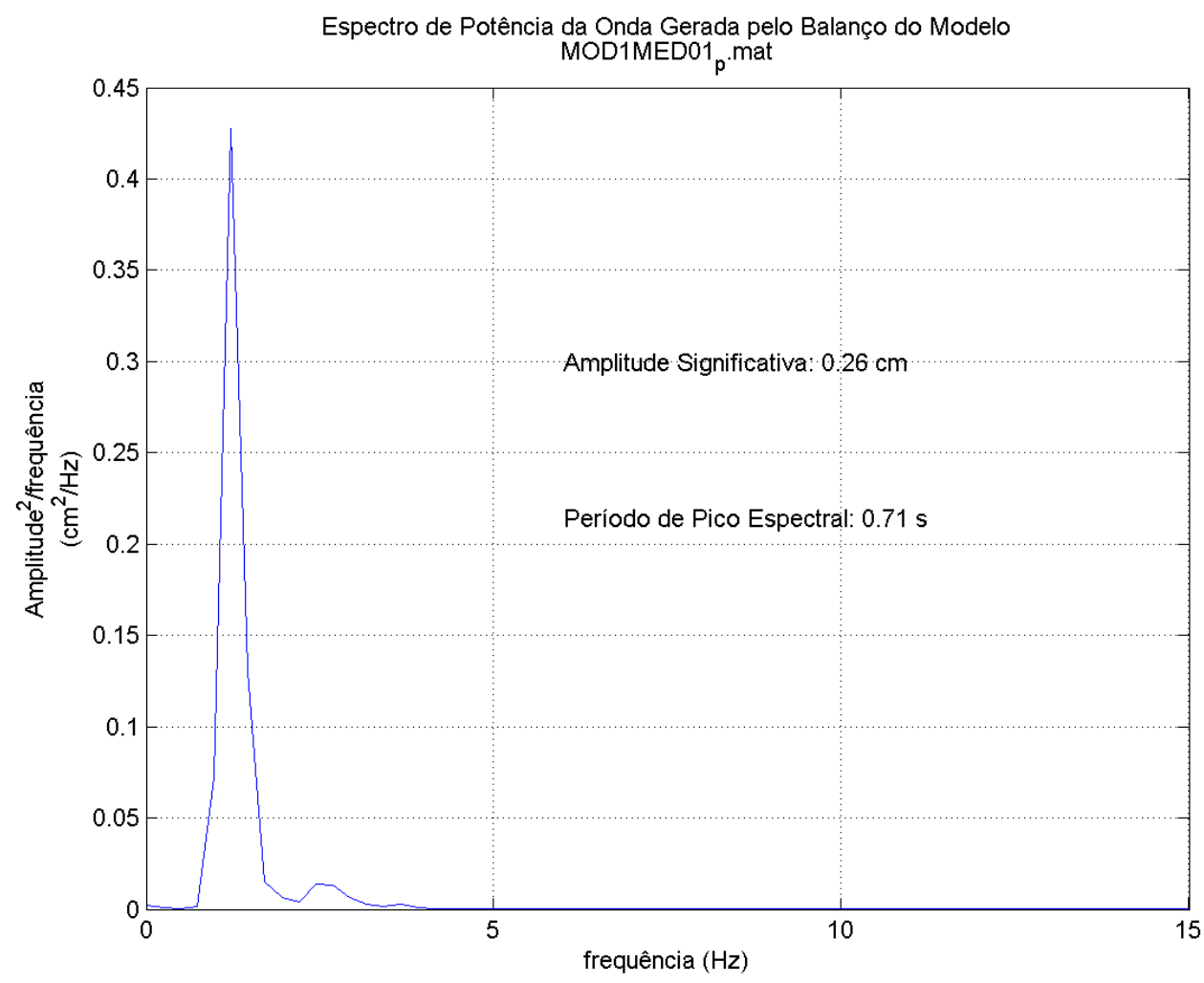

Figura 4.23: Espectro de potência da onda gerada pelo modelo na condição bojo arredondado no calado médio.

Por meio da obtenção dos parâmetros de altura e período de onda, foi estimada a energia mecânica ( cinética + potencial) transportada pela onda.

Pode-se observar que o bojo arredondado apresenta uma menor dissipação de energia mecânica através das ondas irradiadas, para o calado médio. A parcela de energia dissipada pelas ondas não é importante nas condições ensaiadas para a dissipação da energia do movimento. 


\begin{tabular}{|c|c|l|l|}
\hline Geometria & Energia Potencial do Modelo & $\begin{array}{l}\text { Energia Mecânica } \\
\text { da Onda }\end{array}$ & $\begin{array}{l}\text { Energia convertida } \\
\text { em ondas }\end{array}$ \\
\hline & Joules $/ \mathrm{m}$ & Joules $/ \mathrm{m}$ & $\%$ \\
\hline Bojo arredondado & 0.0693 & $2.4064 \mathrm{e}-004$ & 0.35 \\
\hline Bolina menor & 0.0917 & $8.5605 \mathrm{e}-004$ & 0.93 \\
\hline Bolina maior & 0.0730 & $5.1392 \mathrm{e}-004$ & 0.70 \\
\hline Bojo quinado & 0.1078 & 0.0010 & 0.94 \\
\hline
\end{tabular}

Tabela 4.12: Estimativa da energia carregada pela onda irradiada e sua participação na energia potencial no início do decaimento

\subsection{Análise: obtenção do amortecimento e da inércia adi- cionada}

\subsubsection{Seleção de Modelo}

A partir dos dados processados, realizaram-se as análises para obtenção do amortecimento e da inércia adicionada.

A análise com modelo linear para o amortecimento através da determinação das amplitudes máximas em cada meio ciclo não se mostrou robusta para todas as geometrias ensaiadas, como se verá a seguir.

No caso do bojo arredondado, que apresenta menor amortecimento, e por isto, maior número de ciclos com períodos aproximadamente próximos, a análise por ciclos médios apresentou bons resultados na reprodução da curva de decaimento por simulação.

A figura 4.24 ilustra o resultado acima descrito para o calado médio.

Aplicando-se este mesmo procedimento para o caso de bojo quinado, obtém-se resultado diverso. Uma vez que esta condição apresenta menos ciclos para análise, além de uma diferença maior entre os períodos destes ciclos devido ao maior amortecimento, a reconstrução da série temporal apresentou resultados inferiores aos obtidos anteriormente.

A figura 4.25 refere-se à comparação entre a simulação e a série temporal do ensaio com análise de ciclos médios. Observa-se uma discrepância na reprodução dos períodos entre ciclos.

Uma explicação para esta discrepância é o fato de que a análise de ciclos médios contempla apenas as amplitudes máximas de cada ciclo. Se o modelo é moderadamente amortecido, 


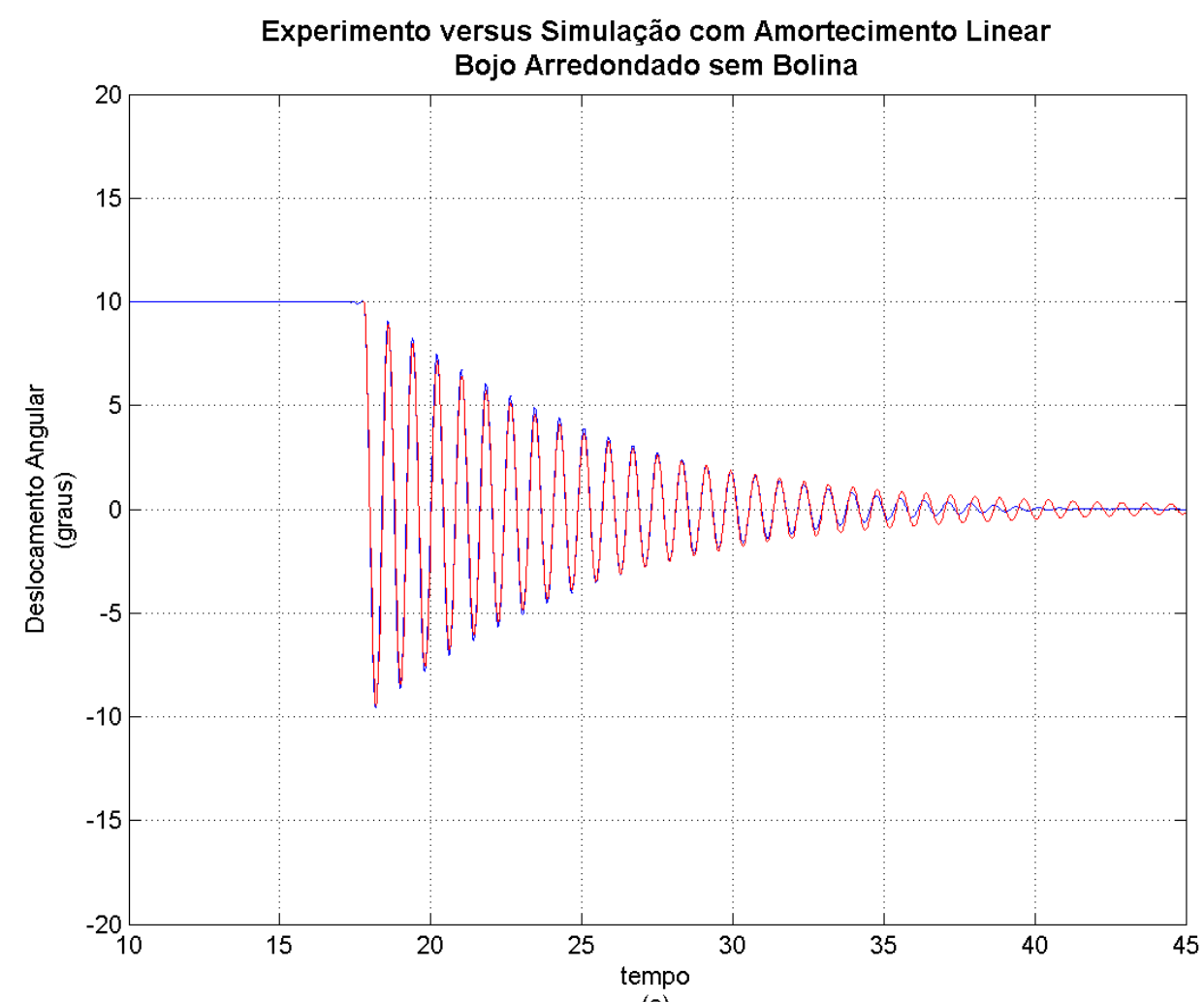

(s)

Figura 4.24: Comparação entre registro temporal e simulação com coeficientes obtidos através de análise por ciclos médio para o caso bojo arredondado. 


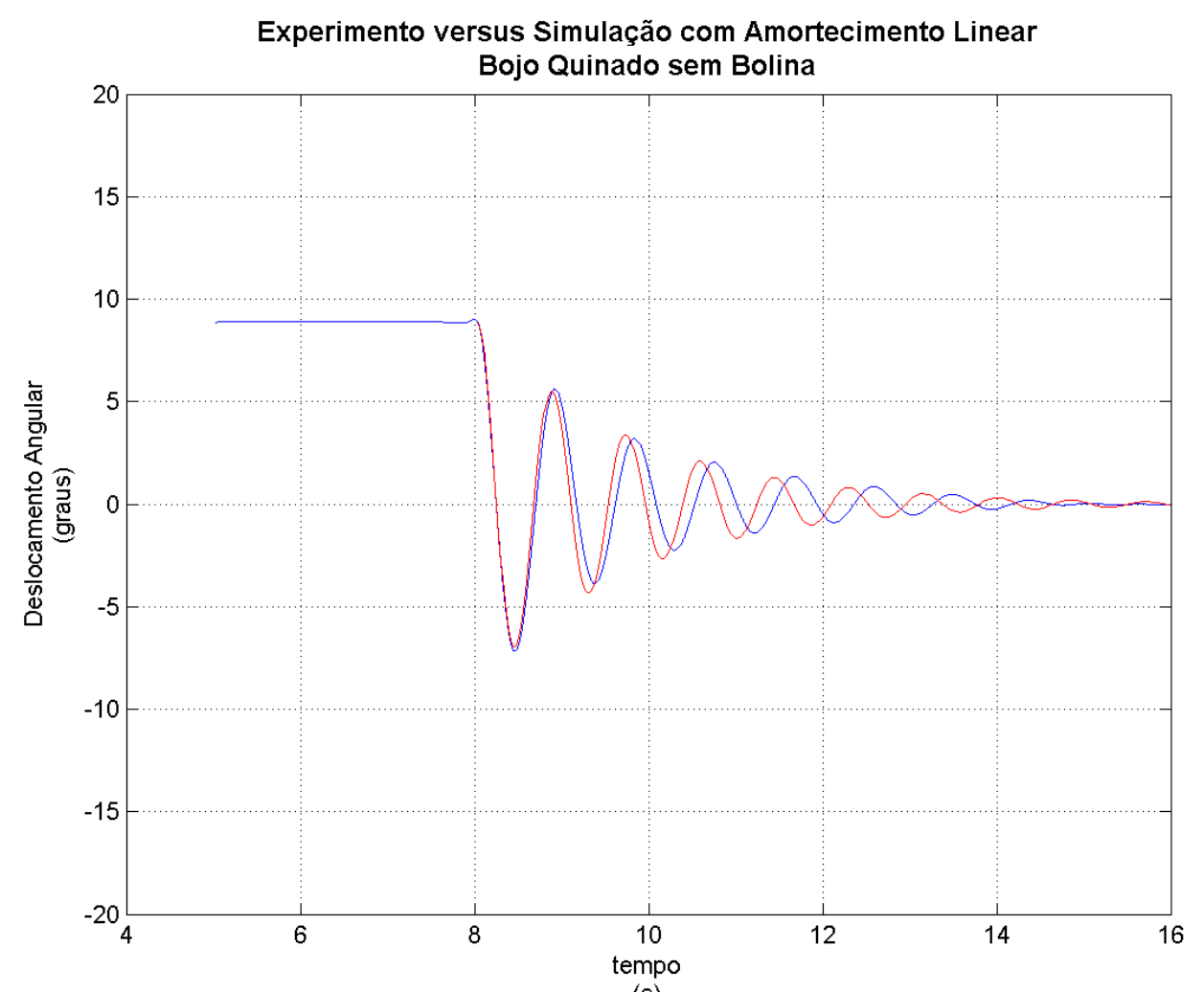

(s)

Figura 4.25: Comparação entre registro temporal e simulação com coeficientes obtidos através de análise por ciclos médio para o caso bojo arredondado. 
com valores superiores a 10\%, a diferença entre os períodos medidos dos ciclos pode crescer causando uma estimativa grosseira da frequência natural.

O método por energia utiliza todos os pontos da série temporal para ajustar o modelo através de quadrados mínimos para o balanço de energia. Desta maneira, mais informação é utilizada na estimativa do período natural e do amortecimento, resultando em ajustes mais aderentes.

O método mostra-se mais aderente, mesmo no caso em que se considera apenas o amortecimento linear, como o método dos ciclos médios.

Na figura 4.26, segue a comparação do mesmo caso de bojo quinado através do método da energia. Pode-se observar a melhor aderência de qualquer uma das modelagens adotadas, mesmo no caso de amortecimento linear.
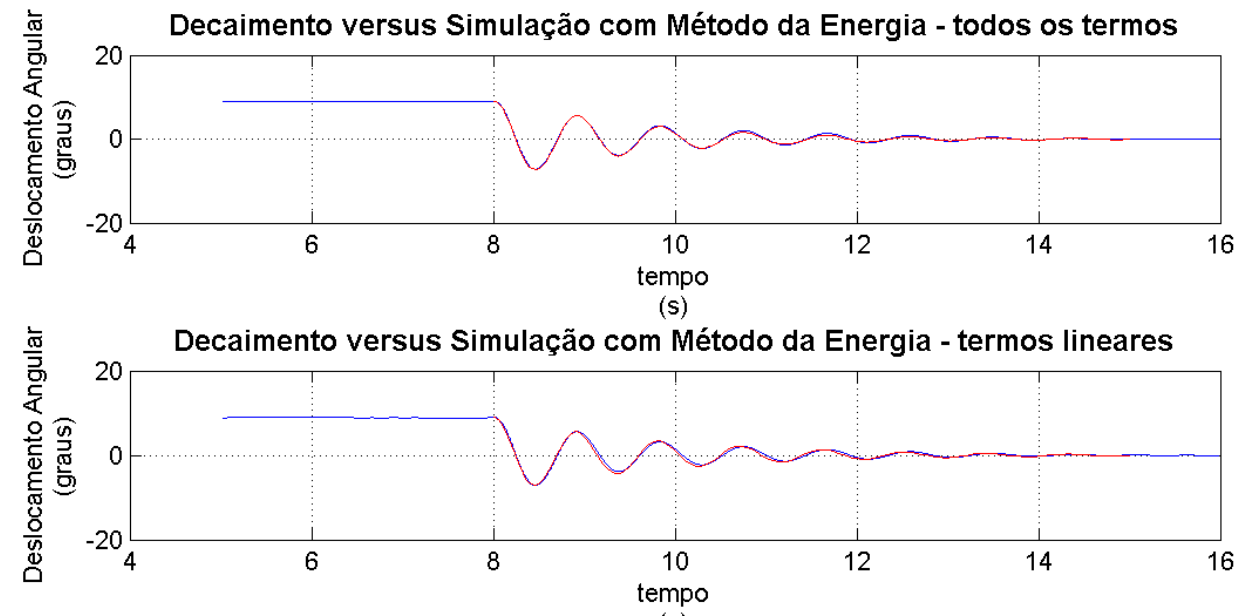

(s)

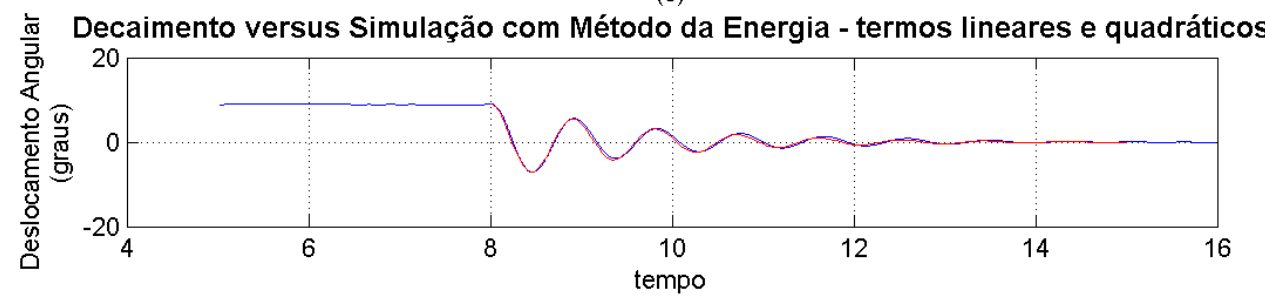

(s)

Figura 4.26: Comparação entre registro temporal e simulação com coeficientes obtidos através de análise por ciclos médio para o caso bojo arredondado. 


\subsubsection{Análise dos resultados}

Os parâmetros de massa adicionada e amortecimento para as geometrias ensaiadas são melhor recuperados pela análise de balanço de energia do que pela linearização equivalente por ciclo médio. Tal fato deve-se à existência de muitos casos com poucas oscilações. O reduzido número de ciclos não permite uma adequada apreensão das características do amortecimento e restauração pelo método de energia média entre ciclos, que se utiliza somente dos extremos dos meio-ciclos para a análise.

O método da energia, por sua vez, consegue apreender melhor as características do atributos hidrodinâmicos uma vez que realiza o ajuste dos coeficientes incorporando no cálculo da energia todos os pontos dos registros temporais medidos. A utilização de modelos não-lineares para a restauração e amortecimento não melhoraram substancialmente a qualidade da simulação do balanço em relação aos modelos lineares. Os modelos lineares mostraram-se suficientes para a reprodução das curvas de decaimento ao serem confrontadas com os resultados experimentais. Uma vez que as geometrias da seção possuem costados retos, o termo de restauração tem comportamento linear em relação à restauração hidrostática .

A parcela de energia de ondas dissipada durante os decaimentos mostrou-se cerca de $1 \%$ da energia potencial do modelo antes do início da balanço. Tal fato mostra que para os ensaios aqui realizados o amortecimento devido à geração de ondas é de menor importância. 


\section{Capítulo 5}

\section{Conclusões e recomendações}

\subsection{Conclusões}

A adequação de uso do método de aproximação logarítmica dos picos locais da curva de decaimento depende do número de picos, ou, como consequência, do amortecimento.

Verificou-se que o método da energia com termos lineares para restauração e amortecimento é adequado para a representação dos atributos hidrodinâmicos das seções em balanço aqui consideradas, a saber: bojo arredondado, bojo com bolina maior, bojo com bolina menor e bojo quinado, nos calados menores e médios.

Para as seções no calado maior, os atributos hidrodinâmicos apresentam características mais adequadamente modeladas por termos não lineraes, casos em que o método da energia deve ser empregado com modelagem progressivamente mais complexa.

Em primeira abordagem, o modelo linear para ambos os parâmetros deve ser empregado pelos seguintes motivos:

1. elimina a necessidade de empregar muitos termos para explicar o fenômeno, daí resultando em uma representação mais simples do sistema;

2. nos casos em que não é suficiente para a modelagem de todos os termos, os termos lineares podem ser utilizados como solução inicial na utilização de modelos não-lineares; 
Após o confronto com a simulação numérica, caso os resultados não sejam satisfatórios, deve-se progressivamente aumentar a complexidade do modelo em quantidade de termos não lineares empregados, como tentativa de se obter solução representativa.

Adiciona-se, então, termos dependentes de $\dot{\phi}^{2}$ e outros termos dependentes de $\phi$ e $\dot{\phi}$ para o amortecimento. O modelo de restauração deve permanecer linear, salvo se a geometria do corpo justificar.

Caso o modelo imediatamente mais complexo apresentar mudanças radicais de valores, com uma brusca mudança no coeficiente de amortecimento linear, é possível que se esteja incorrendo em flutuações numéricas da solução do sistema linear. Uma vez que quando é ampliada a complexidade da solução pode-se acabar com mais de uma solução para o sistema de equações que estima os atributos.

Neste caso, emprega-se a imposição da solução numérica do modelo simplificado nos coeficientes da solução com termos de ordem superior. Desse modo, somente os termos de ordem superior são estimados.

\subsection{Recomendações}

A presente dissertação insere-se em um trabalho de pesquisa mais amplo cujo objetivo é o desenvolvimento de ferramentas numéricas e experimentais para avaliação de propriedades hidrodinâmicas de embarcações e sistemas oceânicos.

Em continuidade ao desenvolvimento de ferramentas experimentais, emprega-se técnica de PIV para medição do escoamento no entorno das seções aqui ensaiadas em oscilando forçada.

Emprega-se modelos numéricos para escoamento potencial do tipo elementos de contorno e compara-se os resultados obtidos em termos dos parâmetros hidrodinâmicos de interesse.

Modelos de dinâmica dos fluidos computacional do tipo RANS - Reynolds Average NavierStokes são desenvolvidos com o subsídio dos resultados numéricos e experimentais anteriores. 


\section{Referências Bibliográficas}

[1] Asghari, M.; Zeraatgar, H.; Bakhtiari-Nejad, F. - An Analytical and Experimental Study on Dynamic Stability of a Vessel, Archives of Civil and Mechanical Engineering, v. VII, n. $3(2007)$

[2] Asghari, M.; Bakhtiari-Nejad, F. - A Study of the Roll Motion by Means of a Free Decay Test, Journal of Offshore Mechanics and Arctic Engineering, v. 132 (Agosto/2010)

[3] Bass, D.; Haddara, M.R. - Nonlinear Models of Ship Roll Damping, International Shipbuilding Progress, Vol. 35, pp. 401. (1988)

[4] Bearman, P.W.; Graham, J.M.R.; Obasaju, E.D; Drossopoulos, G.H. - The influences of corner radius on the forces experienced by cylindrical bluff bodies on oscillatory flow, Applied Ocean Research, vol 6, pp.83-89, (1984)

[5] Bearman, P.W. - Vortex trajectories in oscillatory flow, Procedures of Separated Flow around Marine Structures, pp.133-154, Trondheim (1985)

[6] Chakrabarti, S. K. - Advanced Series of Ocean Engineering - Volume 9 - Offshore Structure Modelling, World Scientific Publishing Co., Singapore (1994)

[7] Chakrabarti, S. K. - Handbook of Offshore Engineering: Volume I, Chapter 13 - Physical Modelling of Offshore Structures, Elsevier Ltd (1995)

[8] Chakrabarti, S. K. - Empirical calculation of roll damping for ships and barges, Ocean Engineering, Vol. 28, pp. 915-932. Pergamon (2001) 
[9] Chan, H. S. Y.; Xu, Z.; Huang, W. L. - Estimation of Nonlinear Damping Coefficients from Large-Amplitude Ship Rolling Motions, Applied Ocean Research, v. 17, p. 217-224 (1995)

[10] Contento, G.; Francescutto, A.; Piciullo, M. - On The Effectiveness of Constant Coefficients Roll Motion Equation, Ocean Engineering, v. 23, n.7, p. 597-618 Pergamon (1996)

[11] Den Hartog, J.P. - Vibrações nos sistemas mecânicos, Edgard Blucher, Ed. da Universidade de São Paulo (1972)

[12] Faltinsen, O.M.; Sortland, B. -Slow drift eddy making damping of a ship, Applied Ocean Research, vol 9, 1, pp. 37-46. (1987)

[13] Faltinsen, O.M. - Sea Loads on Ships and Offshore Structures, pp. 68-73, Cambridge University Press, New York (1990)

[14] Faltinsen, O.M. - Sea Loads on Ships and Offshore Structures, pp. 234-238, Cambridge University Press, New York (1990)

[15] Faltinsen, O.M. - Sea Loads on Ships and Offshore Structures, pp. 240-244, Cambridge University Press, New York (1990)

[16] Fernandes, A. C.; Kroff S. A. B. - Método Alternativo para Análises de Balanço Transversal de Embarcações com Aplicação em Unidades FPSO, Congresso Panamericano de Engenharia Naval COPINAVAL, Colômbia (1999)

[17] Fernandes, A. C.; Ferreira, A. C. - The roll damping assessment via decay model testing (new ideas about an old subject), Journal of Marine Science Applied, Vol. 8, pp. 144-150. (2009)

[18] Ferrari Jr, J.A.; Ferreira, M. D. A. - Assessment of the effectiveness of the bilge keel as an anti-roll device, Proceedings of the Twelfth Intenational Offshore and Polar Engineering Conference, Kitakyushu, Japan (2002) 
[19] Ferziger, J.H; Peric, M. - Computational Methods for Fluid Dynamics, 3.,rev. ed., Springer, pp. 5 -6, London (2002)

[20] Feynman, R.P.; Leighton, R.B., Sands, M. - The Feynman Lectures on Physics: Volume II, California Institute of Technology, Sixth printing (1977)

[21] Franco, A.S. - Análise Linear de Ondas Teoria e Prática, pp. 14-19, Publicação do Instituto de Pesquisas Tecnológicas do Estado de São Paulo (1984)

[22] Froude, J.P.W. - The Papers of William Froude, INA Publications, London (1955)

[23] Graham, J.M.R.; - The forces on sharp edged cylinder in oscillatory flow at low KeuleganCarpenter numbers, Journal of Fluid Mechanics, vol 97, pp. 331-346 (1980)

[24] Haddara, M.R.; Bennett, P. - A Study of the angle dependence of roll damping moment, Ocean Engineering, Vol. 16, No. 4, pp. 411-427. Pergamon (1989)

[25] Himeno, Y. - Prediction of Ship Roll Damping - State of the Art, University of Michigan, Department of Naval Architecture and Marine Engineering Report no. 239 (setembro/1981)

[26] Ikeda, Y.; Komatsu, K.; Himeno, Y.; Tanaka, N. -On the rolling damping force of ship. Effect of hull surface pressure created by bilge keels, Journal Kansai Society of Naval Archtects, vol 165, pp.31-40, Japan (1977)

[27] Irvine, M.; Longo, J.; Stern, F. - Towing-Tank Tests for Surface Combatant for Free Roll Decay and Coupled Pitch and Heave Motions, Proceedings of the 25th Symposium on Naval Hydrodynamics St. John`s and Labrador, Newfoundland, Canada (Agosto/2004)

[28] Jang, T. S.; Kwon, S. H.; Lee, J. H. - Recovering the Functional Form of the Nonlinear Roll Damping of Ships From a Free-Roll Decay Experiment: An Inverse Formulism, Ocean Engineering, v. 37, n. 14-15, p. 1337-1344 Pergamon (Outubro/2010). 
[29] Jung, K. H.; Chang, K. A.; Huang, E. T. - Two-dimensional flow characteristics of wave interactions with a free-rolling rectangular structures, Ocean Engineering, Vol. 32, pp. 1-20. Pergamon(2005)

[30] Lewandowski, E.M. - The Dynamics of Marine Craft : Maneuvering and Seakeeping, Advanced Series on Ocean Engineering - Volume 22, p. 274-277 World Scientific Publishing Co. Pte. Ltd. (2004)

[31] Lewis, E.V. - Principles of Naval Architecture Second Revision: Volume I Stability and Strength, The Society of Naval Architects and Marine Engineers (1988)

[32] Lewis, E.V. - Principles of Naval Architecture Second Revision: Volume III Motion in Waves and Controllability, The Society of Naval Architects and Marine Engineers (1988)

[33] Moinuddin, K.A.M.; Joubert, P.N.; Chong, M.S.;Hafez, S. - Experimental investigation of turbulent boundary layer developing along a steamwise external corner (chine), Experimental Thermal and Fluid Science, Vol. 27, pp. 599-609 (2003)

[34] Newman, J.N. - Marine Hydrodynamics, The MIT Press Cambridge, Massachusetts (1977)

[35] Oliveira, A.C.; Fernandes, A.C. - The Behaviour for FPSO Rolling Motions, Proceedings of the 9th International Conference on Stability of Ships and Ocean Vehicles, Rio de Janeiro (Agosto/2006)

[36] Sarpkaya, T.; -Force on a circular cylinder in viscous oscillatory flow at low KeuleganCarpenter numbers, Journal of Fluid Mechanics, vol 165, pp. 61-71 (1986)

[37] Schlichting, H. - Boundary-Layer Theory, McGraw-Hill Book Company, New York, (1979)

[38] Sim, W. - Discussion to the 25th ITTC Ocean Engineering Commite, Proceedings of the 25th International Towing Tank Conference, Vol. III, pp. 710;713, Fukuoka, Japão (2008) 
[39] Souza Jr, J, R,; Fernandes, A. C.; Masetti, I. Q.; da Silva, S.; Kroff, S. A. B. - Non Linear Rolling of an FPSO with Larger than Usual Bilge Keels, Proceedings of the 17th International Conference on Ocean, Offshore and Arctic Engineering, Lisbon, Portugal (1998)

[40] Surendran, S.; Lee, S. K.; Reddy, J. V. R.; Lee, G. - Non-linear roll dynamics of a Ro-Ro ship in waves, Ocean Engineering, v.32, p. 18181828 Pergamon (2005)

[41] Tanaka, N.; Ikeda, Y.; Nishimo, K. - Hydrodynamic viscous force acting on oscillating cylinders with various shapes, Proc. 6th Symp. of Marine Technology. The Society of Naval Archtects of Japan (1982)

[42] Taylan, M. - The Effect of Nonlinear Damping and Restoring in Ship Rolling, Ocean Engineering, v. 27, p. 921932 Pergamon (2000)

[43] Ueno, K.; Kimura, N.; Amagai,K. - Estimation of Coefficients of the Equation of Nonlinear Roll Motion for Fishing Boats by Improved Energy Method and Genetic Algorithm, Japan J. Indust. Appl. Math., v.20 , p. 155-192 (2003)

[44] Veiga, J. P. C. - Hidrodinâmica Aplicada ao Navio, pp. V-21 - V-25, Publicação do Departamento de Engenharia Naval e Oceânica, Escola Politécnica, Universidade de São Paulo (março/1979)

[45] Zhao, R.; Faltinsen, O.M.; Krokstad, J.R.; Aanesland, V. - Wave-currente interaction effects on large volume structures, Procedures of the International Conference on the Behaviour of Offshores Structures (BOSS'88), vol. 2, pp.623-638, Trondheim, Tapir publishers (1988) 


\section{Apêndice A}

\section{Relação de ensaios}

A seguir são apresentadas quatro tabelas contendo a relação dos ensaios, em conjunto com o ângulo inicial de movimento e a propriedades de inércia utilizadas. Os ensaios estão agrupados nas tabelas por geometria de seção. 


\begin{tabular}{|c|c|c|c|c|c|c|c|c|c|c|c|c|c|c|c|c|c|}
\hline 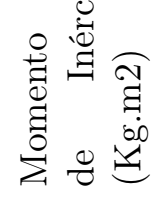 & 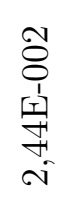 & 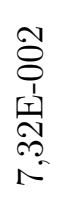 & 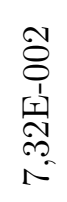 & 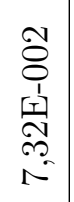 & 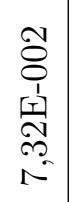 & 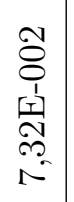 & 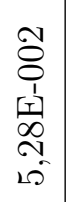 & 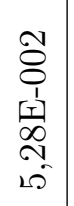 & 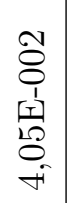 & 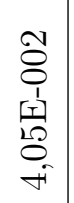 & 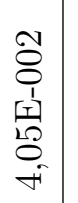 & 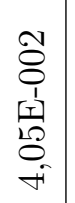 & 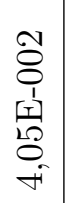 & 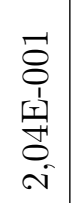 & 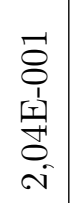 & 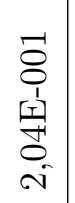 & 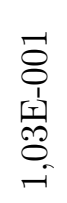 \\
\hline 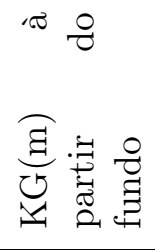 & $\begin{array}{l}1 \\
0 \\
\stackrel{1}{0} \\
0\end{array}$ & $\begin{array}{l}\stackrel{2}{0} \\
\stackrel{0}{0}\end{array}$ & $\begin{array}{l}\mathscr{m} \\
\stackrel{0}{0} \\
0\end{array}$ & $\begin{array}{l}\mathscr{O} \\
\stackrel{0}{0} \\
O\end{array}$ & $\begin{array}{l}\mathscr{O} \\
\stackrel{0}{0}\end{array}$ & $\begin{array}{l}\mathscr{m} \\
\stackrel{0}{0} \\
0\end{array}$ & $\begin{array}{l}\sqrt{2} \\
0 \\
0\end{array}$ & $\begin{array}{l}\overrightarrow{3} \\
0 \\
0\end{array}$ & $\begin{array}{l}18 \\
0 \\
0 \\
0\end{array}$ & $\begin{array}{l}12 \\
8 \\
0 \\
0\end{array}$ & $\begin{array}{l}12 \\
\mathscr{8} \\
0 \\
0\end{array}$ & $\begin{array}{l}12 \\
8 \\
0 \\
0\end{array}$ & $\begin{array}{l}\qquad 8 \\
8 \\
0 \\
0\end{array}$ & 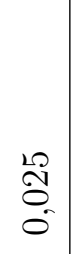 & $\begin{array}{l}\stackrel{L P}{O} \\
\stackrel{O}{0} \\
0\end{array}$ & $\begin{array}{l}\stackrel{L P}{O} \\
\stackrel{O}{O} \\
0\end{array}$ & $\begin{array}{l}8 \\
8 \\
0 \\
0\end{array}$ \\
\hline 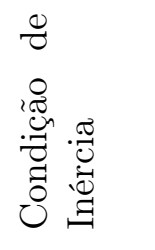 & & $\neg$ & $\neg$ & - & - & $\neg$ & $\sim$ & $\curvearrowright$ & - & $\neg$ & - & - & $\neg$ & - & - & - & N \\
\hline 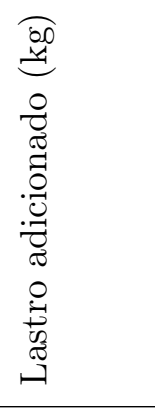 & 0 & $\stackrel{\infty}{\sim}$ & $\stackrel{\infty}{N}$ & $\stackrel{\infty}{\infty}$ & $\stackrel{\infty}{N}$ & $\stackrel{\infty}{N}$ & $\stackrel{\infty}{\sim}$ & $\stackrel{\infty}{N}$ & $\sim$ & N & N & N & N & $\stackrel{H}{\sim}$ & $\stackrel{H}{\longrightarrow}$ & $\stackrel{H}{\leftrightarrow}$ & $\stackrel{+}{\stackrel{4}{\longrightarrow}}$ \\
\hline 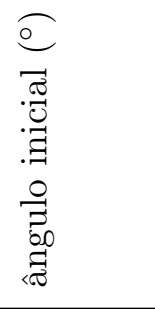 & & $\begin{array}{l}20 \\
2 \\
0\end{array}$ & $\begin{array}{l}\stackrel{a}{1} \\
\text { II }\end{array}$ & $\begin{array}{l}\hat{n} \\
20 \\
10\end{array}$ & $\begin{array}{l}20 \\
\text { is }\end{array}$ & $\begin{array}{l}\stackrel{H}{N} \\
\stackrel{D}{0}\end{array}$ & $\begin{array}{l}\infty \\
\stackrel{\sim}{\sim}\end{array}$ & $\frac{N}{10}$ & $\begin{array}{l}\bar{b} \\
\infty\end{array}$ & $\begin{array}{l}\infty \\
\infty_{-}\end{array}$ & $\begin{array}{l}\vec{\infty} \\
\text { m }^{-}\end{array}$ & $\begin{array}{l}\stackrel{8}{\infty} \\
\infty\end{array}$ & $\begin{array}{l}\stackrel{8}{0} \\
\infty\end{array}$ & $\stackrel{\stackrel{\mathscr{D}}{\sim}}{\stackrel{f}{H}}$ & $\stackrel{0}{0}$ & $\begin{array}{l}\text { ig } \\
10\end{array}$ & $\begin{array}{l}\text { is } \\
\text { is }\end{array}$ \\
\hline 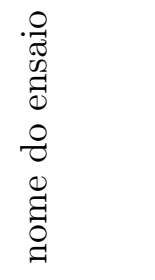 & & 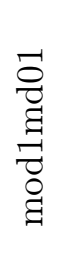 & 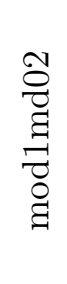 & 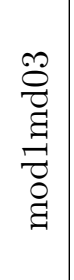 & 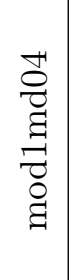 & 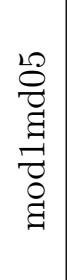 & 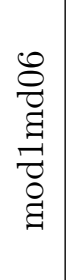 & 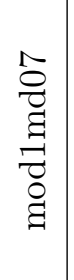 & 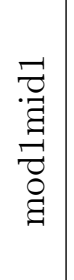 & 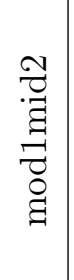 & 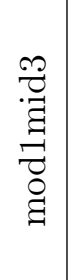 & 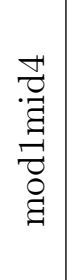 & 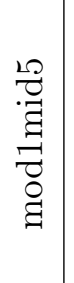 & 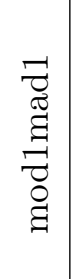 & 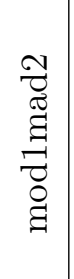 & 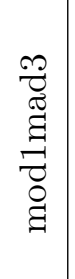 & 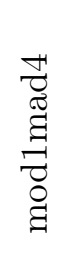 \\
\hline 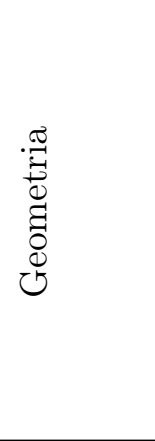 & 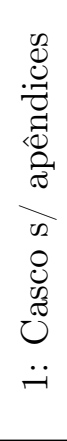 & 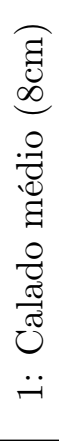 & & & & & & & 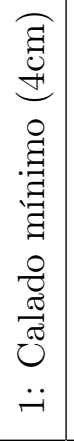 & & & & & 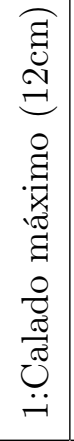 & & & \\
\hline
\end{tabular}




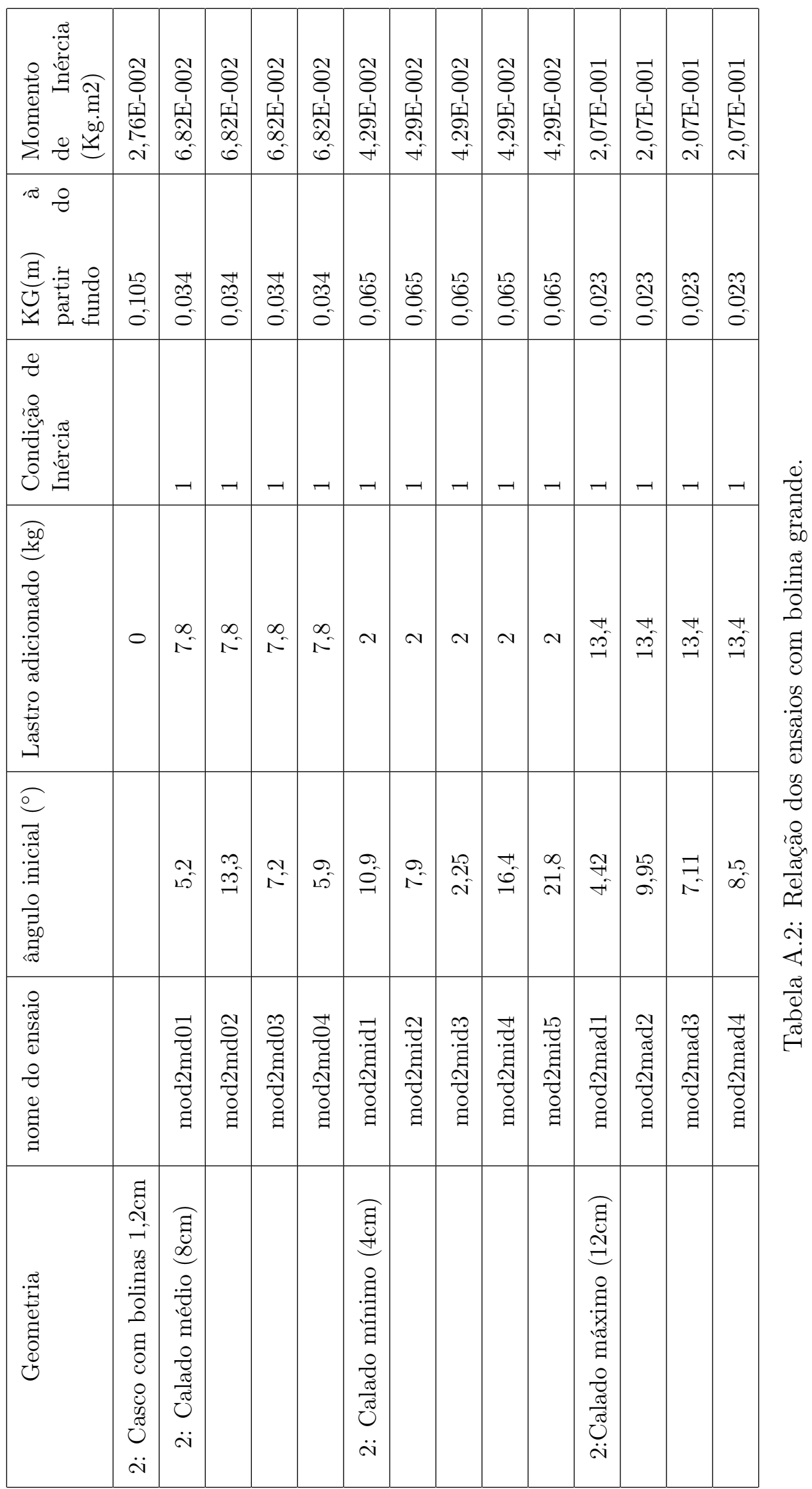




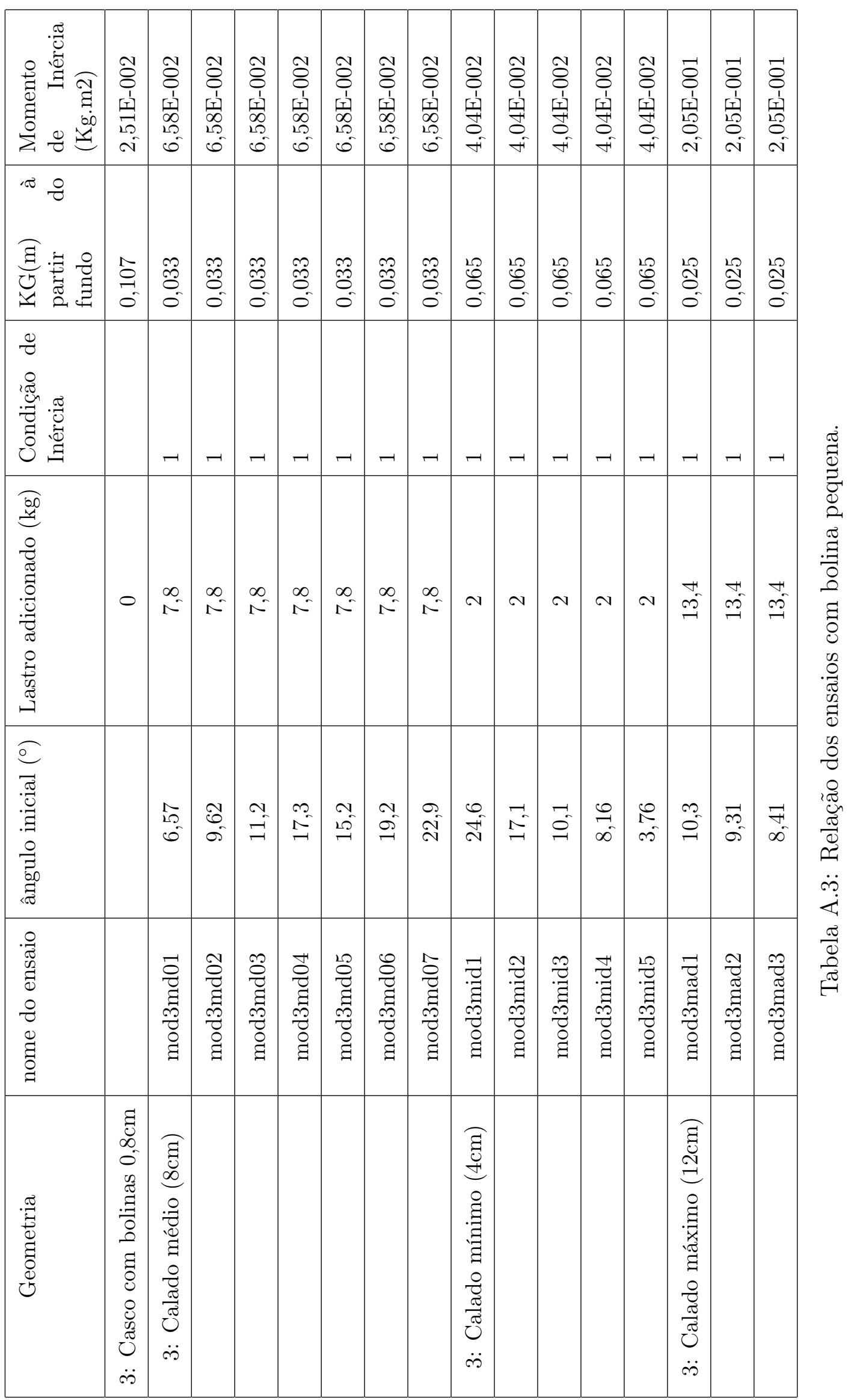




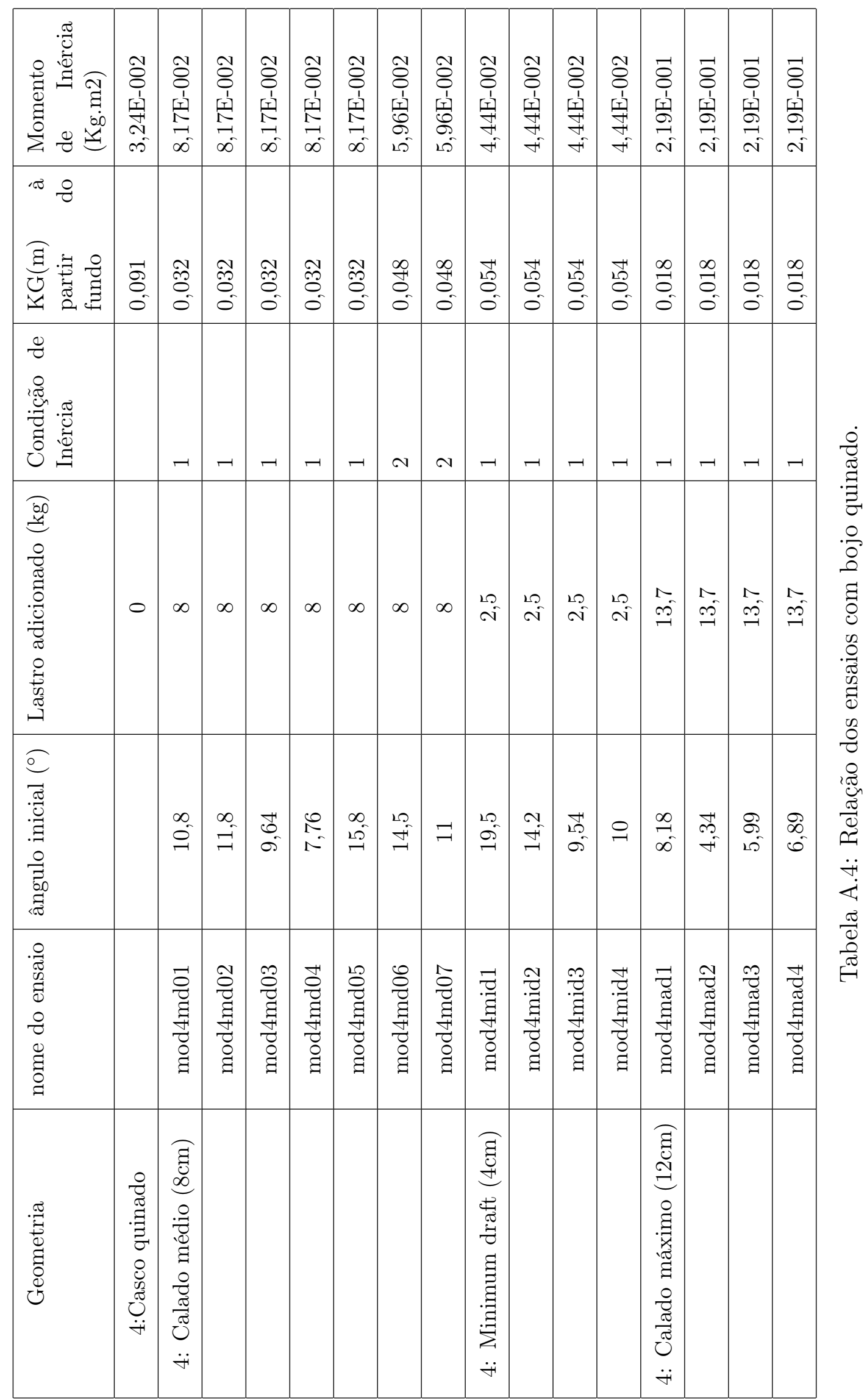




\section{Apêndice B}

\section{Registro fotográfico dos ensaios}

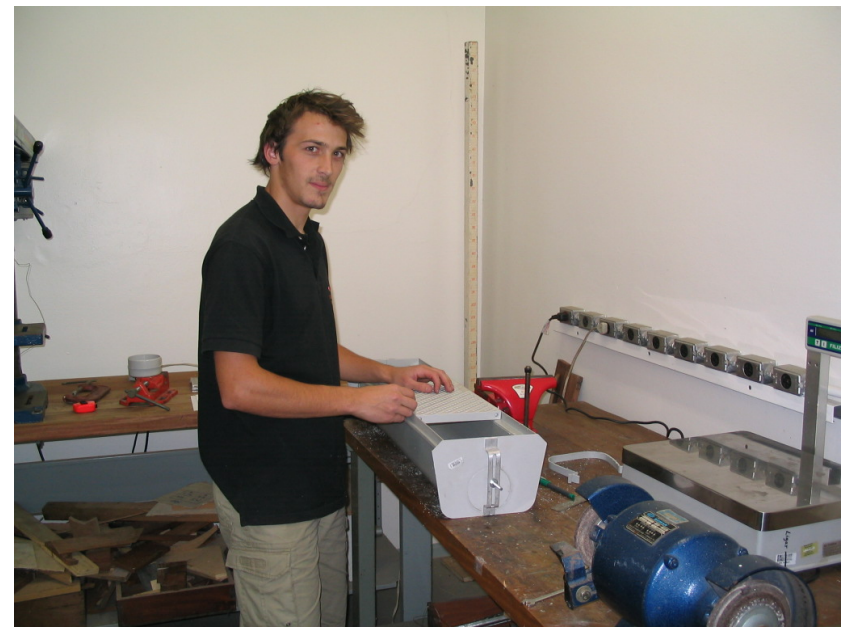

Figura B.1: Geometria confeccionado na bancada do Laboratório do Departamento de Engenharia Naval e Oceânica. 


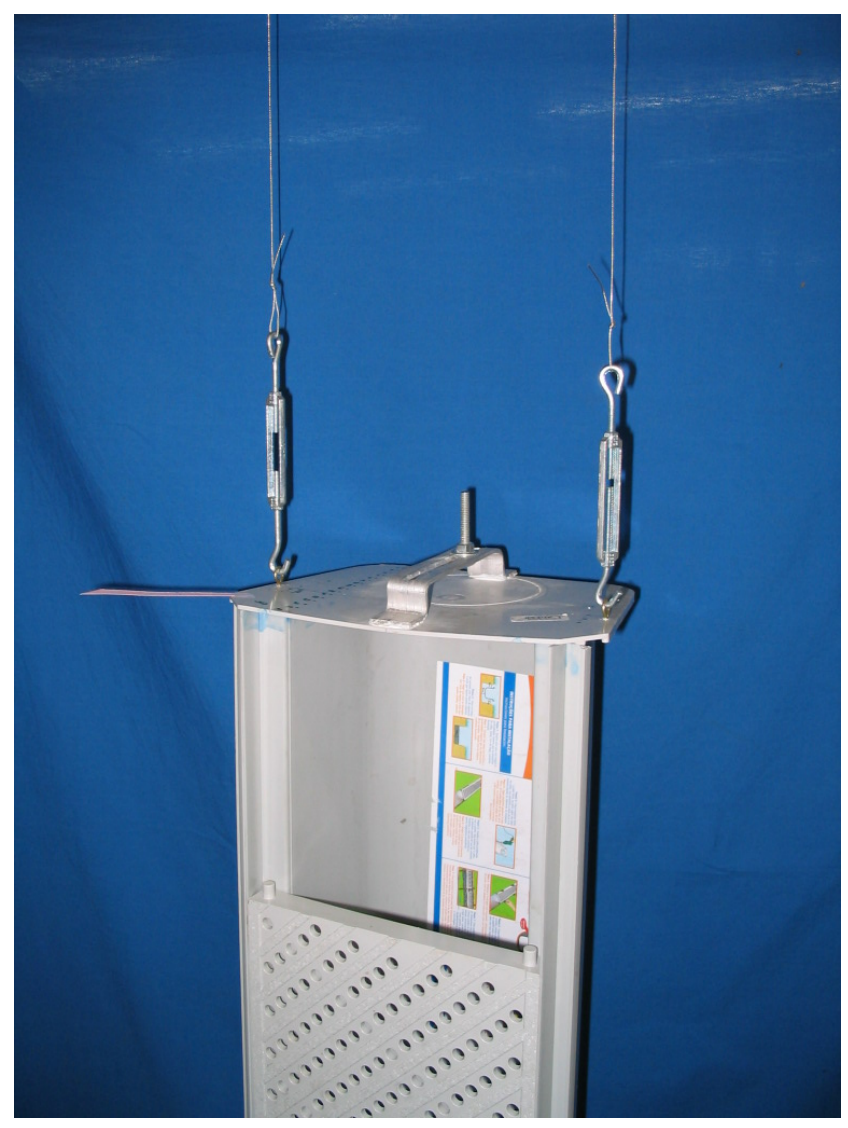

Figura B.2: Calibração da seção no laboratório. Medição do momento de inércia por meio de ensaio bifilar. 


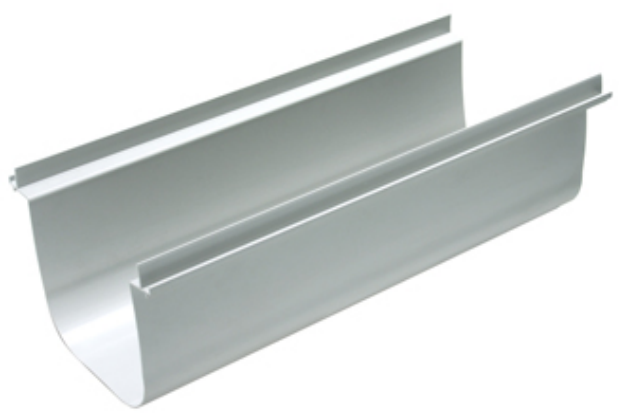

(a) Calha.

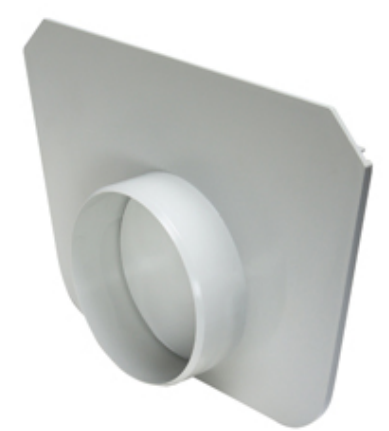

(b) Tampas laterais.

Figura B.3: Foto da tampa e da calha utilizadas na confecção da seção cilíndrica.

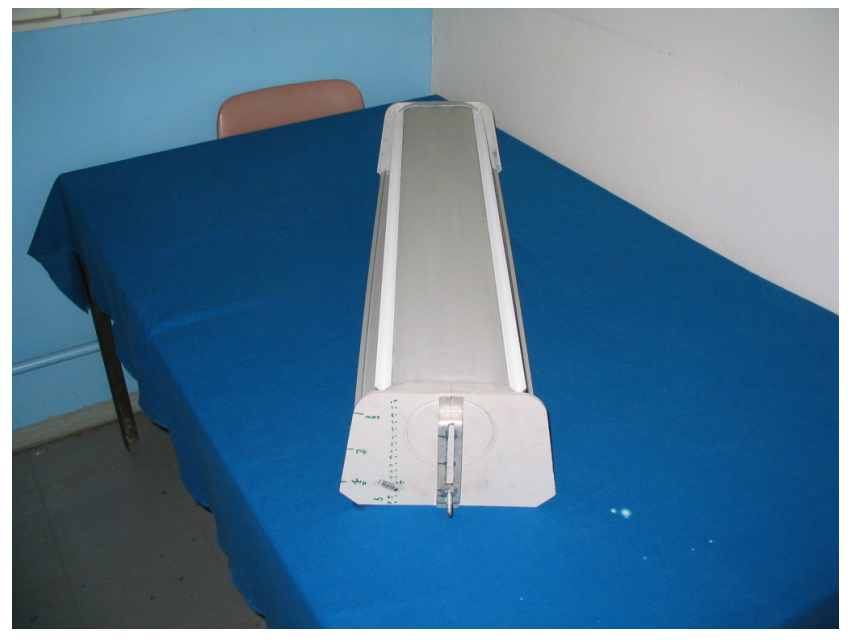

Figura B.4: Geometria bojo arrendondado com bolina maior. 


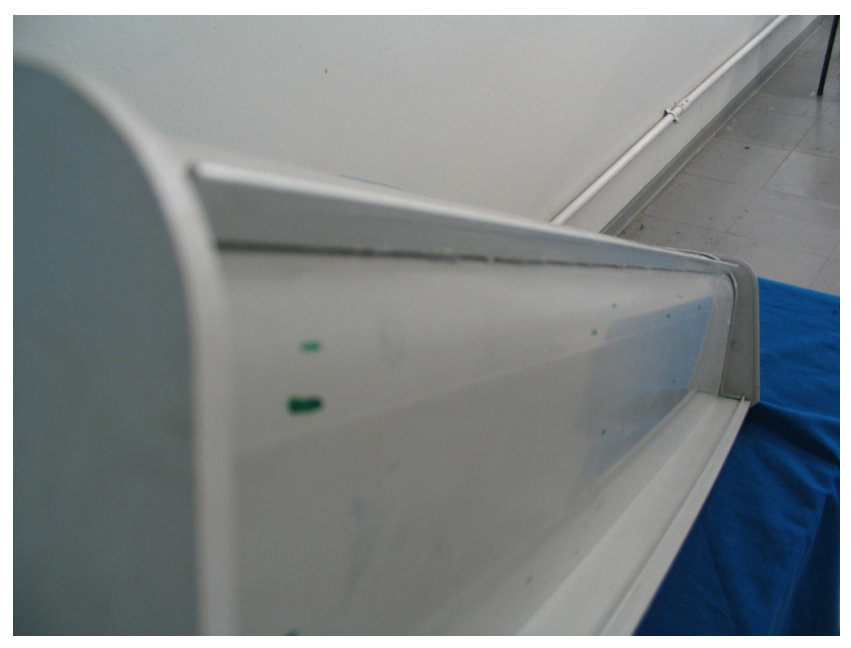

Figura B.5: Detalhe da fixação da geometria bojo arrendondado com bolina maior.

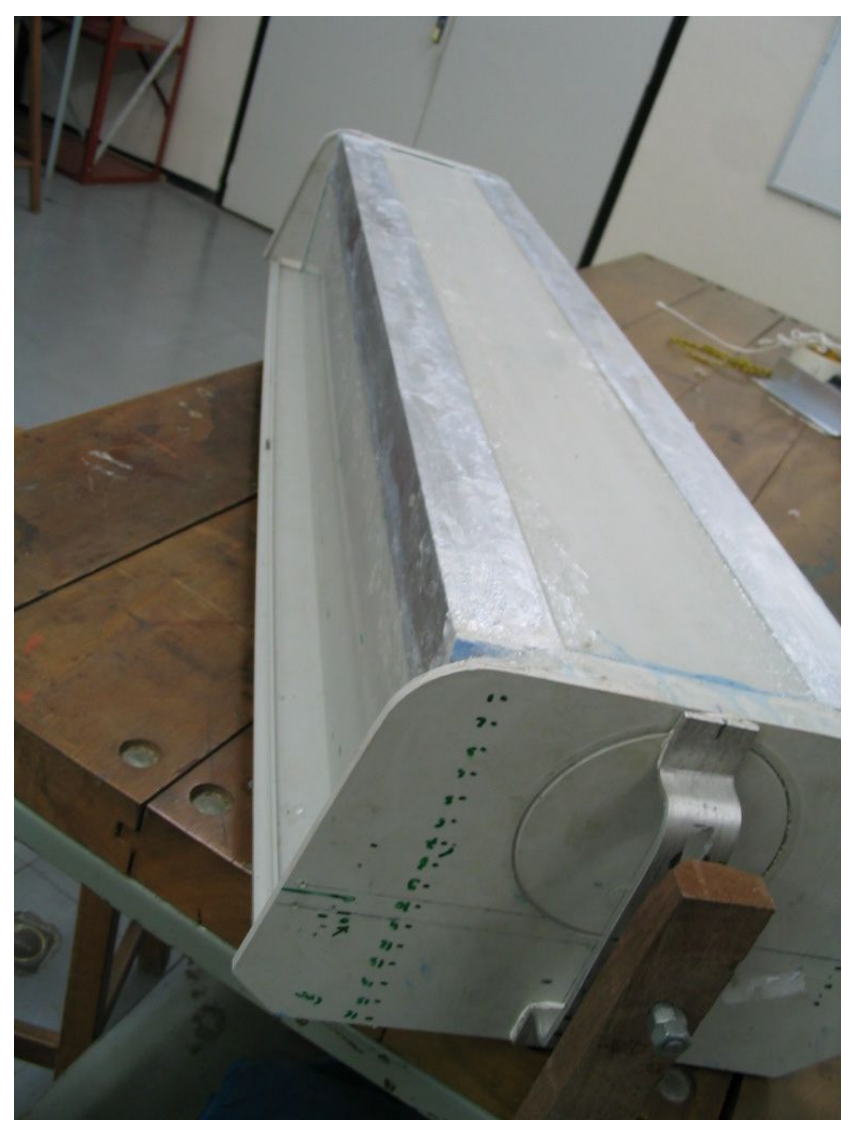

Figura B.6: Geometria bojo quinado com o sistema de pivotamento em primeiro plano. 


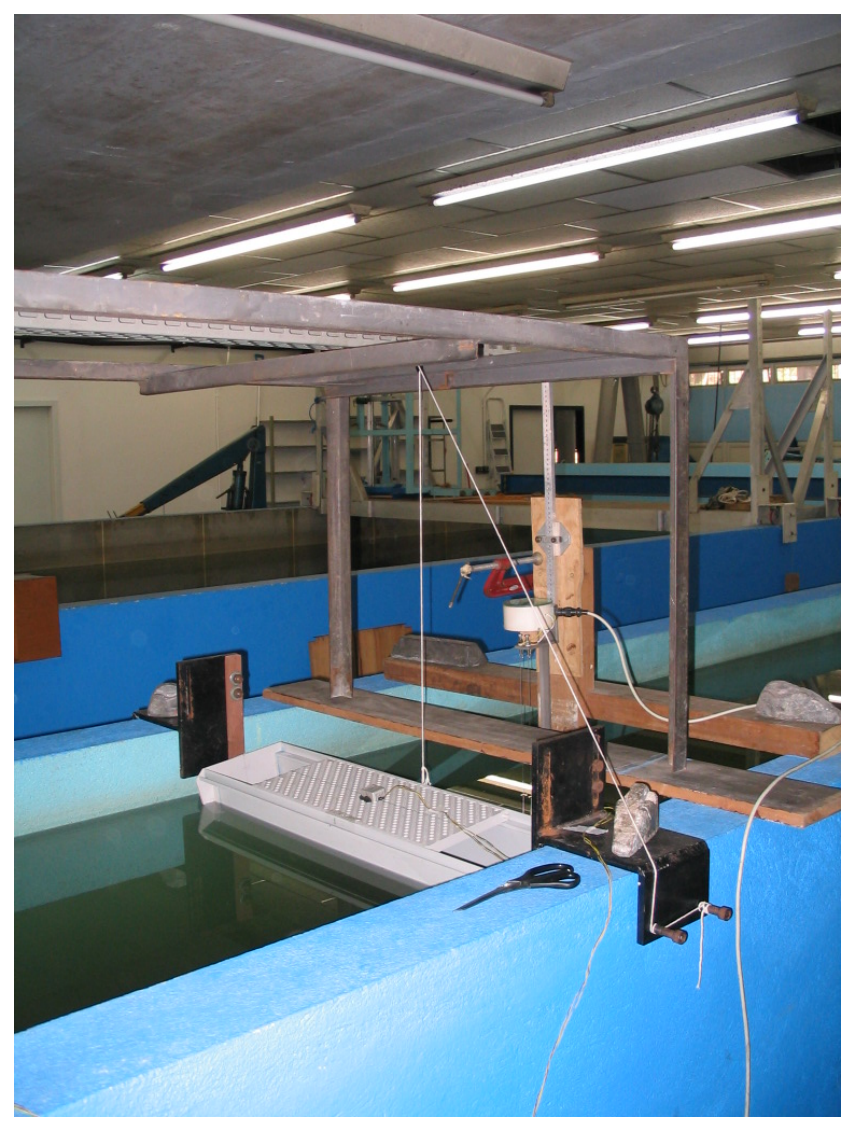

Figura B.7: Setup do ensaio em posição inicial.

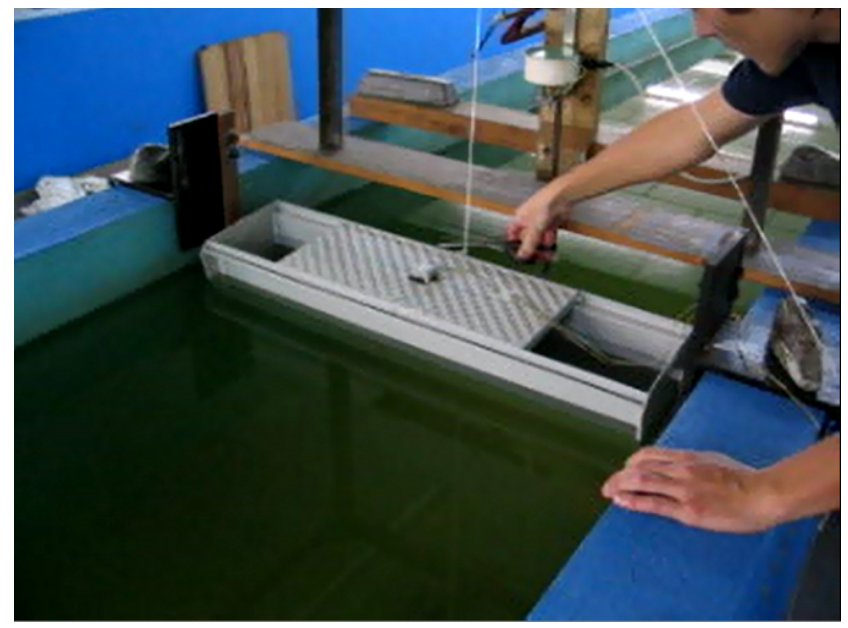

Figura B.8: Liberação do corpo para oscilar livremente. 